\title{
Exoatmospheric Plowshares: Using a Nuclear Explosive Device for Planetary Defense Against an Incoming Asteroid
}

David A. Koplow

Georgetown University Law Center, koplow@law.georgetown.edu

This paper can be downloaded free of charge from:

https://scholarship.law.georgetown.edu/facpub/2197

https://ssrn.com/abstract=3229382

UCLA Journal of International Law \& Foreign Affairs, Spring 2019, Issue 1, 76.

This open-access article is brought to you by the Georgetown Law Library. Posted with permission of the author. Follow this and additional works at: https://scholarship.law.georgetown.edu/facpub

Part of the Air and Space Law Commons, International Law Commons, Law and Philosophy Commons, and the National Security Law Commons 


\title{
EXOATMOSPHERIC PLOWSHARES:
}

\section{USING A NUCLEAR EXPLOSIVE DEVICE FOR PLANETARY DEFENSE AGAINST AN INCOMING ASTEROID}

\begin{abstract}
David A. Koplow ${ }^{*}$
"They shall bear their swords into plowshares, and their spears into pruning hooks"
\end{abstract}

Isaiah $2: 4$

\begin{abstract}
What should be done if we suddenly discover a large asteroid on a collision course with Earth? The consequences of an impact could be enormous-scientists believe that such a strike 60 million years ago led to the extinction of the dinosaurs, and something of similar magnitude could happen again. Although no such extraterrestrial threat now looms on the horizon, astronomers concede that they cannot detect all the potentially hazardous
\end{abstract}

\footnotetext{
* Professor of Law, Georgetown University Law Center. The author gratefully acknowledges the valuable comments from the following experts, colleagues and friends who reviewed prior drafts of this manuscript: Hope M. Babcock, Michael R. Cannon, Pierce Corden, Thomas Graham, Jr., Henry R. Hertzfeld, Edward M. Ifft, Raymond Jeanloz, Daniel H. Joyner, Barry Kellman, Rob R. Landis, Paul B. Larsen, Daniel D. Mazanek, Steven A. Mirmina, Scott Pace, Gabriel Swiney, James B. (Bart) Wager, Jr., and Brian Weeden. The author also thanks Danielle B. Ellison for her extraordinarily effective research assistance throughout the project. The opinions expressed herein are those of the author and do not necessarily represent the views of the U.S. government or any other entity.
} 
"near-Earth objects," and even more striking, they acknowledge that if such a danger were discerned, there is currently no proven capability for diverting or destroying it.

One possible response to this type of incipient catastrophe could be to send into space a nuclear explosive device, hoping the massive blast could alter the asteroid's trajectory. Indeed, if time were short, that might be the only effective remedy. But two major nuclear arms control treaties-which have been joined by most of the leading countries and are widely appreciated as fundamental to global security-specifically forbid that approach.

This Article examines that critical clash of legal, political, and technical values, and concludes that the best response would be for the UN Security Council to adopt a binding resolution pursuant to its powers under Chapter VII of the UN Charter, to deal with the emergency on an expeditious, global basis. A proposed draft of such a resolution is presented, along with explanatory annotations.

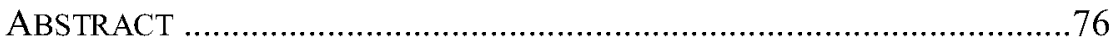

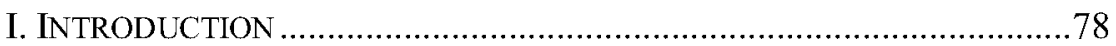

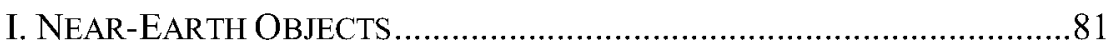

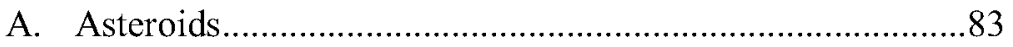

B. Impact Damage to Earth .....................................................8

C. Assessing the Probabilities ............................................... 92

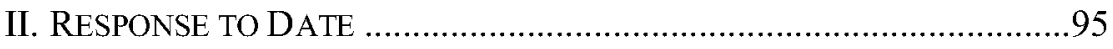

III. INTERNATIONAL LAW REGARDING NUCLEAR WEAPONS IN SPACE

A. The Outer Space Treaty ................................................... 105

1. Place in Earth Orbit ................................................ 108

2. Install on a Celestial Body ........................................109

3. Station in Space in Any Other Manner ........................110

4. Nuclear Weapons or Any Other Kinds of Weapons of Mass Destruction ....................................................... 111

5. Weapons of Mass Destruction......................................118

B. Limited Test Ban Treaty ................................................... 119

C. Nuclear Non-Proliferation Treaties ...................................123

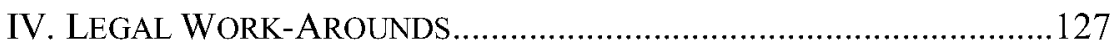

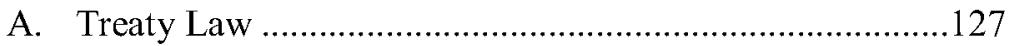

1. Amendment ............................................................127

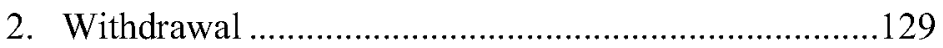

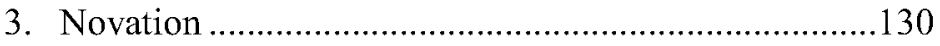


4. Action by Non-Parties 130

5. Excuse the Non-performance .....................................131

B. UN Security Council Action ...........................................135

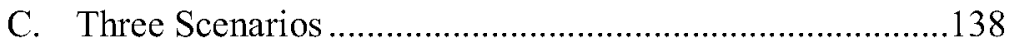

V. PROPOSED SECURITY COUNCIL RESOLUTION ……..........................142

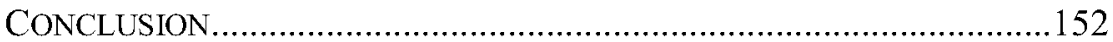

\section{INTRODUCTION}

What should be done if we suddenly discover a large asteroid on a collision course with Earth? The consequences of a major impact could be extreme: scientists now believe that it was just such a space intruder 60 million years ago that led to the extinction of the dinosaurs, and something of comparable magnitude could strike again at any time.

Fortunately, people need not immediately panic about this idea: at the moment, no such extraterrestrial threat looms on the horizon, and the statistical odds are heavily stacked against that form of Armageddon any time soon. But people should also not relax too much: Earth is regularly pummeled by space rocks of varying size and consequence; astronomers acknowledge that they are unable to detect every possible such risk; and even more ominous, the world has virtually no proven capability for intercepting and diverting or destroying this type of hazard. This scenario presents the classic case of an event that has a very low probability of occurring at any specific point in time, but a very high adverse consequence if and when it does occur, and we are not remotely prepared.

This challenge - which experts in the field label "Planetary Defense" lies overwhelmingly within the domain of science and technology, but it presents important, unresolved legal questions too. This Article explores one of those legal conundrums: the possible use of a nuclear explosive device against the galactic invader.

A nuclear explosion would not be the automatic or preferred choice as a

1 Planetary Defense Frequently Asked Questions, NAT'L AERonautics \& Space Admin., https://nasa.gov/planetarydefense/faq [https:/perma.ce/UK4J-K7TK] [hereinafter NASA FAQ]; Planetary Defense Coordination Office, NAT'L AERonautics \& SPACE ADMIN, https://www.nasa.gov/planetarydefense/overview [https://perma.cc/YVR3-4H8S]. The key tasks of planetary defense include finding and tracking potentially hazardous space objects; characterizing the trajectory, size, mass and other parameters of those items; warning about potential effects of a collision; and planning and implementing measures to deflect or disrupt the object and to mitigate the effects of an impact that cannot be prevented. Id. 
solution to an incoming asteroid. The primary methods - favored on the grounds of feasibility, cost, and safety - would employ a variety of other less problematic techniques with more finesse. But those alternative modes have not been operationally tested and proven, and they would take longer to operate, requiring lengthy advance notice. If the time interval is short between the warning and the potential impact (as it may well be), a nuclear explosive device may become the only available implement, relying upon a relatively mature technology.

However, international law, in the form of two important, longstanding, and widely adhered to treaties, specifically forbids that path. The United States and most other spacefaring countries have emphasized these constraints as fundamental, not only to the security of space, but also to the preservation of nuclear stability on Earth.

What should be done to resolve this potential conflict? How can the world dodge or reconcile the antagonism between the exigencies of planetary defense, the demands of nuclear security, and the commitment to the rule of law? This Article explores that interdisciplinary puzzle, contemplates a variety of potential legal remedies, and recommends the most viable solution, in the form of a resolution to be adopted by the UN Security Council pursuant to its powers under Chapter VII of the UN Charter. ${ }^{2}$ A draft of such a resolution is provided for consideration.

The Article proceeds as follows. After this Introduction, Part II discusses the potential asteroid challenge, describing the diverse population of these cosmic interlopers and the characteristics that make them physically so problematic. The Earth is constantly bombarded by material from space, most of it too small to notice or care about. Sometimes, larger fragments manage to penetrate the planet's protective atmosphere, providing souvenirs for museums. Occasionally, still larger pieces inflict considerable damage; in the worst case, a planet-jarring impact could be regarded as an "extinction-level" event, threatening human civilization. Large asteroids are rare, but statistically, collisions are inevitable.

Part III addresses the incipient human reaction to this danger. Many disparate elements in national space agencies, universities, professional associations, and elsewhere have considered the phenomena, studied the dangers, and calculated the odds, but they have barely begun to forge a reliable mechanism capable of reacting effectively. More recently, the world has begun to coalesce upon a type of collective response, and a shared technical

${ }^{2}$ See UN Charter art. 39. 
and political dialogue - nestled within the United Nations system, but largely independent of it-has arisen. These discussions have identified a variety of possible (or at least conceivable) mitigation techniques, including kinetic interceptors, so-called "slow push/pull" techniques, gravity tractors, and in the extreme case, nuclear detonations.

Part IV turns to the international law of space and nuclear devices, highlighting two critical bulwarks. The 1967 Outer Space Treaty ${ }^{3}$ is the foundational document in the field, establishing widely-accepted principles, including specific mandates against nuclear weapons in space. The 1963 Limited Test Ban Treaty ${ }^{4}$ includes an express prohibition against exoatmospheric nuclear explosions of any sort. In addition, several other vital, widely-respected international agreements restricting nuclear proliferation also come into play. Here, the Article parses the texts of these instruments with care to determine exactly which activities are legally proscribed, and how those constraints might implicate planetary defense capabilities.

Part $\mathrm{V}$ attempts a reconciliation between the specter of asteroid danger and the insistent demands of arms control and international law. It sketches possible routes for circumnavigation of the conflict and concludes that a binding Security Council resolution offers the best way forward. Importantly, any solution must address three rather different sets of circumstances. The first is an urgent and certain global emergency, in which an imminent massive peril could motivate a hasty worldwide agreement to suspend the usual legal niceties in pursuit of our species' sheer survival. The second case would be a more contingent or limited crisis, in which the probability of an Earth impact was high, but not certain, or where the likely harm to be inflicted by the asteroid was best calculated to be of regional, but not universal, scope. The third situation arises at a far earlier point, when one or more countries, apprehending a possible future peril, might seek to develop, test, and deploy capabilities that could one day be necessary for a planetary defense mission, but that might also pose a direct and immediate challenge to the nuclear arms control regime that has for decades underpinned global peace and security.

\footnotetext{
${ }^{3}$ Treaty on Principles Governing the Activities of States in the Exploration and Use of Outer Space, Including the Moon and Other Celestial Bodies, opened for signature Jan. 27, 1967, 18 U.S.T. 2410, 610 U.N.T.S. 205 (entered into force Oct. 10, 1967) [hereinafter Outer Space Treaty or OST].

${ }^{4}$ Treaty Banning Nuclear Weapon Tests in the Atmosphere, in Outer Space and Under Water, opened for signature Aug. 5, 1963, 14 U.S.T. 1313, 480 U.N.T.S. 6964 (entered into force Oct. 10, 1963) [hereinafter Limited Test Ban Treaty or LTBT]. This treaty is also known as the Partial Test Ban Treaty.
} 
Part VI then proffers a draft of a Security Council resolution to address all those scenarios. The suggested language is explained, and alternative approaches and formulations are described.

Finally, Part VII tenders some concluding thoughts, including the acknowledgement that serious analysis and discussion of this topic are fraught with fundamental cognitive impediments. First, some readers may wholly disregard a contingency with such low and distant likelihood of occurrence. If the problem may not arise for thousands or millions of years, why worry about it today when there are so many other more imminent dangers clamoring for attention? Humans systematically under-prepare for high-severity/lowprobability events, to our collective peril. Alternatively, some readers may be skeptical about the relevance of law in a true planetary emergency, reasoning that if human survival were at stake, people and their governments would simply tear up any treaties or other constraints that seemed to stand in the way of an effective response.

This Article is dedicated to the proposition that we should be able to do better than that. Even an event of very low probability demands attention when the stakes are so unthinkably high, and prudently attending to planetary defense need not divert us too badly from other priorities. Likewise, it is not asking too much to demand that international lawyers help develop a pathway to vouchsafe our physical security while not wholly dispensing with the rule of law. We should be able to resist an asteroid and simultaneously preserve our international legal and security architecture. Advance planning and farsighted legal analysis can accomplish that much, and it seriously degrades the value of treaties today if we blithely assume that we will simply shred the law when necessary tomorrow.

\section{NEAR-EARTH OBJECTS}

The population of potentially-hazardous near-Earth objects (NEOs) comprises a marvelously diverse array of characters. ${ }^{5}$ This Article

\footnotetext{
${ }^{5}$ A near-Earth object is usually defined as an asteroid or comet that comes closer to the Sun than 1.3 times Earth's average distance from the Sun, i.e., about 200 million km. INTERAGENCY Working Group for Detecting and Mitigating IMPact of EARth-Bound Near-Ear Objects, U.S. Sci. \& Tech. Council, National Near-Earth ObJect Preparedness StRATEGy AND ACTION Plan 2 n.1 (2018), https://www.whitehouse.gov/wpcontent/uploads/2018/06/National-Near-Earth-Object-Preparedness-Strategy-and-ActionPlan-23-pages-1MB.pdf [https://perma.cc/YP54-REX5] [hereinafter STRATEGY AND ACTION PLAN]. Alternatively, sometimes NEO is defined as an object that passes within about 50 million km of Earth's orbit. See NASA Off. of THE InSPECtoR GEN., NASA's EfForTs to
} 
concentrates on asteroids, the millions of small rocky or metallic objects without atmospheres, orbiting the Sun. They are most plentiful in the belt between Mars and Jupiter, but as they jostle each other, and as they experience competing gravitational forces from miscellaneous objects, they may be found in a variety of other locations and trajectories. ${ }^{6}$ A meteoroid is now widely defined simply as a small asteroid, less than one meter in diameter. ${ }^{7}$ A comet, in contrast, is composed of ice, rock, and dust; it often follows a more extreme elliptical path around the Sun, and is typically accompanied by a bright trailing stream when it is in proximity to the Sun. ${ }^{8}$

This Part describes what is known, and some important unknowns, about the congregation of NEOs; what the consequences of an Earth impact have been in the past and may be in the future; and what the probability estimates are for various types of incidents and catastrophes. ${ }^{9}$

Identify Near-Earth OBJects and Mitigate Hazards 1 (2014), https://oig.nasa.gov/docs/IG-14-030.pdf [https://perma.cc/P8A7-8Y7M] [hereinafter AUDIT REPORT]; NASA FAQ, supra note 1. If the object passes within 8 million $\mathrm{km}$ and is large enough to reach the surface of the Earth, it is regarded as "potentially hazardous." Id.; NAT'L. Aeronautics and Space Admin., Near-Earth Object Survey and Deflection Analysis OF AlteRnAtIVES 7 (2007), https://www.nasa.gov/pdf/171331main_NEO_report_march07.pdf [https://perma.cc/U7WD-FNEN] [hereinafter ANALYSIS OF ALTERNATIVES].

${ }^{6}$ See NASA FAQ, supra note 1; ANALYsis of ALTERnAtIVEs, supra note 5, at 5; NEAR-EARTH Object Science Definition Team, Nat'l aeronautics and Space admin., Update to Determine the Feasibility of Enhancing the Search and Characterization of NEOs 910 (2017), https://cneos.jpl.nasa.gov/doc/2017 neo sdt final e-version.pdf [https://perma.cc/6FJA-GGVM] [hereinafter DEFINITION TEAM]. An asteroid is also referred to as a type of minor planet. $I d$.

7 IAU Commission F1, Definitions of Terms in Meteor Astronomy, InT'L Astronomical UNION (Apr. 30 , 2017), https:/www.iau.org/static/science/scientific_bodies/commissions/f1/meteordefinitions_appro ved.pdf [https://perma.cc/TX65-DBRK]; Alan E. Rubin and Jeffrey N. Grossman, Meteorite and Meteoroid: New Comprehensive Definitions, 45 Meteoritics \& PlaneTaRy Sci. 114, 114 (2010). A "meteor" is an asteroid or meteoroid that enters Earth's atmosphere and glows as a "shooting star." A "meteorite" is a fragment of a meteor that survives the descent through Earth's atmosphere and reaches the surface. IAU Commission F1, supra note 7; Meteors \& Meteorites, NAT'L AERONAUTICS \& SPACE ADMIN., https:/solarsystem.nasa.gov/asteroidscomets-and-meteors/meteors-and-meteorites/in-depth/ [https:/perma.cc/7VV8-648W].

${ }^{8}$ See Comets, Nat'l Aeronautics \& SpaCe Admin., https://solarsystem.nasa.gov/asteroidscomets-and-meteors/comets/in-depth/ [https:/perma.cc/7WKD-55VG]; DonALD K. YEOMANS, Near-Earth Objects: Finding them Before they Find Us 7 (2013) (noting that the difference between an asteroid and a comet is not precise). There are far fewer comets near Earth, and they are not the focus of this Article. Definition Team, supra note 6, at 1, 12-15 (noting that 16,000 asteroids, but only 106 comets, have been identified to date).

${ }^{9}$ This Article addresses the dangers from natural objects in space, such as asteroids. A separate 


\section{A. Asteroids}

Asteroids vary greatly in a number of parameters that can strongly influence the ability to detect, track, divert, and destroy them, and the amount of damage they would inflict in an Earth strike: ${ }^{10}$

- Size: One asteroid (Ceres) is nearly 1,000 km across, and two

problem concerns the proliferation of human-made orbital debris, such as defunct satellites, spent booster rockets, and other detritus from human space missions. Although not presenting the risk of potentially cataclysmic impact on Earth that larger asteroids carry, that type of artificial debris can pose a significant impediment for safe space operations, and states have undertaken significant efforts to mitigate its further accumulation. See Donald J. Trump, Space Policy Directive - 3, National Space Traffic Management Policy Sec. 3 (c), WHITE House (June 18, 2018), https:/www.whitehouse.gov/presidential-actions/space-policy-directive-3national-space-traffic-management-policy/ [https://perma.cc/ANW9-9ADS](recognizing that "[o]rbital debris presents a growing threat to space operations."). See generally FRANCIS LyALL \& Paul B. Larsen, Space Law: A Treatise 270-80 (2018); Peter Stubbe, State Accountability for Space Debris, 12 Stud. Space L. 534 (2017); Comm. on the Peaceful Uses of Outer Space, Active Debris Removal-An Essential Mechanism for Ensuring the Safety and Sustainability of Outer Space, U.N. Doc. A/AC.105/C.1/2012/CRP.16 (2012); INTER-AGENCY SPACE DEBRIS Coordination Committee, iAdC Space Debris Mitigation Guidelines (2007) http:/www.unoosa.org/documents/pdf/spacelaw/sd/IADC-2002-01-IADC-Space_DebrisGuidelines-Revision1.pdf [https://perma.cc/ACP5-Y9QJ] [hereafter IADC Guidelines]; U.N. Office for Outer Space Affairs, Space Debris Mitigation Guidelines of the Committee on the Peaceful Uses OF Outer SPaCe (2010), http://www.unoosa.org/pdf/publications/st_space_49E.pdf__[https://perma.cc/ULR9-Z2U9]; Frans G. von der Dunk, Defining Subject Matter under Space Law: Near Earth Objects Versus Space Objects, 51 Proc. Int'L Inst. Space L. 293 (2008); J.-C. Liou, Nat'L Aeronautics \& Space Admin., U.S. Space Debris Environment, Operations, and Research Updates (2018), http:/www.unoosa.org/documents/pdf/copuos/stsc/2018/tech-14E.pdf [https://perma.cc/4DNY-SVH2].

10 See generally, Nat'l Acad. of Sci., Comm. to Review Near-Earth-ObJect Surveys and Hazard Mitigation Strategies, Defending Planet Earth: Near-Earth-Object SuRveYs AND HAZARD Mitigation StRategies 51 (2010) [hereinafter NAS SuRveys AND STRATEGIES]; NASA FAQ, supra note 1; Steve Eckersley, D7.5.1: Trade Offs of Viable Alternative Mitigation Concepts (Sept. 12, 2012), in NEOSHIELD, A GLobAl APProACH to Near-Earth Object Impact Threat Mitigation (Steve Eckersley ed., 2013) 1, 16 http://www.neoshield.net/wp-content/uploads/2015/02/NEOShield_D7.5_Trade-Offs-ofViable-Alternative-Mitigation-Concepts.pdf_[hereinafter NEOSSHIELD]; INTERAGENCY Working Group for Detecting and Mitigating the Impact of Ear th-Bound Near-Earth Objects (NEOs)(DamiEN), U.S. Nat'L Sci. \& Tech. Council, National Near-Earth ObJect Preparedness StRategy 9 (2016) [hereinafter DAMIEN Strategy] (observing that the population of asteroids is diverse, that the effects of an impact with Earth are not well understood, and that efforts to track and catalogue asteroids are relatively new); STR ATEGY AND Action Plan, supra note 5. 
others are larger than $500 \mathrm{~km}$, but most are much smaller. ${ }^{11}$ Until more is known about the mass, composition, and other variables, size is frequently cited as the leading shorthand indicator of the degree of harm an asteroid would inflict in a collision with Earth. ${ }^{12}$

- Location and flight path: The orbits of most asteroids never intersect that of the Earth, but as elaborated infra, there are many for which the paths do eventually cross. Calculating with accuracy the far-future trajectory of an asteroid is extremely complex; often only a rough estimate is possible and substantial uncertainty will long persist. ${ }^{13}$

11 Asteroids, NASA SCI., https:/solarsystem.nasa.gov/asteroids-comets-andmeteors/asteroids/in-depth/ [https:/perma.cc/3LZA-79C6] (last updated Mar. 12, 2019); Ceres, NASA SCI., $\quad$ https://solarsystem.nasa.gov/planets/dwarf-planets/ceres/in-depth/ [https://perma.cc/77XR-FSVP] (last updated Dec. 10, 2018); 4 Vesta, NASA ScI., https:/solarsystem.nasa.gov/asteroids-comets-and-meteors/asteroids/4-vesta/in-depth/

[https:/perma.cc/UZ37-AVG9] (last updated Dec. 8, 2017); Edward F. Tedesco, Pallas, ENCYCLOPEDIA BRITANNICA, https:/www.britannica.com/topic/Pallas (last visited Apr. 15, 2019) [https:/perma.cc/J9BT-M6FW]. The two largest near-Earth asteroids are Ganymed (32 $\mathrm{km}$ in diameter) and Eros (11 km). DEFINITION TEAM, supra note 6, at 9; Rob Landis \& Lindley Johnson, Advances in Planetary Defense in the United States, 156 ACta Astronautica 394, 305 n.5 (2019).

12 See Duncan I. Steel et al., Are Impacts Correlated in Time?, in HAZARDs Due to Comets AND AsTEROIDS 463, 473 (Tom Gehrels ed., 1994) (suggesting that a collision with a cluster of somewhat smaller asteroids might inflict more damage and might be more common than an impact with a single larger body).

13 See Richard P. Binzel, The Torino Impact Hazard Scale, 48 PlanetaRy \& SPACE Sci. 297, 297 (2000) (observing inherent uncertainties in estimating a distant NEO's trajectory, leading to representations of an "error ellipse" to describe where it might impact Earth); RUSSELL L. Schweickart et al., Ass'n of Space Explorers, Asteroid Threats: A Call for Global RESPONSE 12, 15 (Jessica Tok ed., 2008) [hereinafter GloBAL RESPONSE]; InT'L ACAD. OF Astronautics, Dealing with the Threat to Earth from Asteroids and Comets, 47-49 (Ivan Bekey ed., 2009), https:/iaaweb.org/iaa/Scientific\%20Activity/Study\%20Groups/SG\%20Commission\%203/sg3 5/sg35finalreport.pdf [https://perma.cc/5TH9-Y28Q] (identifying categories of NEOs for which there might be decades, years, or months of warning time); Sentry: Earth Impact Monitoring, CTR. FOR NEAR EARTH OBJECT https://cneos.jpl.nasa.gov/sentry/intro.html [https://perma.cc/ZZ4W-GTSY] ("[A]n object's orbit is never known perfectly."); David Farnocchia et. al., Orbits, Long-Term Predictions, and Impact Monitoring, in Asteroms IV 815 (Patrick Michel et al. eds., 2015); Steve Chesley \& Paul Chodas, Impact Risk Estimation and Assessment Scales, in HaNdBook of Cosmic Hazards and Planetary Defense 651 (Joseph N. Pelton \& Firooz Allahdadi eds., 2015); Seth D. Baum, Uncertain Human Consequences in Asteroid Risk Analysis and the Global Catastrophe Threshold, 94 NAT. HAZARDS 759, 771 (2018). 
- Composition: Most asteroids fall within three main categories: Ctype (carbon rich, the most common), M-type (metallic, the least common), and S-type (silicate or stony). In general, the metallic strain would be the most dense, making them harder to displace, more likely to penetrate the atmosphere, and more powerful on impact. $^{14}$

- Structure: An asteroid might be a single, solid object; it might consist of two or more bodies orbiting each other; or it might be essentially a pile of rubble loosely bound together. ${ }^{15}$ An asteroid might be roughly spherical, but most are quite irregular in shape. ${ }^{16}$

- Flight characteristics: All asteroids rotate in flight, but they do so at different rates, and some might be tumbling erratically as they fly through space. ${ }^{17}$

- Reflectivity: Some asteroids have a light-colored or reflective surface, making them easier to discern and track from afar. ${ }^{18}$

- Speed: Asteroids in near-Earth space typically travel at $20 \mathrm{~km}$ per second, although depending upon the angle of impact, the relative speed of a collision can be twice that rate. ${ }^{19}$

There are millions of asteroids, but the exact total number is unknown, even if we concentrate mainly on the inner Solar System, the region between the Sun and Jupiter. A 2017 NASA survey estimated that there were $14,915,756$ NEOs larger than 10 meters in diameter, of which 2,983,151 had trajectories and other characteristics that classified them as potentially hazardous to Earth. There were an estimated 10,313 objects between 100

\footnotetext{
${ }^{14}$ Asteroids, NASA SCI., supra note 11; DAMIEN STRATEGY, supra note 10, at 4 (observing that, in general, rocky asteroids are more likely to explode in the atmosphere, causing damage over a wide radius, while metallic types would be more likely to impact the ground, causing more severe but localized harm).

${ }^{15}$ Charles Q. Choi, Asteroids: Fun Facts and Information About Asteroids, SPACE (Sept. 30, 2017), https:/www.space.com/51-asteroids-formation-discovery-and-exploration.html [https:/perma.cc/8TDA-SU3B]; Jean-Luc Margot et. al., Asteroid Systems: Binaries, Triples, and Pairs, in Asteroms IV 355 (Patrick Michel et al. eds., 2015).

${ }^{16}$ Choi, supra note 15 . For convenience, the key measurement of the size of an asteroid is sometimes spoken of as its "diameter," but since most asteroids are irregularly shaped, rather than round, the size given is roughly an average or representative distance across the object. See Strategy and Action Plan, supra note 5, at 2 n.2.

${ }_{17}$ Choi, supra note 15.

${ }^{18}$ NAS SURVEYS AND STRATEGIES, supra note 10 , at 15, 52, 128.

${ }^{19}$ NASA FAQ, supra note 1.
} 
meters and 126 meters (2,063 of them potentially hazardous), and 403 between $1 \mathrm{~km}$ and $1.26 \mathrm{~km}$ (81 potentially hazardous) ${ }^{20}$

The NASA Authorization Act of 2005 required the agency to implement a program to "detect, track, catalogue, and characterize the physical characteristics of near-Earth objects equal to or greater than 140 meters in diameter" and to create a roster containing 90 percent of such objects by $2020 .^{21}$ The program has succeeded in identifying hundreds of previouslyunknown asteroids each year, including virtually all of the biggest ones, but is currently not expected to reach the statutory goal-meaning that there is still a substantial number of unaccounted-for NEOs, some of them large enough to be of grave concern. ${ }^{22}$

As of January 1, 2018, NASA's bookkeeping reported having discovered, identified and tracked some 17,460 near-Earth asteroids (plus 107 comets), 1,877 of which were predicted to come within 7.5 million km of Earth's orbit. Just under half of these objects were gauged to be greater than 140 meters in diameter and nearly 1,000 were greater than $1 \mathrm{~km}$. Some 2,053 asteroids were discovered in 2017 and the bulk of the total inventory had been discovered since 2010, with fewer than 1,000 predating $2000{ }^{23}$ By some estimates, the task of surveying the entire population of near-Earth asteroids may now be $90 \%$ complete for objects larger than $1 \mathrm{~km} ; 50 \%$ complete for objects in the 140 meter range; and less than $10 \%$ complete for objects smaller than 100 meters in diameter. On average, 40 new NEOs are discovered each week. ${ }^{24}$

${ }^{20}$ DefINITION TEAM, supra note 6, at 27; see generally NASA FAQ, supra note 1.

${ }^{21}$ National Aeronautics and Space Administration Authorization Act of 2005, Pub. L. No. 109155, 119 Stat. 2895, 2922 (2005) (codified as amended at 42 U.S.C. $§ 16691$ (2010)). See generally, James C. Howe, US Space Policy and Planetary Defense, SPACE ReV. (Oct. 6, 2014), http:/www.thespacereview.com/article/2612/1 [https:/perma.cc/RX2W-H2DH] (reporting the evolving history of U.S. planetary defense activities); Landis \& Johnson, supra note 11, at 397.

22 See Strategy and Action Plan, supra note 5, at 4; NAS SuRveys AND StRategies, supra note 10, at 1-2, 29-50; AUDIT REPORT, supra note 5, at ii, 2-3.

${ }^{23}$ See Lindley Johnson, InT'L Asterom Warning Network (IAWN) Status Report to STSC 2018, 5-6, (Feb. 1, 2018), http:/www.unoosa.org/documents/pdf/copuos/stsc/2018/tech15E.pdf; NASA FAQ, supra note 1.

${ }^{24}$ LINDLEY JOHNSON, INT'L ASTEROD WARNING NETWORK (IAWN) STATUS REPORT TO STSC 2016, 7 (Feb. 16, 2016), https://www.cosmos.esa.int/documents/336356/932894/LAWN+Report+STSC+2016.pdf/bc1a 8020-fe59-4c8c-8431-9085d533373a [https://perma.cc/WR2D-XRAD];_Twenty Years of Tracking Near-Earth Objects, JeT Propulsion LAB. (July 23, 2018), https://www.jpl.nasa.gov/news/news.php?feature=7194 [https://perma.cc/K7KR-ME5V]. See also Asteroid Hazards: The View from Space, Minor Planet CTR., https://minorplanetcenter.net/asteroid_hazard_videos [https://perma.cc/GZ68-357B], for video 
NASA maintains an ongoing roster of NEOs, punctiliously tracking and publicizing close approaches. ${ }^{25}$ Near misses (at least on the scale of astronomical events) are common. Asteroid 2005 YU 55, for example, with a diameter of 350 meters, passed closer to Earth than the Moon in November $2011 .{ }^{26}$ Even more dramatic, an asteroid now named Apophis, approximately 370 meters in diameter, and discovered only in 2004, is projected to come within $31,000 \mathrm{~km}$ of Earth (i.e., closer than geosynchronous satellites) on April 13, 2029. In fact, until refined measurements were taken in 2013, it appeared that Apophis's 2029 fly-by might fit into a small "keyhole," in which the Earth's gravity would alter the asteroid's future orbit sufficiently to create a collision in 2036 - but it is now projected to miss by a wide margin. It is also noteworthy that because of its proximity to the Sun, Apophis could not be observed from Earth for several years. ${ }^{27}$ At the moment, the highest risk of Earth impact by a major known asteroid is from a 160-meter object designated as $2009 \mathrm{FD}$, which has a 1-in-714 chance of striking the planet in $2185 .{ }^{28}$

Even more startling is the frequency of surprise in this enterprise, when astronomers discover a new celestial body only when it is quite proximate to Earth or even when it has just whizzed past-sometimes disconcertingly closely. Detection is especially challenging if the asteroid is relatively small and dark, if it comes toward Earth from the general direction of the Sun (which can obscure observations), or if it is following a trajectory that is tilted off the plane of most of the Solar System. For example, on October 19, 2017, a

presentations about the abundance and dangers of asteroids.

25 See NEO Earth Close Approaches, Ctr. For NeAR EARTH OBJect Studies, https:/cneos.jpl.nasa.gov/ca/ [https://perma.cc/V3E6-VMXT]. See also Close Approaches, INT'L ASTEROID WARNING NETWORK, http://iawn.net/close-approaches.shtml [https://perma.cc/ZAT3-S97Q] (last updated Oct. 29, 2016).

${ }^{26}$ U.N. Open Forum on Near-Earth Objects, Space Mission Planning Advisory Group Report to STSC 2016, 7 (Feb. 16, 2016), http:/www.unoosa.org/documents/pdf/copuos/stsc/2016/tech-05E.pdf. This asteroid had been discovered in 2005.

${ }^{27}$ NAS SURVEYS AND STRATEGIES, supra note 10, at 58.

28 NASA FAQ, supra note 1; Did You Know..., NAT'L Aeronautics \& Space ADMIN, https://www.nasa.gov/planetarydefense/did-you-know [https://perma.cc/T2QN-HUHS]. Bennu, almost 500 meters in diameter, flies relatively close to Earth every six years and has a 1-in-2700 probability of impact between 2175 and 2189. NASA FAQ, supra note 1 . See also Planetary Defense: The Bennu Experiment, NAT'L Aeronautics \& SPACE Admin. (Dec. 6, 2018), https://www.nasa.gov/feature/planetary-defense-the-bennu-experiment [https:/perma.cc/5TTG-UBDW]. 
survey telescope in Hawaii discovered Oumuamua, the first known interstellar asteroidal object (i.e., one that originated outside our Solar System). The 230meter long body was detected five days after it had already flown past Earth, with a closest approach of 24 million $\mathrm{km}^{29}$ Likewise, the small (4 meter) asteroid 2008 TC3 was detected only 19 hours before it crashed to Earth in October 2008, leaving recoverable fragments in the Nubian Desert in northern Sudan. ${ }^{30}$

Even when an asteroid is detected, the ability to track it over a sustained period of time - in order to predict its future trajectory with confidence-may be erratic. Furthermore, it can be very difficult to discern with accuracy at a long distance the object's size, composition, and other key characteristics that would inform and enable an effective planetary defense operation.

\section{B. Impact Damage to Earth}

Millions of asteroids and smaller space particles collide with Earth every day, sometimes in celebrated meteor showers. Almost all of this material burns up in the atmosphere and the detritus drifts down to the surface without notice as dust. In fact, the planet grows by an incredible 100 tons per day in accreted space particles. ${ }^{31}$ Sometimes, an asteroid is sufficiently large and dense that part of it survives the passage through the atmosphere and crashes to the surface. Most of the time, of course, it falls into the oceans, but frequently shards of meteorite are retrieved on land. Very rarely, the incoming object causes identifiable damage on Earth. No human being is ever known to have been struck by a celestial fragment, ${ }^{32}$ but there have been numerous

29 Phil Davis, Ten Things: Mysterious 'Oumuamua, NASA ScI. (July 2, 2018), https://solarsystem.nasa.gov/news/482/10-things-mysterious-oumuamua/

[https:/perma.cc/TS26-65PL]; Small Asteroid or Comet "Visits" from Beyond the Solar System, NAT'L AERONAUTICS \& SPACE ADMIN, https:/www.nasa.gov/feature/jpl/smallasteroid-or-comet-visits-from-beyond-the-solar-system [https:/perma.cc/VF2T-2M8G]; Solar System's First Interstellar Visitor Dazzles Scientists, NAT'L AERONAUTICs \& SPACE AdMIN., (Nov. 20, 2017), https:/www.nasa.gov/feature/solar-system-s-first-interstellar-visitor-dazzlesscientists [https://perma.cc/BFV7-ETQM].

30 YEOMANS, supra note 8, at 125-27; NAS SURVEYS AND STRATEGIES, supra note 10, at 14 , 49. See also LYALL \& LARSEN, supra note 9, at 239, n. 73 (noting other examples of asteroids detected only just before, or after, they had passed Earth).

${ }^{31}$ NAS SURVEYS AND STRATEGIES, supra note 10, at 12 (estimating accretion of 50-150 tons daily); NASA FAQ, supra note 1. Some experts believe that the frequency of large asteroid impacts on Earth has increased dramatically in the past 300 million years, compared to the early days of the universe. See Sara Mazrouei, et. al., Earth and Moon Impact Flux Increased at the End of the Paleozoic, 363 SCIENCE 253 (Jan. 18, 2019).

${ }^{32}$ Michael B. Gerrard \& Anna W. Barber, Asteroids and Comets: U.S. and International Law 
dramatic instances of asteroid impacts, some of which are noted below in roughly increasing scale of the harm inflicted.

1. Chelyabinsk, Russia, 2013. On February 13, 2013, an asteroid approximately 20 meters in diameter entered the atmosphere at about 19 $\mathrm{km} / \mathrm{sec}$ over Chelyabinsk, a city in southern Siberia. Approaching at a shallow angle from the horizon (rather than plummeting vertically downward), it exploded at approximately $30 \mathrm{~km}$ altitude, with a force now estimated as equivalent to 400-500 kilotons of TNT (i.e., approximately 30 times the power of the 1945 Hiroshima nuclear detonation). The blast inflicted $\$ 30$ million in damage to 7,200 buildings over six cities in the region, and 1,500 people were injured (mostly by flying shards of glass from shattered windows). Remarkably, the asteroid had been completely undetected prior to its arrival, because its origin radiant had been close to the Sun. ${ }^{33}$

2. Tunguska, Russia, 1908. A century earlier, by coincidence also in Siberia, a larger asteroid (variously estimated at 30-100 meters) exploded in a similar airburst fashion about $5-10 \mathrm{~km}$ above the Earth's surface. There were few eye witnesses in that sparsely populated region and no contemporaneous investigations, but it appears that 80 million trees were flattened over 2,000 square kilometers. The explosive force has been estimated as equivalent to 10-50 megatons (roughly 1,000 times the Hiroshima blast). ${ }^{34}$

and the Lowest-Probability, Highest Consequence Risk, 6 N.Y.U EnV'T L. J. 4 (1997); NAS SURVEYS AND STRATEGIES, supra note 10, at 26. But see Evan R. Seamone, Note, When Wishing on a Star Just Won't Do: The Legal Basis for International Cooperation in the Mitigation of Asteroid Impacts and Similar Transboundary Disasters, 87 Iow A L. REV. 1091, 1102-03 (2002) (collecting reports of human casualties caused by space objects).

${ }^{33}$ Natalia A. Artemieva \& Valery V. Shuvalov, From Tunguska to Chelyabinsk via Jupiter, 44 Ann. Rev. Earth \& Planetary Sci. 37 (2016); Don Yeomans and Paul Chodas, Center for Near Earth Object Studies, Additional Details on the Large Fireball Event over Russia on Feb. 15, 2013, CTR. FOR NeAR EARTH OBJect StUd. (Mar. 1, 2013), https://cneos.jpl.nasa.gov/news/fireball_130301.html_[https:/perma.cc/76LE-R276]; Olga P. Popova et. al., Chelyabinsk Airburst, Damage Assessment, Meteorite Recovery, and $\begin{array}{lll}\text { Characterization, } & 342 & \text { SCIENCE } 1069\end{array}$ http://science.sciencemag.org/content/342/6162/1069.full [https://perma.cc/78T6-579P]; William E. Burrows, The Asterom Threat: Defending Our Planet from Deadly NearEARTH OBJECTS 13-31 (2014).

${ }^{34}$ Artemieva \& Shuvalov, supra note 33; Melissa Hogenboom, In Siberia in 1908, A Huge Explosion Came Out of Nowhere, BBC News (July 7, 2016), http:/www.bbc.com/earth/story/20160706-in-siberia-in-1908-a-huge-explosion-came-out-ofnowhere [https://perma.cc/CW3F-7CJV]; Luca Gasperini et al., The Tunguska Mystery-100 Years Later, SCI. AM. (June 30, 2008), https://www.scientificamerican.com/article/thetunguska-mystery-100-years-later/[https://perma.cc/WM74-2E2E]. See also Arnaud Mignan 
3. Barringer Meteor Crater, Arizona. Approximately 50,000 years ago, a 40-50-meter nickel-iron asteroid plunged into what is now north-central Arizona at $13 \mathrm{~km} / \mathrm{sec}$. It immediately excavated a crater that, despite erosion, still measures $1.2 \mathrm{~km}$ in diameter and 170 meters in depth. The impact energy has been estimated at 10 megatons, sufficient to devastate the Ice Age ecology and the nearby mammals. ${ }^{35}$

4. Chicxulub Crater, Mexico. Most infamously, a collision with a 10-15 $\mathrm{km}$ asteroid 66 million years ago is thought to have gouged the enormous crater $(150 \mathrm{~km}$ in diameter and $20 \mathrm{~km}$ deep) at the tip of what is now the Yucatan Peninsula. The global sequelae included sustained environmental changes widely deemed responsible for the sudden extinction of up to $70 \%$ of the Earth's plant and animal species, including most dinosaurs. ${ }^{36}$

An asteroid's destructive mechanisms. A major asteroid impact would trigger a variety of kill mechanisms on Earth, depending on its size, mass, speed, angle, and other characteristics. The location of the strike would obviously be another important factor - if the Tunguska airburst event, for example, had occurred over a major city instead of over unpopulated hinterlands, the results would have been catastrophic. Because only a small fraction of the Earth's surface is densely populated, the statistical odds disfavor that particular scenario. However, many population centers are located on ocean coastlines, rendering them vulnerable to a massive sea surge

et al., Risk Assessment of Tunguska-Type Airbursts, 56 NAT. HAZARDs 869, 869 (2011) (calculating that if the Tunguska event had occurred over modern New York City, it would have caused 3.9 million fatalities and $\$ 1.5$ trillion in property losses).

35 METEOR CRATER, http:/meteorcrater.com/ (last visited March 25, 2019) [https://perma.cc/NXN9-M2DA]; James Tobin, Meteor Crater Arizona, METEORITE EXCHANGE, https://www.meteorite.com/meteor-crater/ (last visited March 25, 2019) [https://perma.cc/G9AL-LZJZ]; NAS SuRveYs AND STRATEGIES, supra note 10, at 13; BARRINGER CRATER Co., https://www.barringercrater.com/the-crater/ (last visited March 25, 2019) [https://perma.cc/G5LY-9W7N]; John S. Lewis, RAIN OF IRON AND ICE: THE VERY REAL THREAT OF COMET AND ASTEROID BOMBARDMENT 30-36 (1996).

${ }^{36}$ About the Chicxulub Crater, ChicXulub Crater, http:/www.chicxulubcrater.org/_(last visited March 25, 2019) [https://perma.cc/88PP-CARR]; EDwaRd BRYANT, TsunAMI: THE UNDERRATED HAZARD 169, 178-80 (3d ed. 2008); Roff Smith, Here's What Happened the Day the Dinosaurs Died, NAT'L Geographic (June 11, 2016), https://news.nationalgeographic.com/2016/06/what-happened-day-dinosaurs-died-chicxulubdrilling-asteroid-science/ [https:/perma.cc/W2KB-V8N7]; Maddie Stone, What Killed the Dinosaurs Was More Devastating Than an Asteroid, Grzmodo (Oct. 1, 2015), https:/gizmodo.com/what-killed-the-dinosaurs-was-more-devastating-than-an-1733831989 [https://perma.cc/95CQ-Z57R]. 
should an asteroid impact the ocean.

If a large asteroid did hit Earth on land, the collision would first traumatically carve a giant crater, ejecting an enormous quantity of rock, soil, and other materials. The larger pieces would crash down relatively nearby, but the smaller debris would ascend into the atmosphere and be carried aloft for great distances and durations. A powerful shock wave would incite massive winds, flattening buildings and trees. The abundance of superheated rock and metal ejected from the crater would ignite firestorms, both near the impact site and at some distance away. The colossal shock wave could trigger massive earthquakes and volcanoes worldwide, and tsunamis would propagate-if the Chicxulub event had occurred in deep water, the resulting megawave could have been $4.6 \mathrm{~km}$ tall. Perhaps most damaging, the dust, ash, and soot that percolated into the atmosphere could remain suspended for years, obscuring sunlight, cooling the planet, and choking off photosynthesis; after only a couple of aborted growing seasons, global famine would ensue. ${ }^{37}$

Notably, in these circumstances, any response that would break the incoming asteroid into pieces could both alleviate and exacerbate the destruction the asteroid would cause. If a planetary defense intervention, such as a nuclear detonation, succeeded in blowing the NEO apart, some of the fragments would probably be thrown into askew trajectories, and they would miss Earth altogether; the fragmentation would also expose more of the asteroid's surface area to the atmosphere, increasing the fraction that would

\footnotetext{
${ }^{37}$ YeOMAns, supra note 8, at 110-14; Richard A. Posner, CATASTROPHE: Risk AND Response 3, 24-27 (2004); NAS SURVEYS AND STRATEGIES, supra note 10, at 20-21; Smith, supra note 36 ; Bryant, supra note 36 , at 172-80 (calculating that if the Chicxulub asteroid had fallen into deep water, it could have generated a tsunami $4.6 \mathrm{~km}$ high; in reality, it was probably 200 meters tall); Carl Sagan, Pale Blue Dot: A Vision of the Human Future in Space 311-12 (1994); John C. Kunich, Planetary Defense: The Legality of Global Survival, 41 A.F.L. REv. 119, 12325 (1997) (describing diverse catastrophic effects of large asteroid impacts); Clemens M. Rumpf et al., Asteroid Impact Effects and Their Immediate Hazards for Human Populations, 44 Geophysical Res. LeTters 3433 (2017); Clark R. Chapman and David Morrison, Impacts on the Earth by Asteroids and Comets: Assessing the Hazard, 367 NATURe 33 (1994); DeALing with tHe Threat TO EARTH From Asteroms AND COMETS, supra note 13, at 24-32; J. Lewis, supra note 35 at 176-82 (listing reports of property damage, injuries and deaths due to meteorite falls); Vitaly V. Adushkin \& Ivan V. Nemchinov, Consequences of Impacts of Cosmic Bodies on the Surface of the Earth, in HAZARDS DuE TO COMETS AND AsTERODS 721 (Tom Gehrels ed., 1994); Mark Boslough, Airburst Modeling, in HandBook of Cosmic HazARDS AND Planetary Defense 665 (Joseph N. Pelton and Firooz Allahdadi eds., 2015); Souheil M. Ezzedine \& Paul L. Miller, Water Impact Modeling, in HANDBOoK of Cosmic HAZARDS AND Planetary Defense 693 (Joseph N. Pelton and Firooz Allahdadi eds., 2015); Baum, supra note 13 , at 761 .
} 
burn before impact. However, the larger effect of the explosion would likely be adverse-it would create multiple simultaneous strikes over an even larger area, resulting in greater total devastation than a single, larger blow. ${ }^{38}$

\section{Assessing the Probabilities}

The following NASA charts summarize many of the key variables affecting planetary defense strategy. ${ }^{39}$

\footnotetext{
${ }^{38}$ NAS SURVEYS AND STRATEGES, supra note 10, at 84; PosNer, supra note 37, at 28; Mark Strauss, Helpful Tips for Nuking an Asteroid, NAT'L GEOGRAPHIC (Aug. 3, 2015), https:/news.nationalgeographic.com/2015/08/150803-space-nasa-asteroids-comets-nuclearweapons-defense/ [https://perma.cc/6XSF-WJ7W]; Bong Wie, Hypervelocity Nuclear Interceptors for Asteroid Disruption, 90 ACTA AsTRONAUTICA 146 (2012); SAGAN, supra note 37, at 317; Clay Dillow, How It Would Work: Destroying an Incoming Killer Asteroid with a Nuclear Blast, POPULAR ScI., Apr. 9, 2012, https://www.popsci.com/technology/article/201204/how-it-would-work-destroying-incoming-killer-asteroid-nuclear-blast

[https:/perma.cc/566U-SNJF]; Bong WIE ET. al., Final TeChnical Report of a NIAC Phase 2 Study: An InNovative Solution to NASA's NEO Impact Threat Mitigation Grand Challenge and Flight Valdition Mission Architecture Development 108-10 (2014), https:/www.nasa.gov/sites/default/files/files/Bong_Wi_Final_Report.pdf

[https://perma.cc/F77J-ZS9K]; DEALING WITH THE THREAT TO EARTH FROM ASTEROIDS AND COMETS, supra note 13, at 53-54. Notably, as an additional danger, if the fragmentation of the asteroid was the result of a nuclear explosion, then the dispersed pieces would carry hazardous radioactivity over a large area. But see Nahum Melamed \& Andre Brochier, Planetary Defense Far and Near: NASA GNC Webcast, AEROSPACE CORP. (June 20, 2018), https://mediaexserver.larc.nasa.gov/Academy/Play/96d8662a31a0427cbb5fb96d324c5bd11d (proposing a short-range kinetic intercept, to fracture an incoming asteroid that is discovered only very close to Earth, in order to disperse its effects); Peter Garretson, Now We Can Start to Defend Planet Earth, Over The Horizon J. (July 27, 2018), https://othjournal.com/2018/07/27/now-we-canstart-to-defend-planet-earth/[https://perma.cc/88X8-4ZN9].

${ }^{39}$ Chart 1 is from Audit RePorT, supra note 5, at 2; Chart 2 is from Strategy AND ACTION PLAN, supra note 5, at 2.
} 
Table 1. Approximate Impact Frequencies and Consequences from Near-Earth Objects

\begin{tabular}{|c|c|c|c|}
\hline 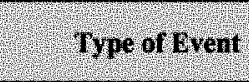 & 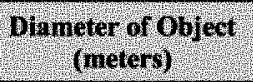 & 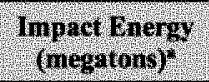 & 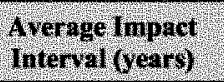 \\
\hline High altitude break-up & $<30$ & $<5$ & $1-50$ \\
\hline Tunguska-like event & $>30$ & $>5$ & $250-500$ \\
\hline Regional event & $>140$ & -150 & 5,000 \\
\hline Larye sub-global event & $>300$ & $-2,000$ & 25,000 \\
\hline Low global effect & 3600 & $-30,000$ & 70,000 \\
\hline Medium global affect & 31,000 & $>100,000$ & 1 millon \\
\hline High global effect & $>5,000$ & $>10$ million & 6 million \\
\hline Extinction-class event & $>10,000$ & 3100 million & 100 milition \\
\hline
\end{tabular}

* A megaton is a unit of measurenent deserbing the amount of energy released from an explosion. One megation equals the monnt of energy relessed from one million tons of TNT.

Source: NASA.

The first graphic indicates, for example, that events roughly comparable to the Chelyabinsk asteroid might occur once every 50 years, while the bigger Tunguska-like strike might be a once-in-250- or 500-year phenomenon. A regional event, which could endanger tens of thousands of square miles, would be expected every 5,000 years. At the high end of the spectrum, an extinction class occurrence, such as Chicxulub, would be anticipated on average, every 100 million years. ${ }^{40}$

The second chart depicts NASA's progress in identifying NEO threats. It suggests that nearly all of the largest asteroids (more than $1 \mathrm{~km}$ in diameter) have been detected, but that the survey is barely $50 \%$ complete for objects in the range of 150 meters, and that in accounting for smaller-but still potentially quite important - asteroids, a great deal more remains to be done.

${ }^{40}$ See also Igor Ashurbeyli, Protecting Planet Earth from Military and Non-Military Space Threats, in McGill Monograph Series V: Conflicts IN Space and the Rule of Law 3, 7 (Maria Manoli and Sandy Belle Habchi, eds., 2018) (estimating that in the past 600 million years, Earth has been struck about 60 times by asteroids $5 \mathrm{~km}$ or larger; collisions with asteroids up to a kilometer in size occur every 10 or 100 thousand years; objects up to hundreds of meters in diameter strike at intervals between tens and thousands of years; and during the past 100 years, four celestial bodies of between 40 and 60 meters have hit); SAGAN, supra note 37, at 314 (calculating that there is about a one-in-two-thousand chance that a catastrophic asteroid collision will occur within the lifetime of a baby born today; Michael R. Rampino \& Bruce Haggerty, Extraterrestrial Impacts and Mass Extinctions of Life, in HAZARDS DUE TO COMETS \& Asteroms 827 (Tom Gehrels ed., 1994) (observing that there have been multiple catastrophic extinction-level impacts by asteroids). 


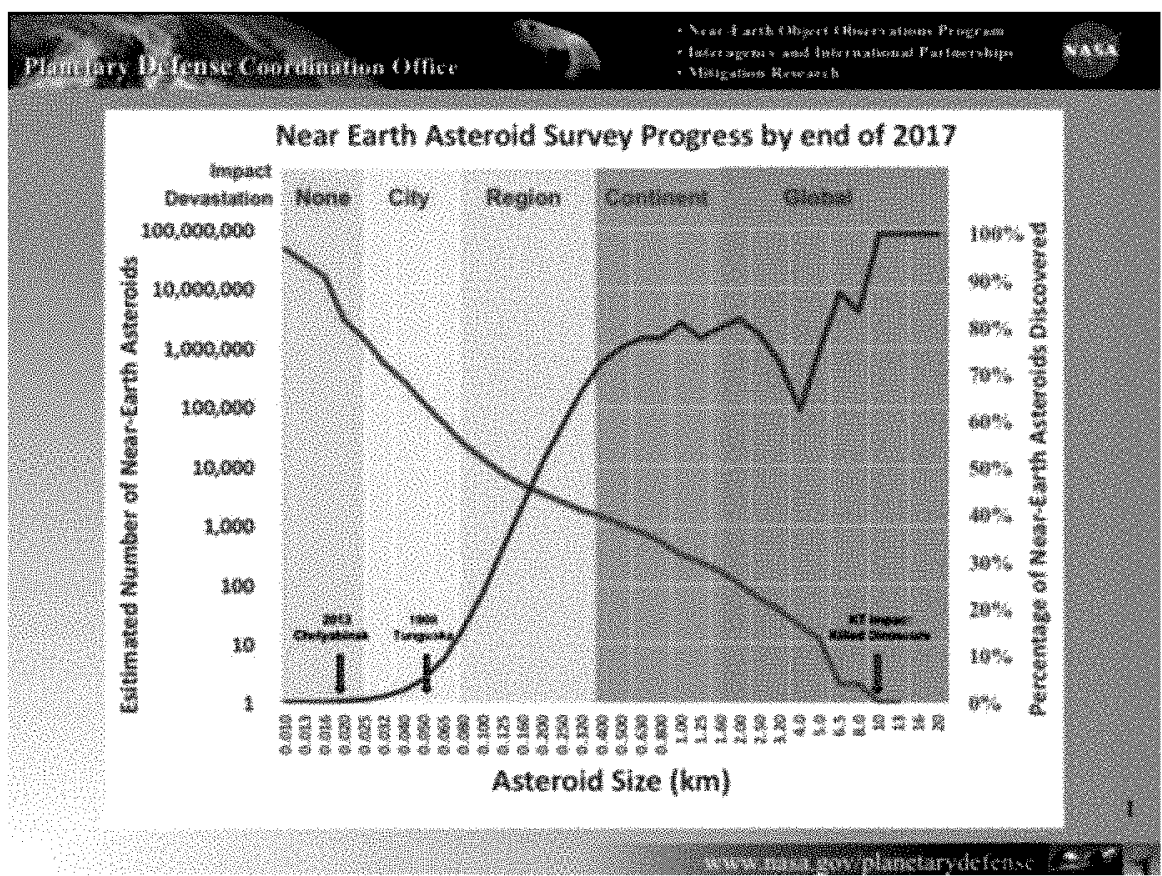

In response to these dangers, the two leading international planetary defense bodies, the Space Mission Planning Advisory Group (SMPAG) and the International Asteroid Warning Network (IAWN) have begun to develop a series of threshold criteria for responding to possible NEO strikes. In simplified form, these standards identify three levels of action:

- If an impact with an object greater than 10 meters in size is more than $1 \%$ probable, a global warning will issue.

- If the incoming object is greater than 20 meters in size and the probability of impact is greater than $10 \%$ within 20 years, terrestrial preparedness planning should begin.

- If the object is greater than 50 meters in size and the probability of collision is greater than $1 \%$ within 50 years, planning should begin for an eventual space mission to intercept the asteroid. ${ }^{41}$

${ }^{41}$ INT'L Asterod WARNing NeTWORK, SMPAG Action ItEM 5.1: ReCOMMENDED CRITERIA \& Thresholds FOR ACtION FOR POTENTIAL NEO IMPACt Threat (2017), https:/www.cosmos.esa.int/documents/336356/1503750/SMPAG_5.1_Report_NASA.pdf/f3 99e4eb-5947-867c-2422-b9dcb7e3649c; Romana Kofler et al., International Coordination on 
With today's limited technologies, if an incoming asteroid is smaller than approximately 100-140 meters in diameter, the primary response would likely have to be solely terrestrial. The logical protocol could include mass evacuation of the to-be-afflicted area (or region), sheltering of the population, preparation of first responders and other civil authorities, and assembly of relief and response supplies - comparable, in some respects to the actions undertaken in anticipation of a very large hurricane. ${ }^{42}$ If the threat is much larger than that, however, earthbound responses alone would not suffice, and a space mission would be undertaken, as discussed in the next Part.

\section{RESPONSE TO DATE}

A growing cadre of national space agencies, university observatories, non-governmental associations, hobbyists, and others have immersed themselves in the tasks of detecting, observing, tracking, and characterizing NEO dangers-and now, in beginning to develop plausible response strategies. While NASA and its U.S. associates have bankrolled the lion's share of the effort to date-now up to $\$ 50$ million per year-important contributions have come from many foreign azimuths too. ${ }^{43}$

Planetary Defense: The Work of the IAWN and the SMPAG, 156 Acta Astronautica 409 (2019). See also Jet Propulsion Laboratory Center for Near Earth Object Studies, Torino Impact Hazard Scale, https:/cneos.jpl.nasa.gov/sentry/torino_scale.html [https://perma.cc/Z2GN-SDVA] (describing the Torino Scale, adopted by the International Astronomical Union in 1999 as a method for assessing the danger of an asteroid, depending upon its size and location); David Morrison et al., Impacts and the Public: Communicating the Nature of the Impact Hazard, in Mitigation OF HAZARDous COMETS AND Asteroms (Michael J.S. Belton et al. eds., 2004); see also Palermo Technical Impact Hazard Scale, JET Propulsion LABORATORY CENTER FOR NEAR EARTH OBJECT StUdes https://cneos.jpl.nasa.gov/sentry/palermo_scale.html [https://perma.cc/2W2P-78T8] (describing another system for classifying the risk posed by an asteroid).

${ }^{42}$ NAS SuRVEYS AND STRATEGIES, supra note 10, at 66-70. See generally, I. Waddington et al., J-Value Assessment of Remediation Measures Following the Chernobyl and Fukushima Daiichi Nuclear Power Plant Accidents, 112 Process SAFETy \& ENvTL. Projection 50 (2017) (doubting the efficacy of evacuation as a response to a mass disaster).

${ }^{43}$ DAMIEN STRATEGY, supra note 10, at 4 (presenting U.S.' current leadership in dealing with asteroid dangers and identifying the need for further international cooperation); STRATEGY AND ACTION Plan, supra note 5, at 7, 13-14 (describing NASA as the global leader, but seeking enhanced international cooperation); Landis \& Johnson, supra note 11, at 394 (asserting that since 1998, "NASA-funded efforts have discovered more than $98 \%$ of the 16,000 NEOs currently known"); SEcure World Found., Near-Earth ObJects: ResPonding to the InTERNATIONAL Challenge 8, 12 (2014), https://swfound.org/media/170684/swf_neosresponding_to_the_international_challenge_2014.pdf (describing contributions from 
Two institutional frameworks-SMPAG and IAWN-have arisen to focus and coordinate these international NEO efforts. Each was inaugurated in 2014 after endorsement by the UN General Assembly and specifically by the Scientific and Technical Subcommittee of the UN Committee on the Peaceful Uses of Outer Space, ${ }^{44}$ but both are essentially creatures of the states and other organizations that founded them. They report annually to the Subcommittee, but retain their autonomy.

The mandate of IAWN includes to discover, monitor, and characterize the NEO population; to provide a recognized international clearinghouse for processing information from diverse sources; to coordinate campaigns for close observation of space objects identified as potentially hazardous; to establish criteria and thresholds for warning and action; and to develop an agreed data base of potential impact consequences. Thirteen space institutions from the United States, Europe, Russia, China, and elsewhere are official participants, and they collected nearly 22 million observations of asteroids and comets in 2017.45

numerous countries and entities); Adam Mann, B612 Plans Asteroid Hunt with Fleet of Small Satellites, 360 SCIENCE 842 (2018) (describing the efforts of the private organization B612 to improve the discovery and tracking of asteroids). As of 2010, NASA was spending approximately $\$ 4$ million per year on efforts to detect NEOS and approximately $\$ 1$ million annually on developing mitigation techniques. NAS Surveys and Strategies, supra note 10, at 1,30-34. The NASA budget allocation for planetary defense has risen sharply, to $\$ 50$ million in 2018, much of which is devoted to the DART mission, discussed infra, text accompanying note 52. See Landis \& Johnson, supra 11, at 397; Bryan Bender, NASA's Asteroid Defense Program Aiming for More Impact, Politico, Sept. 21, 2018 (noting a proposed increase in the budget of the NASA planetary defense office from $\$ 60$ million to $\$ 150$ million).

${ }^{44}$ Kofler et al., supra note 41; Secure World Found., supra note 43, at 17-20. The Committee on the Peaceful Uses of Outer Space has been the primary vehicle for pursuit of broad international cooperation in the exploration and use of space. It was created by the UN General Assembly in 1959 and has helped broker the major developments in space law and policy. See generally Committee on the Peaceful Uses of Outer Space, U.N. OFFICE FOR OUTER SPACE AFFAIRS

http:/www.unoosa.org/oosa/en/ourwork/copuos/index.html_[https:/perma.cc/TD6H-EXCR]. See G.A. Res. 68/75, International Cooperation in the Peaceful Uses of Outer Space, 18 (Dec. 11, 2013) (endorsing IAWN and SMPAG); Comm. on the Peaceful Uses of Outer Space, Status Report by the International Asteroid Warning Network (IAWN) and the Space Mission Planning Advisory Group (SMPAG) to the Scientific and Technical Subcommittee of the Committee on the Peaceful Uses of Outer Space, U.N. Doc. A/AC.105/C.1/2017/CRP.25 (Feb. 3, 2017).

${ }^{45}$ Int'l asterod Warning Network, Statement of Intent for Participation in the INTERNATIONAL ASTEROD WARNING NETWORK (2014), http:/iawn.net/documents/iawn_statement_of_intent.pdf; Membership, INT'L ASTEROD WARNING NETWORK, http:/iawn.net/about/members.shtml [https://perma.cc/5GVK-4QLC]; 
The companion institution SMPAG exists to help "prepare for an international response to a NEO impact threat through the exchange of information, development of options for collaborative research and mission opportunities, and NEO threat mitigation planning activities." ${ }^{46}$ SMPAG has 23 members and observers, ${ }^{47}$ and is addressing, inter alia, recommendations for planetary defense techniques, mitigation measures, and mission scenarios. ${ }^{48}$ SMPAG has also chartered an ad hoc lawyers' working group to advise it about the international law implications of potential courses of action. $^{49}$

The SMPAG and IAWN participating groups have undertaken a variety of NEO-related activities, including marshalling an ever-widening array of observation capabilities, and some national space agencies have initiated or planned operational space missions of various sorts. For example, JAXA, the Japanese space agency, is conducting the Hayabusa2 mission to land on asteroid 162173 Ryugu, survey it for a year and a half, collect samples, and return them to Earth in 2020. ${ }^{50}$ The European Space Agency's Gaia satellite

Kofler et al., supra note 41.

${ }^{46}$ Terms of Reference for the Near-Earth Object Threat Mitigation, Space Mission PLAnning ADVISORY GROUP, https:/www.cosmos.esa.int/web/smpag/terms-of-reference-v0 [https://perma.cc/PQ5Q-55PE] [hereinafter SMPAG Terms of Reference]; Kofler et al., supra note 41.

${ }^{47}$ Members, EuR. SPACE AGENCY, https://www.cosmos.esa.int/web/smpag/smpag members [https://perma.cc/58EK-3ES4].

${ }^{48}$ SMPAG Terms of Reference, supra note 46, ๆ 3; Space Mission Planning Advisory Group, Work Plan, Doc. No. SMPAG-PL-001/1.3 (October 2017), https:/www.cosmos.esa.int/documents/336356/336472/SMPAG-PL001_1_3_Workplan_11_October_2017.pdf/e09d002c-3112-acf6-2422-b05e56d07d3b.

${ }^{49}$ Space Mission Planning Advisory Group, Terms of Reference for the Space Mission Planning Advisory Group's Ad Hoc Working Group on Legal Issues (Oct. 11, 2017), https://www.cosmos.esa.int/documents/336356/336472/ToR_SMPAG_Ad_hoc_Working_Gr oup on Legal-Issues 1 0 2017-10-11.pdf/2bb8d5c1-c01c-dca0-2b25-1ffcecb1c270; Kofler et al., supra note 41 . The author has served as a member of this ad hoc legal working group, as a part-time consultant to NASA.

50 Asteroid Explorer "Hyabusa2," JAPAN AERosPaCE EXPLORATION AGENCY, http:/global.jaxa.jp/projects/sas/hayabusa2/ [https:/perma.cc/PDB6-XSMS] Dennis Normile, Asteroid Mission Faces "Breathtaking" Touchdown, 363 SCIENCE 16 (2019); Elizabeth Howell, Hayabusa2: Japan's 2nd Asteroid Sample Mission, SPACE.COM (October 23, 2018), https://www.space.com/40161-hayabusa2.html [https://perma.cc/Z7FJ-DTS5]; Hayabusa-2: Asteroid Exploration Mission, SPACEFLIGHT 101, http://spaceflight101.com/spacecraft/hayabusa-2/ [https://perma.cc/2XL9-TA9V]. See also Namrata Goswami, China in Space: Ambitions and Possible Conflict, 11 Strategic Stud. Q. 
maps the Solar System's asteroid population, providing more detailed modelling of the bodies and surveying swaths of the sky not already studied. ${ }^{51}$ NASA's Double Asteroid Redirection Test (DART) will be the first experiment to assess the kinetic impact method (described infra) to measurably modify the trajectory of a small asteroid (actually a 150 meter moonlet circling the larger asteroid Didymos) 11 million $\mathrm{km}$ from Earth in $2022 .{ }^{52}$

Nonetheless, despite this impressive and growing array of research and a surging interest in planetary defense, the actual operational capability to deflect a large incoming asteroid is still starkly limited. If a massive, proximate NEO were detected today, the world has shockingly little in situ capability for mounting any tested and well-established response. There are theories, concepts and drawing board illustrations, but no one could have sufficient confidence in the efficacy of any of the proffered schemes. What follows are thumbnail descriptions of a few of the leading candidates for arresting a threatening asteroid, each of which may have advantages and disadvantages in particular circumstances or against selected categories of targets-but none of which has been validated or even rigorously attempted and measured. ${ }^{53}$

74, 85 (2018) (discussing China's planetary defense activities and interests); Space Mission Planning Advisory Group, Roadmap of Relevant Research for Planetary Defense, Doc. SMPAG-RP-001 (Oct. 2017) (compiling a roster of NEO research activities undertaken by space agencies and others around the world); M. Antonietta Barucci et al., The Flybys of Asteroids (2867) Steins, (21) Lutetia, and (4179) Toutatis, in AsTERODS IV 433, 448 (Patrick Michel et al. eds., 2015).

${ }^{51}$ Challenges Closer to Home: Gaia's Asteroids, Eur. SpaCe Agency (last updated Feb. 9, 2017), http//sci.esa.int/gaia/58562-challenges-closer-to-home-gaia-s-asteroids/ [https://perma.cc/SD27-YKH4].

52 Double Asteroid Redirection Test (DART) Mission, NAT'L Aeronautics \& SPACE ADMIN., https://www.nasa.gov/planetarydefense/dart [https:/perma.cc/J2N2-U278] [hereinafter NASA's DART Interceptor]; Landis \& Johnson, supra note 11, at 407; see also, United States and Russia Sign Agreement to Further Research and Development Collaboration in Nuclear Energy and Security, ENERGY.GOv (Sept. 16, 2013), https:/www.energy.gov/articles/unitedstates-russia-sign-agreement-further-research-and-development-collaboration-nuclear

[https://perma.cc/WBM2-BRWB] (describing planned bilateral collaboration in several fields, including "defense from asteroids"); Jeffrey Lewis, Armageddon 2: The Supremely Bad U.S.Russian Plan to Nuke Asteroids, ForeIGN POL'Y, Sept. 24, 2013, https://foreignpolicy.com/2013/09/24/armageddon-2/ [https://perma.cc/QZ6T-PMBA] (critiquing the concept of using nuclear explosions against asteroids).

${ }^{53}$ See generally NAS Surveys AND StRategIES, supra note 10, at 4, 70-79; Asteroid and Comets Watch, Overview, NaT'L Aeronautics \& Space Admin., https://www.nasa.gov/mission_pages/asteroids/overview/index.html (last updated Aug. 3, 
Kinetic impactor. The simplest concept, and perhaps the most well developed, would be to launch a spacecraft (the more massive the better) to intersect the asteroid and ram into it at high velocity. A head-on collision could slow the asteroid a bit; an engagement from the rear could speed it up. Either way, the concussion could disrupt the timing of the asteroid's projected conjunction with Earth's orbit. Whether this sort of perturbation would alter the NEO's pathway sufficiently to miss our planet altogether would depend on multiple factors, such as the relative mass, speed, porosity, and trajectory of the two objects, but it might not take much of a shove to have the desired effect. A NASA study has assessed that a series of kinetic impactors could succeed in diverting an asteroid up to $1 \mathrm{~km}$ in diameter over a period of decades. The notion of kinetic interception has been confirmed, albeit to a very limited extent, by NASA's 2005 Deep Impact spacecraft, which released a small probe to collide with comet Tempel 1 . However, this concept would be less applicable to an asteroid that consisted of multiple small bodies (e.g., a rubble pile bound only loosely by gravity). ${ }^{54}$

2017) (observing that "no government agency, national or international, has been tasked or accepted the responsibility to stop such an asteroid"); YEOMANS, supra note 8, at 140-48; NEOSHIELD, supra note 10, at 22; J.P. Sanchez et. al., Multicriteria Comparison Among Several Mitigation Strategies for Dangerous Near-Earth Objects, 32 J. GuIDANCE ConTROL \& Dynamics 121 (2009) (comparing six deflection strategies); STRATEgy and Action Plan, supra note 5, at 11-12 (establishing a national goal of developing improved technologies for NEO deflection and disruption); Analysis of Alternatives, supra note 5, at 3-4, 19-23; DeALING With the Threat to EARTH FROM As TEROIDS AND COMETS, supra note 13, at 51-66; Alan W. Harris et. al., Asteroid Impacts and Modern Civilization: Can We Prevent a Catastrophe?, in As TERoIDS IV 835 (Patrick Michel et al. eds., 2015). Some countries' military forces have demonstrated some capacity for intercepting and shooting down satellites or incoming missile warheads in near-Earth space, but those operations are quite different from the problem of dealing with an incoming asteroid. See generally, BRIAN WEEDEN \& VICTORIA Samson, Global Counterspace Capabilities: An Open Source Assessment (2018); TodD Harrison et al., Space Threat Assessment 2018: A Report of the CSis aerospace SECURITY ProjeCt (2018).

${ }^{54}$ See NAS SuRveys AND StRATEgies, supra note 5, at 4, 73-76; Brent W. Barbee et. al., Options and Uncertainties in Planetary Defense: Mission Planning and Vehicle Design for Flexible Response, 143 AcTA AstronaUtica 37 (2017); Wie, supra note 38, at 151; NEOShIELD, supra note 10 , at 23-24, 82; DeAling WITH the Threat to EARTH From Asteroms AND Comets, supra note 13, at 55, 56; David P.S. Dearborn \& Paul L. Miller, Defending against Asteroids and Comets, in HandBook of Cosmic Hazards and Planetary DefEnse 733 (Joseph N. Pelton and Firooz Allahdadi eds., 2015). See also Thomas Drake Miyano, Moon-Based Planetary Defense Campaign, 5 J. SPACE SAFETy ENGINEERING 85 (2018) (advocating building kinetic interceptors on the Moon, and launching against asteroids from there, as a less expensive alternative). 
Gravity tractor. In this scenario, a relatively large spacecraft would rendezvous with the NEO, but instead of colliding, would travel alongside it on a parallel course. The conceit is that the microgravity attraction between the asteroid and the spacecraft would pull them toward each other; as the spacecraft continues to power itself incrementally away, the asteroid would (very minutely) follow. The amount of deflection would be infinitesimal (depending on the relative mass of the two objects) but over a long period of time (likely many years or even decades) it could result in a margin of safety for an Earth fly-by. This concept could succeed even on an asteroid that was rotating or that comprised multiple objects, but it would require a relatively massive and long-lived spacecraft. ${ }^{55}$

Propulsion. The mission concept here would be to land softly onto the asteroid and emplace some sort of engine, which would exert a direct propulsion, to nudge the asteroid in a desired direction. Alternatively, the lander could undertake to mine fragments of the asteroid and fling them into space, with the reverse thrust from that operation moving the asteroid subtly in the opposite direction. Again, these approaches - part of a group known collectively as "slow push-pull" methods-would work less efficiently with an unstructured clump of space material, or with an asteroid that is rapidly spinning or tumbling in space. ${ }^{56}$

Ion beam shepherd. Here, a hovering interceptor spacecraft would continuously shoot a column of high-velocity neutral particles (xenon or other) at the asteroid. The plasma would strike the asteroid, slowly pushing it forward. The spacecraft would require another propulsion system, to maintain its own position relative to the asteroid and shepherd it along, but no docking with the asteroid would be necessary. ${ }^{57}$

Laser ablation. A planetary defense mission could place a compact high-

\footnotetext{
${ }_{55}$ Daniel D. Mazanek et al., Enhanced Gravity Tractor Technique for Planetary Defense (4th IAA Planetary Defense Conference, IAA-PDC-15-04-11 (Apr. 13-17, 2015), https:/selenianboondocks.com/wp-content/uploads/2015/05/LAA-PDC-15-04-11_Final.pdf [https://perma.cc/5DWM-H9WU]; Edward T. Lu \& Stanley G. Love, Gravitational Tractor for Towing Asteroids, 438 NATURE 177 (2005); Claudio Bombardelli \& Jesus Peláez, Ion Beam Shepherd for Asteroid Deflection, 34 J. GUIDANCE Control \& Dynamics 1270 (2011); NAS SURVEYS AND STRATEGIES, supra note 10, at 72-73; NEOSHIELD, supra note 10, at 29-32; Karl Atkinson \& Steve Eckersley, D7.5.4: Ion Beam Shepherd Deflection Concept (July 7, 2012), in NEOSHIELD, supra note 10; Sanchez, supra note 53, at 131-34; DeALING WITH THE THREAT TO EARTH FROM ASTEROIDS AND COMETS, supra note 13, at 58-59.

${ }^{56}$ NAS Surveys and Strategies, supra note 10, at 72; Lu \& Love, supra note 55; Sanchez, supra note 53, at 126-30; Russell L. Schweickart et. al., The Asteroid Tugboat, 289 ScI. AM. 54 (2003).

${ }^{57}$ Bombardelli \& Pelaez, supra, note 55; NEOSHIELD, supra note 10 , at 32.
} 
energy laser onto a spacecraft and use the laser beam's energy to flashvaporize particles on the asteroid's surface. As those particles sublimate off the object, they impart a reverse thrust, which, repeated many times, could slowly nudge the asteroid in the opposite direction. Again, this concept would be most applicable to a relatively coherent, non-spinning NEO.$^{58}$

Albedo change. Here, the concept is to paint the asteroid (or part of it) with white or light-colored powder or fine chalk, altering its albedo (its light reflectivity or brightness). The new surfacing material would reflect sunlight more than the dark sections of the asteroid, which would therefore absorb more solar energy. As the asteroid spins in flight and re-radiates the energy, those differences in energy transfers would slightly alter its flight path. ${ }^{59}$

Explosions. Multiple possible strategies are implicated here, involving one or more conventional or nuclear explosions near, on, or inside the asteroid, to take advantage of different types of physical effects. A surface detonation would tend to thrust the asteroid somewhat in the opposite direction. Alternatively, the goal might be to fracture the object; for that purpose, a subsurface explosion would be more effective. To reach the interior of the asteroid, a drilling operation might be conducted, or a sequence of penetrating impactors could be launched against the same specific location on the asteroid, with each boring further to deposit its energy.

A more plausible and deft scenario would call for a nuclear detonation at some short distance from the asteroid, using the explosion principally as a source of energy that could gently nudge the asteroid. The radiated $\mathrm{x}$-rays and neutrons from the explosion would quickly excite volatile molecules on the object's surface. That heating would cause materials to evaporate or sublimate and fly off the asteroid; as they do so, they impart an opposite momentum to the body.

In all these scenarios, nuclear explosions are hundreds of times more efficient than ordinary high explosives. Fission and fusion reactions impart

\footnotetext{
${ }^{58}$ NEOSHIELD, supra note 10, at 33-34; Steve Eckersley \& Alistair Wayman, D7.5.5: Laser Ablation Deflection Concept (Aug. 6, 2013 report), in NEOSHIELD, supra note 10; Sanchez, supra note 58, at 130-31; DEALING WITH THE THREAT TO EARTH FROM AsteroIDS AND COMETS, supra note 13, at 60; Philip Lubin \& Gary B. Hughes, Directed Energy for Planetary Defense, in Handbook of Cosmic Hazards and Planetary Defense 941 (Joseph N. Pelton \& Firooz Allahdadi eds., 2015).

${ }^{59}$ D.C. Hyland et. al., A Permanently-Acting NEA Mitigation Technique via the Yarkovsky Effect, 48 Cosmic Res. 430 (2010); Rebecca Boyle, NASA's Bold Plan to Save Earth from Killer Asteroids, NBC News (Jan. 9, 2017); David Vokrouhlicky et al., The Yarkovsky and YORP Effects, in Asteroms IV 509 (Patrick Michel et al. eds., 2015).
} 
enormously more energy per weight than any conventional explosive could offer, and would likely be the only efficacious method for dealing with a large object ( 500 meters in diameter or bigger) within a short time (a few years). ${ }^{60}$

Again, to emphasize, none of these contrivances (with the partial exception of an experiment with the kinetic interceptor model) has ever been attempted in any operational mode; we are dealing, at this early stage, with raw concepts and untested hypotheses. It is possible that experiments in future decades can validate or exclude some candidates; for the interim, it may be worth pursuing multiple approaches. If an emergency arose today, operators might attempt multiple technologies, tools, and techniques, not knowing which method would be most efficacious; redundant and fallback concepts might have to be marshalled. ${ }^{61}$

But it is also clear, even now, that in some scenarios, a nuclear explosive device would carry unique advantages. Especially if the available time is short and the NEO is large-meaning that many of the gentler methods might not be effective-recourse might be had to the favorable weight-to-yield power

${ }^{60}$ NAS SUR VEYS AND STRATEGIES, supra note 10, at 76-79; M. Bruck Syal et al., Nuclear and Kinetic Approaches to Asteroid Defense: New Numerical Insights (46th Lunar and Planetary Science Conference, 2015); WIE ET AL., supra note 38; YeOMANS, supra note 8, at 145-48; NEOSHIELD, supra note 10, at 25-27, 42, 85, 137-38; Sanchez, supra note 53, at 123-26; DeALING WITH THE Threat to EARTH FROM As TEROIDS AND COMETS, supra note 13, at 63-66; Robert B. Adams et. al., Near Earth Object (NEO) Mitigation Options Using Exploration Technologies 14-15, 32-34 (2007 Planetary Defense Conference Paper), http://space.nss.org/media/2007-Near-Earth-Object-Mitigation-Options-Using-ExplorationTechnologies.pdf_[https:/perma.cc/3R5S-6FAB] (finding that a package of nuclear devices could divert a 100-500 meter asteroid within two years); R. Ryan C. Clement, et al., Impact Hazard Mitigation: Understanding the Effects of Nuclear Explosive Outputs on Comets and Asteroids (Sept. 2009), https:/amostech.com/TechnicalPapers/2009/Astronomy/Clement.pdf [https://perma.cc/B67U-VV92]; WIE ET AL., supra note 38 (proposing a subsurface nuclear explosion as the most effective means for dealing with an incoming asteroid if only a short warning time is available). In the near-vacuum of space, the blast (mechanical shock) effects of a nuclear explosion, which normally predominate in Earth-borne detonations, are virtually eliminated; conversely, the radiation effects, which are attenuated by the atmosphere, would be magnified in space. Nuclear Weapon Effects in Space, NaT'L Aeronautics \& SPACE ADMIN., https:/history.nasa.gov/conghand/nuclear.htm [https://perma.cc/T6QL-WBVG]. A nuclear explosion in space in the vicinity of Earth would generate electromagnetic effects that could damage or destroy satellites even at a substantial distance. 9 July 1962: 'Starfish Prime,' Outer Space, Preparatory Commission for the Comprehensive Nuclear-Test-Ban Treaty ORG., https:/www.ctbto.org/specials/testing-times/9-july-1962starfish-prime-outer-space [https://perma.cc/TM32-8KSS] (describing a U.S. nuclear test in low space that damaged several satellites).

${ }^{61}$ NAS SURVEYS AND STRATEGIES, supra note 10, at 86 (emphasizing uncertainties in any mitigation procedure and the consequent desirability of developing multiple approaches). 
of nuclear energy. However, international law imposes substantial special impediments to this option, as discussed in the next Part.

\section{INTERNATIONAL LAW REGARDING NUCLEAR WEAPONS IN SPACE}

Any use of a planetary defense mechanism would pose significant and diverse legal challenges. ${ }^{62}$ Concerns about environmental protection, ${ }^{63}$ tort

62 Note that the concept and mission of planetary defense are quite distinct from those of the
similar-sounding planetary protection. Planetary protection is concerned with the avoidance of
contamination via space missions-either accidentally carrying life forms from Earth to another
celestial body, or the reverse. See Office of Planetary Protection, NAT'L AERONAUTICs \&
SPACE ADMIN., https://planetaryprotection.nasa.gov/ [https://perma.cc/3UDA-4M95]; Review
and Assessment of Planetary Protection Policy Development Processes, NAT'L ACADEMIES OF
SCI. ENGINEERING \& MED. (2018), https://www.nap.edu/read/25172/chapter/HIi [https://perma.cc/2PM7-PYMQ]; Jeff Foust, A New Era of Planetary Protection, SPACE REv. (Apr. 30, 2018), http:/www.thespacereview.com/article/3483/1 [https://perma.cc/52SGZV6D].

${ }^{63}$ Numerous aspects of international environmental law are relevant for space missions, including planetary defense operations. For example, the importance of avoiding the creation of unnecessary long-lived debris in orbital space has given rise to widely-accepted international standards. See IADC Guidelines, supra note 9. In addition, the Outer Space Treaty requires parties to avoid "harmful contamination" of space and celestial bodies. OST, supra note 3, art. IX. International law also imposes on a state a duty to avoid allowing its territory to be used in a way that strongly adversely affects others. See Draft Articles on Prevention of Transboundary Harm from Hazardous Activities, with Commentaries, Rep. of the Int'l L. Comm'n 146, 53d Sess., Apr. 23-June 1, July 2-Aug. 10, 2001, U.N. Doc. A/56/10; President of the Int'l Court of Justice Ronny Abraham, Address to the Sixth Committee of the General Assembly (Oct. 28, 2016), https:/www.icj-cij.org/files/press-releases/0/19280.pdf [https:/perma.cc/2PT3-7JRA] (president of ICJ citing cases for the proposition that "the existence of the general obligation of States to ensure that activities within their jurisdiction and control respect the environment of other States or of areas beyond national control is now part of the corpus of international law relating to the environment.") More generally, the Precautionary Principle holds that even in cases of doubt or incomplete information, care should be taken to avoid harmful environmental effects. See generally U.N. Conference on Environment and Development, Rio Declaration on Environment and Development, U.N. Doc. A/CONF.151/26/Rev.1 (Vol. I), annex I (Aug. 12, 1992), http:/www.un.org/documents/ga/conf151/aconf15126-1annex1.htm [https:/perma.cc/3FTH-36B4]; Evan R. Seamone, The Precautionary Principle as the Law of Planetary Defense: Achieving the Mandate to Defend the Earth Against Asteroid and Comet Impacts While There Is Still Time, 17 Geo. InT'L ENvTL. L. REv. 1 (2004) (arguing that the precautionary principle requires governments to take action against threatening asteroids, even if the degree and timing of the possible harm is uncertain); Paul B. Larsen, Application of the Precautionary Principle to the Moon, 71 J. AIR L. \& Com.295 (2006); Hope M. Babcock, The Public Trust Doctrine, Outer Space, and the Global Commons: Time to Call Home ET, 69 
liability for unfavorable outcomes ${ }^{64}$ and other issues ${ }^{65}$ would be daunting, but are generally outside the scope of this Article. Moreover, international law has relatively little to say about the choice among most of the various planetary defense concepts described above. The selection of a gravity tractor, albedo change, or conventional explosion would pose immense challenges and require complex decision-making about tradeoffs for the scientific community, but most of the contemplated techniques are essentially indistinguishable from the perspective of international law. ${ }^{66}$

On the other hand, the possible employment of a nuclear explosive device is much more fraught under international law. Two principal treaties, as well as a number of others, seem diametrically opposed to the deployment and operation of nuclear weapons in space, and it is very difficult to finesse a nuclear planetary defense mission around these legal impediments. None of these international documents was crafted with anything like the asteroid

Syracuse L. Rev. (forthcoming 2019). See also Gerrard \& Barber, supra note 32, at 22-31 (contemplating the possibility that an anti-asteroid activity could require review under the National Environmental Policy Act).

${ }^{64}$ Convention on International Liability for Damage Caused by Space Objects, Mar. 29, 1972, 24 U.S.T. 2389, 961 U.N.T.S. 187 (hereinafter Liability Convention) presents an important set of related issues beyond the scope of this Article. Under that treaty, a party launching a space object is legally responsible to compensate victims for damage done by that object: the liability is "absolute" for damage inflicted on the surface of Earth or to aircraft in flight, and for "fault" if the damage is done to another state's objects in space. $I d$. arts. II, III. This potential liability could be enormous for an incompletely successful planetary defense operation (i.e., an intervention that succeeded in altering the trajectory of an asteroid, but did not suffice to cause it to miss Earth entirely, so it impacted a different location from where it would have otherwise struck). That potential liability could constitute an important deterrent to any state contemplating a planetary defense mission, and a Security Council resolution such as that proposed infra, Part VI, that authorized the operation would likely have to address the liability aspect in some fashion.

${ }^{65}$ For example, any program entailing an important degree of international cooperation in hightechnology areas such as space flight and nuclear weapons would require addressing the concerns of national and international export controls and technology transfers. See Overview of U.S. Export Control System, DEP'T OF STATE, https://www.state.gov/strategictrade/overview/ [https://perma.cc/R4JU-GNFY]; Compliance with U.S. Export Control Law, Regulations and Policies, Acquisition Guide, in DeP'T of ENERgY, ACQUisition GuDE ch. 25.001 (June 2016), https://www.energy.gov/sites/prod/files/2017/01/f34/Acq\%20Guide\%2025-

001\%20Compliance\%20with\%20US\%20Export\%20Control\%20Laws\%20June\%202016.pdf [https://perma.cc/C4JP-LLAL].

${ }^{66}$ This Article addresses mitigation measures that would be undertaken in space; in addition, terrestrial actions, such as sheltering in place, evacuations of regions that might be impacted, training and equipping of various types of first responders, and general civil defense programming, would be vitally important. 
problem in mind; the negotiators were concerned, instead, with the imperative of avoiding the proliferation of nuclear weapons, the radioactive contamination of the environment, or the extension into space of the perilous terrestrial nuclear arms race. ${ }^{67}$ Nonetheless, a plain reading of the texts of these long-standing and widely adhered to agreements poses a substantial bulwark against the kinds of prophylactic planetary defense measures now being contemplated.

This Part addresses first the 1967 Outer Space Treaty, the foundational instrument for all of space law; then the 1963 Limited Test Ban Treaty and its successors, which address nuclear explosions in various environments; and then a congeries of nuclear non-proliferation agreements which may impede possible patterns of international collaboration in a future nuclear planetary defense operation. As a framing matter, it should be understood that a future planetary defense mission might be undertaken by a single state (perhaps especially by the United States ${ }^{68}$ ), by a coalition of states (some of whom may not be parties to all of the relevant treaties described below), or by a consortium of states and non-state actors (such as private corporations or supra-national organizations which would not be directly bound by the treaties, but for whom the international requirements are still relevant).

\section{A. The Outer Space Treaty}

The Outer Space Treaty (OST) is the cardinal instrument of space law, containing several key provisions of "constitutional" significance. ${ }^{69}$ It has

\footnotetext{
${ }^{67}$ See Fabio Tronchetti, International Legal Consideration of Cosmic Hazards and Planetary Defense, in Handbook of Cosmic Hazards and Planetary Defense 1027, 1029 (Joseph N. Pelton \& Firooz Allahdadi eds., 2015) (observing that it is not surprising that it took some time for international law to begin to address planetary defense issues, because "The space treaties were formulated when the primary goal of their drafters was not to address hypothetical threats coming from outer space but to lay down basic rules enabling all States to participate in the exploration and use of outer space and prevent outer space from becoming an area of conflict."); Gerrard \& Barber, supra note 32, at 38 (concluding that the OST "was clearly concerned with protecting the Earth from threats of an Earthly origin and did not contemplate the need to use weapons to protect Earth from potential impacts by asteroids or comets.").

${ }^{68}$ See Strategy and Action Plan, supra note 5, at 5 (asserting that the United States must be prepared to act independently in all aspects of planetary defense); NAHUM MELAMED \& AVISHAI Melamed, Ctr. for Space Pol'y and Strategy, Planetary Defense Against Asteroid STRIKES: RISKS, OPTIONS, AND COSTS 2 (Jan. 2018), https:/aerospace.org/sites/default/files/2018-05/NEO-Defense_0.pdf_[https:/perma.cc/29WNW7XE].

${ }^{69}$ See generally Lyall \& LARSEN, supra note 9, at 49-73; Paul G. Dembling \& Daniel M.
} 
been joined by virtually all the leading spacefaring states, and its central mandates have been generally accepted as customary international law, thereby binding even non-parties. ${ }^{70}$ The treaty stipulates, for example, that space "shall be free for exploration and use by all States", ${ }^{71}$ that activities in space "shall be carried out for the benefit and in the interests of all countries", ${ }^{72}$ and that parties are to conduct their space activities "in accordance with international law, including the Charter of the United Nations, in the interest of maintaining international peace and security". ${ }^{73}$

For present purposes, article IV - especially its first sentence - contains the passages of greatest interest: ${ }^{74}$

States Parties to the Treaty undertake not to place in orbit around the Earth any objects carrying nuclear weapons or any other kinds of weapons of mass destruction, install such weapons on celestial bodies, or station such weapons in outer space in any other manner.

Arons, The Evolution of the Outer Space Treaty, 33 J. AIR L. \& Com. 419 (1967); Frans von DER DunK (rapporteur), Legal Aspects of NEO Threat Response and Related Institutional Issues: Final RePORT (Feb. 9, 2010), https:/docplayer.net/49137464-Legalaspects-of-neo-threat-response-and-related-institutional-issues-final-report.html [http:/perma.cc/26Z8-QC5L ] [hereinafter InstituTIONAL IssuEs]; Raymond L. Garthoff, The Outer Space Treaty: 1967 to the Present, 2 ENCYClOPEDIA OF ARMS CONTROL AND Disarmament 877 (Richard Dean Burns ed., 1993); Robert A. Ramey, Armed Conflict on the Final Frontier: The Law of War in Space, 48 A.F. L. Rev. 1 (2000).

${ }^{70}$ LyALL \& LARSEN, supra note 9, at 63-73; Stubbe, supra note 9, at 77-78; RESTATEMENT (ThiRd) of Foreign Relations Law In the United States $§ 1.02$ n.2 (Am. Law Inst. 1987) [hereinafter Restatement]. Bolivia, Columbia, Iran, and Malaysia, among others, have signed, but not ratified the OST; Cambodia, Latvia, and Liechtenstein are among those who have not signed. Comm. on the Peaceful Uses of Outer Space, Status of International Agreements Relating to Activities in Out Space as at 1 Jan. 2018, U.N. Doc. A/AC.105/C.2/2018/CRP.3 (Apr. 9, 2018), http:/www.unoosa.org/documents/pdf/spacelaw/treatystatus/AC105_C2_2018_CRP03E.pdf [http://perma.ce/UWF4-2R5U].

${ }^{71}$ OST, supra note 3, art. I, para. 2.

${ }^{72} \mathrm{Id}$. art. I, para. 1.

${ }^{73} \mathrm{Id}$. art. III.

${ }^{74}$ This Article sets aside the question of whether an effort to divert an incoming asteroid would constitute "appropriation" of that celestial body in contravention of article II of the OST. See id. art. II; see also Paul B. Larsen, International Regulation of Near Earth Objects (NEOs), Ger. J. AiR \& Space L. 104 (2018); Frans G. von der Dunk, Black Holes BV, Report on Legal Parameters for an Asterom Deflection Demonstration Mission as Part of the EADP 22 (Mar. 25, 2015), https:/www.black-holes.eu/resources/EADP_Report.pdf [http://perma.cc/GQY5-ZS99]. 
The Moon and other celestial bodies shall be used by all States Parties to the Treaty exclusively for peaceful purposes. The establishment of military bases, installations and fortifications, the testing of any type of weapons and the conduct of military maneuvers on celestial bodies shall be forbidden. The use of military personnel for scientific research or for any other peaceful purposes shall not be prohibited. The use of any equipment or facility necessary for peaceful exploration of the Moon and other celestial bodies shall also not be prohibited. ${ }^{75}$

A careful parsing of the first sentence reveals three distinct verbs that must be considered for evaluating a nuclear planetary defense mission: OST parties are forbidden: 1) to place a nuclear weapon in orbit around Earth; 2) to install such a weapon on a celestial body; and 3) to station such a weapon in space. The following Subparts scrutinize each element in sequence, as well as elaborating other key terms of art contained in that text.

First, however, a brief commentary about interpretive methodology: Under the Vienna Convention on the Law of Treaties, a document is to be interpreted "in good faith in accordance with the ordinary meaning to be given to the terms of the treaty in their context and in the light of its object and purpose." 76 At the same time, "a special meaning shall be given to a term if it is established that the parties so intended."77 As a supplementary means of interpretation, recourse may be had to the "preparatory work of the treaty and the circumstances of its conclusion," if the standard procedure "[l]eaves the meaning ambiguous or obscure; or [1]leads to a result which is manifestly absurd or unreasonable." 78

${ }^{75}$ OST, supra note 3, art. IV; see LYALL \& LARSEN, supra note 9, at 456-69 (parsing the content of OST art. IV); Dembling \& Arons, supra note 69, at 432-35 (history of negotiation of art. IV); Christopher M. Petras, The Debate over the Weaponization of Space - A Military-Legal Conspectus, 28 AnNals AR \& SPACE L. 171, 182-86 (2003).

${ }^{76}$ Vienna Convention on the Law of Treaties, art. 31, May 23, 1969, 1155 U.N.T.S. 331, 8 I.L.M. 679 (1969) [hereinafter VCLT]; Restatement, supra note 70, § 325. See generally, Richard Gardiner, The Vienna Convention Rules on Treaty Interpretation, THE OXFORD GUDE to Treaties 475 (Duncan B. Hollis ed., 2012); Julia Neumann, An Interpretation of the Outer Space Treaty After 40 Years, in InT'L Inst. Space L., Proceedings of the Fifteth COLloquium on THE LaW of OUter SPaCe 431 (2007); Rudolf Bernhardt, Interpretation in International Law, 2 ENCYCLOPEDLA OF INTERNATIONAL LAW 1416 (Rudolf Bernhardt ed., 1995).

${ }^{77}$ VCLT, supra note 76 , at art. 31.4 .

${ }^{78}$ VCLT, supra note 76 , at art. 32. Note, however, that this supplementary procedure serves only to allow interpreters to consult the negotiating history (the travaux preparatoires) and the 


\section{Place in Earth Orbit}

This first clause poses only modest constraints upon the most plausible planetary defense missions, but it might still impede some conceivable options. Most likely, for safety reasons, a mission to intercept an incoming asteroid would aim for a far-distant rendezvous, not in Earth orbit or other near-Earth space. The defensive spacecraft might be placed into an orbit around the Sun, but its trajectory would probably escape Earth's gravity altogether. ${ }^{79}$

In principle, it might be advantageous in some situations to pre-deploy the nuclear device temporarily into a near-Earth orbit, from which point it could be quickly dispatched to an intercept, or to have it loiter in orbit, while other elements of a coordinated planetary defense mission were being assembled. But that sort of advanced placement does not provide a major benefit, and would probably not be imperative. ${ }^{80}$

Similarly, sometimes, it is technically advantageous in terms of speed or cost for a spacecraft to circle the Earth a few times in a "transfer orbit," before ascending to a more distant flight path, but that approach would not be required here. ${ }^{81}$ In some other instances, a spacecraft might seek a "gravity boost" by adopting a flight path that whipped it partially around Earth, enabling it to achieve higher speeds for a long-distance mission, but again,

social context of the instrument in order to determine its meaning; art. 32 does not provide any general permission to alter or avoid the clear terms of a treaty that might be considered burdensome or unduly inhibitory. See Active Debris Removal, supra note 9, at 31 (arguing that "the provisions of the existing UN space treaties must, as a matter of necessity, be interpreted and applied in the most useful way in order to achieve optimal results.")

${ }^{79}$ See 1 Cologne COMmentaRy ON SPACE LAw 79 (Stephan Hobe et al. eds., 2009) [hereinafter COLOGNE COMMENTARY] (discussing OST provisions regarding placing nuclear weapons in Earth orbit). This Article does not discuss the Agreement Governing the Activities of States on the Moon and Other Celestial Bodies, Dec. 5, 1979, 1363 U.N.T.S. 3, which has attracted only 18 parties, and does not include the major space powers. That treaty recapitulates or expands some of the OST provisions addressed in this Article, including a prohibition against placing nuclear weapons into orbit around, or on a trajectory toward, the Moon or other celestial bodies within the Solar System. Id. arts. 1, 3.3.

${ }^{80}$ See Jason Mick, Russia, U.S. Eye Team-up to Build Massive Nuke to Save Planet from an Asteroid, DAILY TECH (Oct. 17, 2013), http:/www.dailytech.com/Russia+US+Eye+Teamup+to+Build + Massive+Nuke+to+Save + Pla net + from + an + Asteroid/article33569.htm [(reporting early proposal from Edward Teller to place in orbit anti-asteroid nuclear explosives).

81 Robert A. Braeunig, Orbital Mechanics, http:/www.braeunig.us/space/orbmech.htm [http://perma.cc/9SPQ-2KB3]; David Doody, Basics of Space Flight, NASA (2017), https://solarsystem.nasa.gov/basics/chapter4-1/ [http://perma.cc/S3TR-389X]. 
that is not an essential element, and it does not require the full Earth orbit that the treaty proscribes. ${ }^{82}$

\section{Install on a Celestial Body}

The OST does not define the term "install," but it is generally agreed that this provision was not intended to bar a nuclear device that merely "transits" space, such as while being transported by an ICBM en route to its target. ${ }^{83}$ In a similar vein, a planetary defense mission that directly ascended from Earth to an asteroid and immediately detonated the nuclear device upon impact with its target (or, depending upon the specific mission concept, detonated it in space in proximity to the asteroid) would not be constrained by this aspect of the treaty.

More complicated are scenarios in which the explosive lands on the asteroid prior to detonation. Such a maneuver might be advantageous for several reasons. For example, if the objective were to blast the asteroid into fragments (rather than to divert its pathway) a subsurface explosion would be more effective. ${ }^{84}$ This sort of mission profile could require drilling a borehole and lowering the device some meters below the asteroid's surface- that process looks more like "installing" it. ${ }^{85}$

${ }^{82}$ See ANALYSIS OF AlteRnAtIVES, supra note 5, at 2 (noting advantages of a planetary gravity assist swingby trajectory). See also Garthoff, supra note 69, at 882-83 (describing the legality under the OST of a "fractional orbital" system, under which a nuclear weapon would complete a partial, but not complete, orbit of Earth); 1 COLOGNE COMMENTARY, supra note 79, at 79 (arguing that the OST applies even to space objects placed into a partial orbit); Vladlen S. Vereshchetin, Limiting and Banning Military Use of Outer Space: Issues of International Law, in Essays in International LaW in Honour of Judge Manfred Lachs 671, 674 (Jerzy Makarczyk ed., 1984); Rex Zedalis \& Catherine Wade, Anti-Satellite Weapons and the Outer Space Treaty of 1967, 8 CAL. W. INT'L L. J. 454, 463-65 (1978).

${ }^{83}$ Bill Boothby, Space Weapons and the Law, 93 InT'L L. STUD. 179, 202-03 (2017); Garthoff, supra note 69, at 878; Kunich, supra note 37, at 130-31; JozEF GoLdBLAT, ARMS ConTrol: A Guide to Negotiations AND AgreEments 119-202 (1994) (observing that nuclear weapons in orbit would not be especially advantageous as a military matter); 1 COLOGNE COMMENTARY, supra note 79, at 79-80; Neumann, supra note 76, at 436 (observing that the OST does not include definitions of any of its key terms, and for many of those terms, the ordinary meaning is difficult to assess, so "Quite a lot of the provisions of the Outer Space Treaty thus require recourse to additional means of interpretation.")

${ }^{84}$ ANALYSIS OF ALTERNATIVES, supra note 5, at 20 (reporting that a nuclear detonation below the surface of an asteroid would be 10 to 100 times more efficient than an explosion above the surface); Dillow, supra note 38; WIE ET AL., supra note 38, at 5.

851 COLOGNE COMMENTARY, supra note 79 , at 80 (discussing whether simply placing an object onto a celestial body constitutes "installing" it). If the mission profile included a great deal of 
Alternatively, the concept of operations might be to emplace one or more nuclear explosives on the surface of the asteroid and detonate them in an optimal salvo - and it might be advantageous to deposit them in advance, so they would be ready to fire immediately, if other ongoing planetary defense attempts failed. Whether "placing" a nuclear device onto an asteroid amounts to "installing" it may be debatable, but if the space object's spin and weak gravity required some mechanical tethering or affixing of the devices, the treaty provision would seem to be triggered. ${ }^{86}$

\section{Station in Space in Any Other Manner}

The verb "station" is also undefined, and may be even more imprecise; it has not been subject to authoritative interpretation in practice by political or judicial bodies. Perhaps the negotiators intended the term to connote a permanent placement, at a fixed location - as if connected to the word "stationary." 87 However, in space, nothing is truly stationary-everything is moving at breathtaking speed-and one object may be said to be fixed in location only in reference to some other object. As an illustration of this linguistic puzzle, is the International Space Station stationed in space? ${ }^{88}$

construction or other activity on the surface of the asteroid, then the second paragraph of art. IV of the OST could also become relevant. That passage prohibits the "establishment of military bases, installations and fortifications" on a celestial body. OST, supra note 3 , art. IV; see also Id. at 84. See also Stephen Gorove, Arms Control Provisions in the Outer Space Treaty A Scrutinizing Reappraisal, 3 GA. J. INT'L \& COMP. L. 114, 118 (1973) (questioning whether a very small asteroid would qualify under the OST as a celestial body).

${ }^{86}$ Note that this analysis applies equally to a "test" and to an operational application of a nuclear explosive device on an asteroid. As discussed infra, text accompanying note 179, before using a nuclear device for planetary defense, it would be optimal to gain some practical experience with the techniques. But OST art. IV specifically prohibits "the testing of any type of weapons" on celestial bodies. Infra text accompanying note 101 .

${ }^{87} 1$ COLOGNE COMMENTARY, supra note 79, at 80 (suggesting that "'station' implies that the weapons are assigned a position in outer space for a certain period of time."). $C f$. the second paragraph of art. IV, which bans the "establishment of military bases, installations, and fortifications" on the Moon and other celestial bodies (emphasis added). OST, supra note 3 , art. IV.

${ }^{88}$ See Gorove, supra note 85, at 117 (commenting on the uncertain meaning of the OST's adoption of the word station); Zedalis \& Wade, supra note 82, at 461-63. Ordinary usage of the term "station" is also ambiguous in this regard. For example, sometimes we might say that a ship is stationed in the Mediterranean Sea, even though it moves a great deal through the area. Likewise, if a satellite is dedicated to a particular mission with a specific orbit, maybe it would be considered to be stationed along that entire corridor. In a similar sense, the term "stationkeeping" is routinely used to describe the maneuvers a satellite must occasionally undertake in order to maintain its assigned orbital trajectory. 
If a planetary defense spacecraft were to intercept an asteroid and then, instead of crashing into it, fly alongside it (as with the microgravity tractor concept described supra), it might be appropriate to consider the spacecraft as being "stationed" in space, with respect to the asteroid, even while both were traveling in parallel at high speed. Such an expansive interpretation might be warranted by the OST's emphasis of a prohibition against stationing a nuclear device in space "in any other manner." might be contemplated if, for example, there were multiple types of planetary defense concepts being attempted simultaneously, and the operators wanted to be able to employ the nuclear explosive promptly as a last recourse, if other attempts at diversion proved futile.

The prohibition against stationing would also seem to apply to any strategy that would insert a nuclear explosive device into a Lagrange point. These are the handful of specific locations in space where the gravitational pulls from two celestial bodies (such as the Sun and the Earth) are in equipoise, so the object can maintain its location indefinitely, at minimal energy cost. A spacecraft occupying a Sun-Earth Lagrange point does not orbit Earth, but is plausibly "stationed" in space, in a way that might have some conceivable advantages for a planetary defense mission; however, the OST would prohibit this option. ${ }^{90}$

\section{Nuclear Weapons or Any Other Kinds of Weapons of Mass Destruction}

Next, we must evaluate whether a nuclear explosive device that was employed for a planetary defense mission constitutes a "weapon" for purposes

${ }^{99}$ OST, supra note 3, art IV, para. 1. See Charge d'affaires a.i. of Italy to the United Nations, Letter dated Sept. 9, 1968, addressed to the Secretary-General of the UN General Assembly, U.N. Doc. A/7221 (Sept. 10, 1968) (asserting that OST art. IV would not prohibit a nuclear weapon contained in a space probe moving toward deep space; such a device is not "stationed"); U.N. GAOR 23rd. Sess., 175th mtg. at 1, U.N. Doc. A/7250/Add.1 (Oct. 17, 1968) (representatives of United States, U.S.S.R., and United Kingdom maintain that the OST language does prohibit placing a nuclear weapon into orbit around the Moon or another celestial body, and placing a nuclear weapon aboard a vehicle launched into deep space.)

${ }^{90}$ LyAll \& LARSEN, supra note 9, at 155; 1 COLOGNE COMMENTARY, supra note 79 , at 80; Claudio Maccone, Planetary Defense from Space: Part I - Keplerian Theory, 55 AcTA AstronaUtica 991 (2004) (proposing locating planetary defense missiles at two Earth-Moon Lagrangian points); Claudio Maccone, Planetary Defense from the Nearest 4 Lagrangian Points Plus RFI-Free Radioastronomy from the Farside of the Moon: A Unified Vision, 50 Acta Astronautica 185 (2002); David Wright et al., The Physics of Space Security: A REFERENCE MANUAL 45-46 (2005) (discussing Lagrange points). 
of article IV of the OST. If it does not, then all the above provisions are simply irrelevant. Unfortunately, the treaty is, once again, bereft of definitional assistance. $^{91}$

Some might argue that as germane for planetary defense, a nuclear explosive device should not be regarded as a weapon, because it is not being used for hostile or warlike purposes; it is not intended to inflict pain, damage, or harm upon enemy people or their property. ${ }^{92}$ Many implements can be

${ }^{91}$ See James D. Rendleman \& Brian D. Green, Space Weapons According to Stewart, in Monograph Series V: Conflicts In Space and the Rule of LaW 173 (Maria Manoli and Sandy Belle Habchi eds., 2018) (assessing that there is no generally accepted definition of "space weapon"); LYALL \& LARSEN, supra note 9, at 461 (suggesting that the drafters of the OST may not have contemplated a scenario involving a use of a nuclear device for planetary defense purposes); Fabio Tronchetti, A Soft Law Approach to Prevent the Weaponisation of Outer Space, in Soft Law In Outer Space: The Function of Non-Binding Norms in InTERNATIONAL SPACE LAW 361, 363-64 (Irmgard Marboe, ed., 2012) (observing that the term "space weapon" is not defined in any space treaty or domestic legislation); Michael Mineiro, The United States and the Legality of Onter Space Weaponization, 33 ANNALS OF AIR \& SPACE L. 441, 446-48 (2008) (surveying various definitions of space weapon); Cord-Georg Hasselmann, Weapons of Mass Destruction, Article IV Outer Space Treaty, and the Relationship to General Disarmament, in InT'L Inst. of SpaCe Law, Proceedings of the Twenty-Fifth Colloquium on the Law of Outer Space, September 27-October 2, 1982, Paris, France 101 (1983). See also Treaty on the Prevention of the Placement of Weapons in Outer Space, the Threat or Use of Force Against Outer Space Objects, June 10, 2014, art. I(b), http:/reachingcriticalwill.org/images/documents/Disarmament-

fora/cd/2014/documents/PPWT2014.pdf [http://perma.cc/49H3-NLDK] (draft treaty, referred to as PPWT, proposed by Russia and China, which defines the term "weapon in outer space" as any "outer space object or its component produced or converted to eliminate, damage or disrupt normal functioning of objects in outer space, on the Earth's surface or in the air, as well as to eliminate population, components of biosphere important to human existence, or to inflict damage to them by using any principles of physics.")

${ }^{92}$ Recourse to various standard or legal dictionary definitions of the term "weapon" does not provide great insight here. Those sources variously refer not only to implements that are used (or designed to be used, or suitable for use) in combat to harm people or property, but also more generally to various means of gaining advantage (citing usages such as "a weapon against cancer" or "laughter can be a great weapon.") See, e.g., Weapon, Google DictionaRY, https://www.google.com/search?q=definition + of + weapon\&rlz=1C1AVUC enUS733US746 \&oq=definition + of + weapon\&aqs $=$ chrome.. $69 \mathrm{i} 57 \mathrm{j} 015.4065 \mathrm{j} 1 \mathrm{j} 7$ \&sourceid $=$ chrome\&ie=UTF-8 (last visited Sept. 17, 2018) (denoting a thing designed or used for inflicting bodily harm or physical damage; a means of gaining an advantage or defending oneself in a conflict or contest); Weapon, MERRIAM-WEBSTER (2018), https://www.merriamwebster.com/dictionary/weapon (last visited Sept. 17, 2018) (something (such as a club, knife, or gun) used to injure, defeat, or destroy; a means of contending against another); Weapon, OXFORD LIVING DICTIONARY (2018), https://en.oxforddictionaries.com/definition/weapon_(last visited Sept. 17, 2018) (a thing 
wielded in multiple modes. A knife, for example, is properly understood to be a weapon when it is used to stab a person, but not when it is used to slice a loaf of bread; dynamite is a weapon when it is applied in combat to blow up an enemy's bridge, but not when it is applied in a peacetime mining operation. In like fashion, a nuclear explosive device can be a weapon (indeed, since the inception of the nuclear age in 1945, that is almost the only role that these implements have played ${ }^{93}$ ), but here it would be employed as a tool for global good. $^{94}$

designed or used for inflicting bodily harm or physical damage; a means of gaining an advantage or defending oneself in a conflict or contest); Weapon, Cambridge Dictionary (2018), https:/dictionary.cambridge.org/us/dictionary/english/weapon (last visited Sept. 17, 2018) (an object used in fighting or war, such as a gun or a bomb, or something used against someone; even laughter can be used as a weapon); Weapon, BLACK's LAW DicTIONARY ( $2 \mathrm{~d}$ ed. 1910) (an instrument used in fighting ; an instrument of offensive or defensive combat). Notably, a weapon can be used against an animal or against the environment (such as poisoning a river or setting oil wells on fire). In addition, there are various "non-lethal" weapons, which are devices intended to control, restrain, or capture, rather than to kill or inflict serious injury; DoD Executive Agent for Non-Lethal Weapons (NLW), and NLW Policy, Directive 3000.03E (Apr. 25, 2013), https://fas.org/irp/doddir/dod/d3000_03.pdf; Boothby, supra note 83, at 182 (adopting a definition of weapon as a device "that is used, intended or designed to cause injury or damage to an adverse party in an armed conflict."); 1 COLOGNE COMMENTARY, supra note 79, at 75-77 (observing that typically a "weapon" is used against an "enemy," and a non-human opponent could be an "enemy"); Anne Dienelt, The Shadowy Existence of the Weapons Review and Its Impact on Disarmament, Sec. \& Peace (forthcoming 2018), https://papers.ssrn.com/sol3/papers.cfm?abstract_id=3190285 (evaluating the meaning of "weapon" in article 36 of Additional Protocol I to the Geneva Conventions); Joan JohnsonFreese, Space and National Security, in The OxFord HANDBook OF U.S. NATIONAL SeCUR ITY 435, 438 (Derek S. Reveron et al. eds., 2018) (describing "a plethora of attempts to define a space weapon" and observing that "any definition that requires a determination of intent is problematic"); William H. BoOthBy, WeApons and the LaW of ARMed CONFLiCt 4-5, 346 (2d ed. 2016) (defining "weapon," for purposes of the law of armed conflict, as "an offensive capability that can be applied to a military object or enemy combatant" and as a device that is used, is intended to be used, or that has been designed for use to cause injury or damage to an adverse party); Weaponeering, DoD DiC TIONARY OF MILITARY AND Assoclated TERMs, (Aug. 2018) (defining "weaponeering" as the process for determining the "means required to create a desired effect on a given target"); Hannes Mayer, Is a Special Legal Regime for Planetary Defence Measures Necessary? (4th IAA Planetary Defense Conference, Paper IAA-PDC-1506-06, 2015) (asserting that an explosive device is not necessarily a weapon).

${ }^{93}$ See infra text accompanying note 112 (discussing Peaceful Nuclear Explosions).

${ }^{94}$ Perhaps it could be argued that the nuclear device deployed in space for a planetary defense mission should not be characterized as a weapon if it would be incapable of being used for an attack against a target on Earth - such as if the device were contained in a space object that did not have the shielding necessary to withstand re-entry through Earth's atmosphere. But even 
It must be acknowledged that for some purposes, the classification of a particular device as a weapon or as something else (e.g., as a tool or a shield) can reasonably depend upon the employment to which it is put or the intention of the designer or user. Nonetheless, some items, such as nuclear explosives, are inherently and permanently regarded as weapons, regardless of their intended immediate application. This Article maintains that the better view of the OST is that the treaty applies to all nuclear explosive devices in space, however they may be labeled or against whatever types of objects they may be directed. ${ }^{95}$ To decide otherwise would rob the treaty of much of its effect, enabling facile circumvention by any party who could simply claim that all of its orbiting nuclear devices were valid because they were intended for beneficent purposes. ${ }^{96}$ The treaty's fundamental object and purpose in article

then, the explosive could potentially be used against an enemy's satellites, and perhaps it could have military value as a "high-altitude nuclear explosion" delivering electromagnetic pulse (EMP) effects. See InstituTIONAL Issues, supra note 69, at 25 (noting "the general impossibility of building a device which is only capable of exercising force against a NEO and not against another space object, or indeed against a target on Earth.") (emphasis in original); Wilmot N. Hess, NASA Technical Note, The Effects of High Altitude Explosions (1964), http:/www.futurescience.com/emp/Hess-Wilmot.pdf [https://perma.cc/V3EY-HT94] (discussing the effects of nuclear explosions in the upper atmosphere or low in space); EMP COMm'N, REPORT OF THE COMmission to Assess the ThreAt to the United STATES from Electromagnetic Pulse (EMP) Attack: Volume 1: Executive Report (2004), available at http://www.empcommission.org/docs/empc_exec_rpt.pdf [https://perma.cc/29BJ-KZQY]; Yousaf M. Butt, The EMP Threat: Fact, Fiction, and Response (Part 1), SPACE REv (Jan. 25, 2010), http:/www.thespacereview.com/article/1549/1__[https://perma.cc/P9XG-HAL6]; Kunich, supra note 37, at 138-43 (arguing that a nuclear device used in space for planetary defense should not be considered a weapon under the OST); Baum, supra note 13, at 768-69. ${ }^{95}$ See Institutional Issues, supra note 69, at 26; 1 COLOGNe COMmEnTARY, supra note 79, at 76-77 (presenting the debate about whether the intended use of a nuclear device controls its designation of a weapon, and concluding that for nuclear devices, "A 'weapon' thus remains a 'weapon' irrespective of whether it may be used for civilian uses.") See also Treaty for the Prohibition of Nuclear Weapons in Latin America and the Caribbean art 5, Feb. 14, 1967, 634 U.N.T.S. 326 (entered into force Apr. 22, 1968), [hereinafter Treaty of Tlatelolco] (defining a nuclear weapon as "any device which is capable of releasing nuclear energy in an uncontrolled manner and which has a group of characteristics that are appropriate for use for warlike purposes."); Eilene Galloway, International Institutions to Ensure Peaceful Uses of Outer Space, 9 ANNALS OF AR \& SPACE L. 303, 311 (1984) (differentiating between the "purpose" of a device, which focuses on the psychological motivation of the user and the "use" of the device, which can be assessed by its actual application, and critiquing the OST for using those two terms interchangeably); Justin McClelland, The Review of Weapons in Accordance with Article 36 of Additional Protocol I, 85 IRRC 397, 404 (2003) (defining a weapon as "an offensive capability that can be applied to a military object or enemy combatant."); Bond v. United States, 572 U.S. 844, 860-62 (2014) (discussing the definition of "chemical weapon.")

${ }^{96}$ Note in response to the examples cited in the previous paragraph that if someone attempted 
IV, to prevent (at least specified aspects of) an arms race in space, would be frustrated if parties could evade its force by donning the garb of dual capability for a nuclear device. ${ }^{97}$

The parties to the OST have not authoritatively elaborated any shared interpretation of this provision of article IV, but it is conspicuous that no state has ever placed a nuclear explosive device into space and claimed justification based upon its purpose, size, or function. ${ }^{98}$ Moreover, this restrictive

to board an airplane or enter another type of secure area while carrying a knife, it would not suffice to explain that he or she intended to use the knife while in flight only to slice a loaf of bread or to open envelopes. The knife would surely be regarded as prohibited due to its inherent nature.

Even if the focus were to be on the intent (or design or purpose) of a nuclear device, rather than on its inherent nature, would we look at the original intent of those who first created the device, the intent of those who adapted it for its current application, or the intent of their future successors, who might have other purposes in mind?

${ }^{97}$ An important precursor for this aspect of art. IV was adopted in UN General Assembly Resolution 1884 on October 17, 1963, which unanimously expressed the members' determination "to take steps to prevent the spread of the arms race to outer space," welcomed the expressions by the U.S.S.R. and the United States of their intention not to station nuclear weapons in space, and called upon states to refrain from that activity and from causing, encouraging, or in any way participating in that conduct. The preamble to the OST recalled resolution 1884. G.A. Res. 18/1884 (Oct. 17, 1963); OST, supra note 3, preamble, para. 7; see also Dembling \& Arons, supra note 69, at 427; Garthoff, supra note 69, at 880. See also Statement by the President Announcing the Reaching of an Agreement on an Outer Space Treaty, 1966 PUB. PAPERS 1441 (Dec. 8, 1966) (in announcing the concluson of negotiations on the OST, U.S. presidential statement refers to the treaty as incorporating a "no bombs in orbit" resolution and highlights the importance of the OST as an arms control measure); Treaty on Outer Space: Hearings Before the S. Comm. On Foreign Rel., 90th Cong. 1 (1967) (statement of Cyrus Vance) (asserting the importance of the treaty as a measure that "prevents the spread of new weapons systems into new areas now.")

Nuclear materials also present another dimension of the dual capability problem. That is, highly enriched uranium may be useful both for nuclear weapons and for generating electrical power for long-duration space missions, potentially including those undertaken for planetary defense. Allowing the peaceful use of these materials while ensuring they cannot covertly be converted to military applications is a challenge the UN General Assembly addressed in its 1992 Resolution on Principles Relevant to the Use of Nuclear Power Sources in Outer Space, G.A. Res. 47/68 (Dec. 14, 1992); Harrison Tasoff, NASA Pushes for Nuclear-Powered Space Missions, ScI. AM. (Jan. 23, 2018), https:/www.scientificamerican.com/article/nasa-pushesfor-nuclear-powered-space-missions/ [https://perma.cc/79BK-8YEJ]. See also, NEOSHIELD D7.5.3: NTP Kinetic Impactor Deflection Concept Report 6-7 (July 19, 2013 report); 1 COLOGNE COMMENTARY, supra note 79, at 76 (discussing controlled nuclear explosions for spacecraft propulsion).

98 See Michelle Bentley, Weapons of Mass Destruction and US Foreign Policy: The 
interpretation is reinforced by the fact that, as a practical matter, if a nuclear device were today to be employed for a planetary defense mission, the device itself would have to be withdrawn from a weapon stockpile (or from a reserve roster of retired devices previously dedicated to weapons applications). All nuclear explosive devices currently held in any country's active inventory were designed, developed, and tested as weapons; there are no existing types that were originally conceived for any other peaceful purposes. ${ }^{99}$ It would ill

STRATEGIC USE OF A CONCEPT 56-57 (2014) (reporting that during the negotiation of the OST, U.S. military authorities had recommended that the treaty should ban "weapons of mass destruction," but not "nuclear weapons" in orbit, because that formulation would allow the deployment of very small nuclear anti-satellite weapons, which could have such localized effects that they did not create "mass" destruction. Ultimately, the United States did not assert that position, but maintained that all nuclear weapons, regardless of size, should be prohibited); U.S. Dep't of State, Foreign Relations of the United States, 1961-1963, at 892 (David W. Mabon \& David S. Patterson eds., Glenn W. LaFantasie gen. ed., 1995); 1 Cologne COMMENTARY, supra note 79 , at 76.

The second paragraph of OST article IV adds a further linguistic conundrum, by restricting the use of the Moon and celestial bodies (but not of space) exclusively to "peaceful purposes." Some authorities have asserted that "peaceful" in this context should be understood to mean "non-military," but the dominant interpretation is "non-aggressive," which allows defensive military activities. LyalL \& LARSEN, supra note 9, at 468-69; Stephan Hobe, The Meaning of "Peaceful Purposes" in Article IV of the Outer Space Treaty, 40 AnNals AR \& SpACE L. 10 (2015); Kubo Mačák, Silent War: Applicability of Jus in Bello to Military Space Operations, 94 InT'L L. StUd. 1, 15-19 (2018); Dembling \& Arons, supra note 69, at 432-35; Garthoff, supra note 69 , at 881; 1 COLOGNE COMMENTARY, supra note 79, at 82-84; Kunich, supra note 37, at 131-38; Gorove, supra note 85, at 119-20. But see Bin Cheng, Military Use of Outer Space: Article IV of the 1967 Space Treaty Revisited, in THE UTILIZATION OF THE WORLD's AIR Space and Free Outer Space In the 21st Century 305 (Chia-Jui Cheng \& Doo Hwan Kim eds., 1997) (arguing that the proper interpretation of "peaceful" in the OST is "non-military"); Vereshchetin, supra note 82, at 680-81.

99 See Tim Fernholz, The Strange But True Reason the US Isn't Destroying Its Old Nukes, DEF. ONE (Oct. 1, 2014), https://www.defenseone.com/business/2014/10/strange-true-reasonus-isnt-destroying-its-old-nukes/95561/ [https://perma.cc/8T3X-YZW4] (reporting that the Department of Energy is retaining some nuclear weapons that were originally slated for destruction, in order to preserve them as an "irreplaceable national asset" for possible use against an asteroid). Note that even if an entirely new type of nuclear device were to be created for planetary defense (rather than simply removing a weapon from military stockpiles and relabeling it) it would in all likelihood be designed, tested, and assembled at the same facilities that manufacture the weapons - there are no other suitable capabilities in the United States or elsewhere (especially if time were short). See David C. Trimble, U.S. Gov'T AcCounTABILITY Office, Department of Energy: Continued actions Needed to Modernize Nuclear InfRastructure AND ADDRess Management Challenges, GAO-18-374T (2018) (describing the facilities at which the United States develops and processes nuclear weapons); Heritage Foundation, U.S. NuClear Weapons Capability 379-93 (Oct. 5, 2017) (assessing the challenges confronting the U.S. nuclear weapons enterprise); OFFICE OF THE DEPUTY 
serve the treaty-makers to now allow a party to escape the OST by merely relabeling and re-purposing a fearsome weapon. ${ }^{100}$

Other potential planetary defense devices, on the other hand, could truly be considered dual-purpose and subject to categorization according to their immediate application. The gravity tractor device, for example, would not be a weapon if it were employed to try to divert an asteroid from Earth impact. But if a state were to attempt, hypothetically, to apply the same technology to steer a NEO toward Earth, to create a devastating shock upon its terrestrial enemy's territory, that employment would make it a weapon. ${ }^{101}$

Assistant SEC. OF Def. For Nuclear Matters, U.S. Nuclear Weapons Infrastructure, in 2016

NUCLEAR MATTERS HANDBOOK $\quad$ 47-56 (2016).

https:/www.acq.osd.mil/ncbdp/nm/nmhb/docs/NMHB2016_Ch4_web.pdf

[https://perma.cc/RE8W-MQTW].

Carl Sagan, among others, has pointed out that a nuclear device in space would be inherently capable of multiple applications: it could be employed for planetary defense, it could be used to threaten or attack enemy locations on Earth or on satellites, and it could potentially be applied to re-route an asteroid to strike targets on Earth. SAGAN, supra note 37, at 314-26 (asserting that the danger of misuse of a deflection capability as an offensive weapon is much greater than the danger of an imminent natural asteroid impact); Carl Sagan \& Steven J. Ostro, Long-Range Consequences of Interplanetary Collisions, 10 Issues SCI. \& TECH. 67, 70 (1994); Alan W. Harris, et al., The Deflection Dilemma: Use Versus Misuse of Technologies for Avoiding Interplanetary Collision Hazards, in HAZARDS DUE TO COMETS AND ASTEROIDS 1145 (Tom Gehrels ed., 1994). See also Gerrard \& Barber, supra note 32, at 19-20 (reporting concerns about the possible application of planetary defense capabilities for attacking an enemy). But see Russell L. Schweickart, The Real Deflection Dilemma (2004), http://research.dynamicpatterns.com/wp-content/uploads/2011/03/The-Real-Deflection-

Dilemma-Schweickart.pdf [https://perma.cc/PN79-96P3] (discounting the feasibility of weaponizing an asteroid).

${ }^{100}$ See infra, text accompanying note 112, (discussing Peaceful Nuclear Explosions).

${ }^{101}$ See generally S. Nozette et al., DoD Technologies and Missions of Relevance to Asteroid and Comet Exploration, in HaZARDs DuE to CoMETs AND Asteroms 671 (Tom Gehrels ed., 1994) (discussing the crossover between military and civilian space technology).

Note that the first sentence of OST art. IV does not mention weapons other than nuclear and other weapons of mass destruction, so conventional high explosives, non-nuclear planetary defense equipment, or other types of devices and techniques are not restricted in Earth orbit or in the void of space. 1 Cologne CoMMENTARY, supra note 79 , at 71,78 . However, the second paragraph of art. IV prohibits "testing of any type of weapons" on a celestial body. NASA's DART interceptor, supra note 52, is intended to ram into an asteroid, to test the ability to alter the asteroid's trajectory. If DART were loaded with explosives, instead of instrumentation, this activity might be regarded as a test of a weapon. If the explosion were done at standoff distance (rather than directly on the surface of the asteroid), but was designed to affect the asteroid, would that qualify as a test "on" a celestial body? (I.e., does "on" refer to the site where the testing hardware is located, or to the location where the effects are to be felt?) See Gorove, 


\section{Weapons of Mass Destruction.}

Do any of the other, non-nuclear planetary defense options (such as a high-energy laser, discussed supra ${ }^{102}$ ) constitute weapons of mass destruction? If so, they would be subject to the same OST article IV limitations elaborated above. Here, again, the OST fails to define one of its critical terms, but other particles of international law supply sufficient guidance.

There is no official or globally-accepted all-purpose definition of a weapon of mass destruction, but the core of the concept traditionally refers to nuclear, chemical, and biological weapons (and often radiological weapons, too). ${ }^{103}$ Some authorities have adapted the vocabulary to embrace additional tools or tactics that cause widespread disruption (such as cyber weapons), as contrasted with destruction, or that are, generally speaking, extraordinarily powerful (such as some modern conventional weapons, which can exceed the force of a small nuclear explosion). ${ }^{104}$ But extending the term so broadly would deprive the concept of weapons of mass destruction of its core function,

supra note 85 , at 121 (observing that the OST prohibits testing, but not use, of weapons in these circumstances); Gerrard \& Barber, supra note 32, at 34 (arguing that the OST would preclude a party "from testing any NEO destruction system even on the smallest, most remote asteroid."); Marcia Smith, Japan Lands Two Tiny Rovers on Asteroid Ryugu, SPACE Policy on Line (Sept. 23, 2018), https://spacepolicyonline.com/news/japan-lands-two-tiny-rovers-on-asteroid-ryugu/ [https://perma.cc/PS52-RTVS] (describing a forthcoming experiment in which a Japanese spacecraft will drop a copper impactor onto an asteroid at high speed, to create a crater, in order to allow access to materials beneath the asteroid's surface, in a test for planetary collision science).

102 See supra text accompanying note 58.

${ }^{103}$ Comm. for Conventional Armaments, Resolutions Adopted by the Commission at Its 13th Meeting, 12 August 1948, and a 2nd Progress Report of the Commission, U.N. Doc. S/C.3/32/Rev.1, 12 (Aug. 12, 1948) (defining weapon of mass destruction as including atomic explosive weapons, radioactive material weapons, and lethal chemical and biological weapons; G.A. Res. 51/37 (Dec. 10, 1996); G.A. Res. $63 / 36$ (Jan. 13, 2009); W. Seth Carus, Defining "Weapons of Mass Destruction" (Ctr. for the Study of Weapons of Mass Destruction Occasional Paper No. 8, Jan 2012) (describing multiple alternative definitions of weapon of mass destruction, and noting (at 39) that some of those definitions would require that the device inflict substantial human casualties); Bentley, supra note 98, passim; 1 Cologne COMMENTARY, supra note 79, at 77-78; Hasselmann, supra note 91, at 106-07.

104 See Robert J. Bunker, Weapons of Mass Disruption and Terrorism, 12 Terrorism \& PoL. VIOLENCE 37 (2000) (examining the effects of cyber and other weapons); Fred Burton, Dirty Bombs: Weapons of Mass Disruption, STRATFOR (Oct. 5, 2006), https://worldview.stratfor.com/article/dirty-bombs-weapons-mass-disruption [https://perma.cc/2HDA-S8XN]; BENTLEY, supra note 98, at 14-17; Hasselmann, supra note 91, at 101-02. 
and the OST here is best understood as intending to differentiate between the three or four most deadly implements and all others. ${ }^{105}$ A laser or a nonnuclear high explosive would therefore not constitute a weapon of mass destruction under the treaty. ${ }^{106}$

In sum, while the interpretation is not free from ambiguity, the best reading of the OST would apply the prohibitions to a nuclear explosive device (but not to a laser, a conventional explosion, or other contemplated tools) employed for a planetary defense purpose. The treaty would permit a directascent mission and a prompt interception and nuclear explosion, but would not allow the device to orbit Earth, to linger in space, to hover near the asteroid, or to land upon it and drill down.

\section{B. Limited Test Ban Treaty}

The Limited Test Ban Treaty (LTBT) is one of a series of instruments that deal with the detonation of nuclear explosive devices; for this purpose, it may be regarded as complementary to the Outer Space Treaty, which regulates the placement or deployment of the mechanisms.

Article I of the LTBT specifies:

Each of the Parties to this Treaty undertakes to prohibit, to prevent, and not to carry out any nuclear weapon test explosion, or any other

\footnotetext{
${ }^{105}$ Some commentators argue that the term weapon of mass destruction is a misnomer, because the three or four devices have so little in common. Spencer Ackerman, Let's All Stop Saying 'Weapons of Mass Destruction' Forever, WIRED (Mar. 29, 2013), https://www.wired.com/2013/03/weapons-of-mass-destruction/ [https://perma.cc/99PS-ASC2] (arguing that the weapons included in the term weapon of mass destruction are so diverse that it is misleading to categorize them together); JosepH CIRINCIONE ET AL., DEADLY ARSENALS: Nuclear, BIOlogical, AND Chemical Threats (2d ed. 2005) (concluding that nuclear weapons are the only true WMD); BENTLEY, supra note 98, at 9-14.

106 BENTLEY, supra note 98, at 53-57 (reporting internal U.S. debates during the OST negotiations about what types of weapons the treaty should address); Garthoff, supra note 69, at 881. But see Zedalis \& Wade, supra note 82, at 465-67. The WMD-related resolutions of the UN General Assembly cited supra note 89 also explicitly contemplate the possibility that new types of WMD might be created in the future, and would be embraced by the same legal analysis and restrictions. G.A. Res. 32/84 (Dec. 12, 1977); UnITED NATIONS InstituTE FOR Disarmament Research, New Types and Systems of WMD: Consideration by the CD (May 2011); Carus, supra note note 103, at 14-18; BentLEY, supra note 98, at 63-66. No new categories of WMD have yet emerged, but perhaps if someone were able in the future to capture an asteroid and direct it toward Earth to devastate an enemy, that might qualify as a new WMD.
} 
nuclear explosion, at any place under its jurisdiction or control: (a) in the atmosphere; beyond its limits, including outer space . . . ${ }^{107}$

As its name suggests, the LTBT was crafted principally to deal with "tests" of nuclear weapons, to interdict the next spin in the arms race by inhibiting the process of creating, refining, and validating new types of weapons. But it expressly also applies to "any other nuclear explosion," in order to ensure coverage of all other detonations, regardless of their function, type, or characterization. The debate recorded supra, about whether the OST applies fully to devices other than "weapons," based upon the purpose to which they are put, is thus inapplicable to the LTBT; ${ }^{108}$ planetary defense enjoys no possible interpretive escape hatch here. ${ }^{109}$ The LTBT also prohibits

${ }^{107}$ LTBT, supra note 4, art. I.1. The treaty also prohibits nuclear explosions under water and allows them only underground where radioactive debris will not spread outside the territory of the testing state. Id. See Garthoff, supra note 69, at 879 (noting that the LTBT negotiators focused on the problem of nuclear testing underground or in the atmosphere, and devoted relatively litte attention to testing in space).

${ }^{108}$ Because the LTBT text from 1963 was available to the drafters of the OST in 1967, there may be an inference that the decision not to use a phrase like "nuclear weapon or any other nuclear device" in the OST was a deliberate choice not to prohibit non-weapon nuclear devices in the newer treaty. That would be a weak inference, because the 1967 drafters did partially follow the LTBT model, by addressing nuclear weapons and other WMD - the 1967 sentence construction does follow the rhythm of the 1963 text. Probably, the 1967 drafters simply did not contemplate space applications of nuclear devices that were not weapons - there had been no discussion of possible peaceful nuclear explosions in space. See Dembling \& Arons, supra note 69, at 423 (citing LTBT as a precedent for the OST); 1 COLOGNE COMMENTARY, supra note 79, at 73-74 (considering the precedents consulted in negotiating OST art. IV). Note also Treaty on the Non-Proliferation of Nuclear Weapons, July 1, 1968, 21 U.S.T. 483, 729 U.N.T.S. 169 [hereinafter NPT] (article V of the NPT concluded in 1968, contemplated that nuclear explosions for peaceful purposes would be made available on a non-discriminatory and inexpensive basis, but again there is no indication that states contemplated conducting those activities in space. See infra, text accompanying note 112 (regarding peaceful nuclear explosions).

${ }^{109}$ But see Kunich, supra note 37, at 144-50 (arguing that the LTBT should be interpreted to allow nuclear explosions for peaceful purposes, such as planetary defense). Under the LTBT text, art. I, there could be a debate about whether a state has "jurisdiction" over the location in space or on the asteroid where it was detonating a nuclear device, since the OST precludes national appropriation, via assertions of sovereignty or otherwise, in space and on celestial bodies. But the concepts of jurisdiction, control and sovereignty are not identical. If the state lands its nuclear device on the asteroid, it does have "control" over that location while it is conducting the explosion; similarly, the state enjoys the relevant degree of control if it detonates the device at a standoff distance in unoccupied space near the asteroid. See Gerrard \& Barber, supra note 32, at 35 (arguing that the term "jurisdiction and control" was included in the LTBT in order to extend its coverage to a party's non-self-governing territories, but not to locations 
its parties from "causing, encouraging, or in any way participating in" a prohibited nuclear explosion that might be conducted by some other state. ${ }^{110}$ The LTBT has been joined by 126 parties, but the roster does not include some states of special interest here, notably France and China. ${ }^{111}$

In this connection, it is noteworthy that many people, throughout the 1950s and 1960s (and even thereafter) had championed the concept of "nuclear explosions for peaceful purposes," also known as "peaceful nuclear explosions" (PNEs). These activities, pursued in the United States under the caption of Project Plowshare, would have employed the high-power detonations for major civil engineering functions, such as digging a canal, excavating an underground storage cavern, or stimulating the recovery of oil and gas. PNEs were eventually discarded due to considerations of cost and environmental protection, but the overlap between PNEs and weapons development activities was problematic, too. In particular, countries feared that a rival's conduct of a PNE could constitute weapons testing in disguiseso any treaty restrictions on weapons tests had to apply fully to all manner of nuclear explosions, regardless of the avowed purposes. The discussion at the time did not mention planetary defense, but the logic applies in full; the LTBT can be read only as banning all nuclear explosions of all types in space. ${ }^{112}$

under enemy control); OST, supra note 3 , art. VIII (specifying that a state shall retain "jurisdiction and control" over an object that it launches into space).

${ }^{110}$ LTBT supra note 4, art. I.2.

${ }^{111}$ Treaty Banning Nuclear Weapon Tests in the Atmosphere, in Outer Space and Under Water, Aug. 5, 1963, 480 U.N.T.S. 43, https:/www.state.gov/t/isn/4797.htm/signatory [https://perma.cc/K842-E82T] (see Signatory List). This Article does not address the possibility that key provisions of the LTBT have become customary international law, binding even on non-parties. See Petras, supra note 75 , at 178 . The LTBT would not apply to nuclear explosions in war. Kunich, supra note 37, at 147-48.

112 Peaceful Nuclear Explosions, Comprehensive Test Ban Treaty Org. Preparatory COMMISsION [hereinafter CTBTO], https://www.ctbto.org/nuclear-testing/history-of-nucleartesting/peaceful-nuclear-explosions/ [https://perma.cc/S3NW-JEKH] (last visited Sept. 18, 2018) (noting that approximately seven percent of the world's nuclear explosions were conducted for peaceful purposes); Peaceful Nuclear Explosions, WORLD Nuclear Ass'N, http:/www.world-nuclear.org/information-library/non-power-nuclear-

applications/industry/peaceful-nuclear-explosions.aspx [https:/perma.cc/BY3E-D4A9 ] (last updated July 2010); Milo D. Nordyke, The Soviet Program for Peaceful Uses of Nuclear Explosions, 7 SCI. \& Global Sec. 1 (1998); Int'l Atomic Energy Agency, Peaceful Nuclear Explosions, 17 Int'L Atomic Energy Agency Bull. 53 (1975); Treaty on Underground Nuclear Explosions for Peaceful Purposes (and Protocol Thereto), U.S.-U.S.S.R., May 28, 1976, 15 I.L.M. 891, 1714 U.N.T.S. 387 [hereinafter PNE Treaty], https://www.state.gov/t/isn/5182.htm [https://perma.cc/8GNE-S9K6] (observing that "There is 
The LTBT would be reinforced by the 1996 Comprehensive Test Ban Treaty (CTBT), which would extend the prohibition to cover all nuclear explosions (both weapon tests and "any other nuclear explosion") at any location and in any environment. ${ }^{113}$ The CTBT has been signed by 183 states and ratified by 166 , but has not yet entered into force. ${ }^{114}$ Nonetheless, the UN Security Council has affirmed that the conduct of a nuclear explosion by a signatory would already be illegal, as an action that would defeat the object and purpose of the CTBT prior to its entry into force. ${ }^{115}$

no essential distinction between the technology of a nuclear explosive device which would be used as a weapon and the technology of a nuclear explosive device used for a peaceful purpose." Therefore, when the United States and the U.S.S.R. subsequently concluded a treaty that limited the size of underground nuclear weapons tests, they also had to conclude a companion instrument to limit PNEs in a similar fashion, to avoid an easy circumvention of the limits); Treaty on Underground Nuclear Explosions for Peaceful Purposes (and Protocol Thereto), U.S.-U.S.S.R., May 28, 1976, 15 I.L.M. 891, 1714 U.N.T.S. 387 [hereinafter PNET]; Threshold Test Ban Treaty, U.S.-U.S.S.R., July 3, 1974, 13 I.L.M. 906 [hereinafter TTBT]. Regarding a possible nuclear planetary defense mission, the PNET and TTBT would supplement the obligations of the LTBT, for the United States, Russia, and other successor states to the U.S.S.R., by requiring that nuclear explosions be conducted only underground and be smaller than 150 kilotons yield. See also Kunich, supra note 37, at 147 (noting that because it was impossible to differentiate between peaceful nuclear explosions and weapons tests, the LTBT negotiators included language to ban both).

113 Comprehensive Nuclear Test-Ban Treaty art. I.1., Sept. 24, 1996, S. TREATY Doc. No. $105-$ 28, 35 I.L.M. 1439, (not yet in force) [hereinafter CTBT]; CTBT parties would also undertake "to refrain from causing, encouraging, or in any way participating in the carrying out of any nuclear weapon test explosion or any other nuclear explosion." Id. at art. I.2. This prohibition effectively includes a complete ban on PNEs, but article VIII of the CTBT contemplates that a Review Conference may in the future return to the question of allowing underground PNEs. Id. at art. VIII; CTBTO, supra note 112.

114 The CTBT contains a highly unusual provision specifying that it will not enter into force for any state until it has been ratified by all forty-four countries named in its Annex II. CTBT, supra note 113 art. XIV.1. Thirty-six of those states have ratified, including France, Russia, and the United Kingdom. China and the United States have signed, but not ratified. Status of Signature and Ratification, Comprehensive Test Ban Treaty Org. Preparatory Comm., https://www.ctbto.org/the-treaty/status-of-signature-and-ratification/ [https://perma.cc/3MRJQW99] (last visited Sept. 18, 2018).

115 Under article 18 of the VCLT, supra note 76, during the interval between signature of a treaty and its entry into force, signatories are required to refrain from acts that would defeat the treaty's object and purpose. On September 15, 2016, the members of the UN Security Council declared that a nuclear test by any country would defeat the object and purpose of the CTBT. Joint Statement on the Comprehensive Nuclear-Test-Ban Treaty by the Nuclear Nonproliferation Treaty Nuclear-Weapon States, U.S. Department of State (2016), https://2009-2017.state.gov/r/pa/prs/ps/2016/09/261993.htm [https://perma.cc/CBR9-3DLZ]; S.C. Res. 2310 (Sept. 23, 2016). 
These restrictions on nuclear explosions remain of fundamental importance for international security and diplomacy. Although the LTBT is now 65 years old, it retains its vitality as a mainstay against a revivified nuclear arms race. President Bill Clinton referred to the CTBT as "the longestsought, hardest-fought prize in the history of arms control," 116 and the world would not lightly countenance any diminution of these treaties' effects.

In sum, the LTBT and the nascent CTBT constitute a blunt and allencompassing prohibition against all nuclear explosions in space, regardless of their purpose. While the treaties were crafted to address problems vastly different from planetary defense, their coverage is unambiguous and loopholefree. ${ }^{117}$

\section{Nuclear Non-Proliferation Treaties}

Finally, this Part addresses a collection of other international agreements that restrict the spread of nuclear weapons and associated materials and capabilities, doing so in a manner that might disrupt some possible patterns of international cooperation in a planetary defense mission.

Foremost among these instruments is the 1968 Nuclear Non-Proliferation Treaty (NPT), which segregates parties into "nuclear weapon states" (NWS), who already possessed nuclear weapons, and "non-nuclear weapon states" (NNWS), who have agreed never to obtain those devices. ${ }^{118}$ The concept is to permit (even to encourage) cooperation between NWS and NNWS on the non-weapons applications of nuclear energy, while interdicting transfers that could further disseminate nuclear weapons or control over them. ${ }^{119}$ The NPT

${ }^{116}$ Bill Clinton, President of the United States, Remarks to the 52nd Session of the UN General Assembly (Sept. 22, 1997), https:/19972001.state.gov/global/arms/ctbtpage/president/excerpt.html [https:/perma.cc/K2LH-XTUE]. 117 The LTBT and CTBT have nothing to say about the various non-nuclear planetary defense concepts described above; these treaties are relevant only to the use of a nuclear explosion.

${ }^{118} \mathrm{NPT}$, supra note 108 , arts. I, II.

119 The NPT is often said to rest on "three pillars," comprising non-proliferation (avoiding the spread of nuclear weapons to additional states), disarmament (reducing the nuclear arsenals of the states possessing them), and peaceful uses (encouraging collaboration regarding the nonweapons applications of nuclear energy). See DeP'T OF STATE, U.S. Delegation to tHe 2010 Nuclear nonproliferation treaty Review Conference, Treaty on the NonProliferation OF NuClear Weapons https:/www.state.gov/documents/organization/141503.pdf_[https:/perma.cc/A2RC-AT8A]; Toby Dalton et al., Toward a Nuclear Firewall: Bridging the NPT's Three Pillars (Mar.

2017),

https://carnegieendowment.org/files/CP_301_Dalton_et_al_Firewall_Final_Web.pdf 
identifies only five NWS: China, France, Russia, the United Kingdom, and the United States; all other parties (including several whose participation in a planetary defense mission could be quite valuable) are NNWS. ${ }^{120}$ In addition, four countries having some measure of nuclear and space capabilities-India, North Korea, Pakistan, and Israel (which has not acknowledged possession of nuclear weapons) - are not parties to the NPT. ${ }^{121}$

Establishing and enforcing a clear demarcation between permitted and prohibited NWS-NNWS collaboration is challenging, precisely because of the dual-purpose character of so much nuclear material, equipment, and technology. Repeated controversies arise regarding the sharing of nuclear power reactors and access to the associated elements of the nuclear fuel cycle. ${ }^{122}$ Even more intense (but largely shrouded from public scrutiny) questions arise regarding patterns of interactions within a military alliance, such as NATO. The precise alignment of national responsibilities regarding a possible use of a nuclear weapon can be fraught: if a German aircraft, flown by a German pilot, for example, might have the authority to drop a U.S. nuclear weapon in wartime, how does that arrangement satisfy the NPT? ${ }^{123}$

[https:/perma.cc/6CGG-28HM]; Treaty on the Non-Proliferation of Nuclear Weapons (NPT), Jul. 1, 1968, 729 U.N.T.S. 161, https:/www.un.org/disarmament/wmd/nuclear/npt/ [https://perma.cc/KB69-K996] (last visited Sept. 18, 2018). Notably, the NPT contemplates that the NWS will provide PNE services to NNWS on a non-discriminatory basis and at a low fee. NPT, supra note 108 , art. V.

${ }^{120} \mathrm{NPT}$, supra note 108 , art. IX.3.

121 Nuclear Weapons: Who Has What at a Glance, ARMS CONTROL Ass'N, https:/www.armscontrol.org/factsheets/Nuclearweaponswhohaswhat [https://perma.cc/L27RXGNQ] (last updated June 2018); Hans M. Kristensen \& Robert S. Norris, Nuclear Notebook: Nuclear Arsenals of the World, BuLl. OF THE ATOMIC SCIENTISTS, https://thebulletin.org/nuclear-notebook/ [https://perma.cc/6EN9-LE4P] (last visited Sept. 18, 2008); David S. Jonas, Variations on Non-Nuclear: May the "Final Four" Join the Nuclear Nonproliferation Treaty as Non-Nuclear Weapon States While Retaining Their Nuclear Weapons?, 2005 MICH. ST. L. REV. 417 (2005).

${ }^{122}$ Pierre Goldschmidt, The Proliferation Challenge of the Nuclear Fuel Cycle in Non-Nuclear Weapon States, INT'L ATOMIC ENERgy Agency (Apr. 26, 2004), https://www.iaca.org/newscenter/statements/proliferation-challenge-nuclear-fuel-cycle-nonnuclear-weapon-states [https://perma.cc/2TUQ-L4UH]; Jackie O'Halloran Bernstein, The NPT at 50: Successes, Challenges, and Steps Forward for Nonproliferation, 48 ARMS CONTROL TODAY 12 (June 1, 2018), https:/www.armscontrol.org/act/2018-06/features/npt-50-successeschallenges-steps-forward-nonproliferation [https://perma.cc/48Q3-USX3]; David S. Jonas \& Ariel E. Braunstein, What's Intent Got to Do with It? Interpreting "Peaceful Purpose" in Article IV.1 of the NPT, 32 EMORY INT'L L. ReV. 351 (2018).

${ }^{123}$ See Andrea Shalal, Germany Wants to Know If the US Will Let It Carry Nuclear Weapons on Its New Fighter Jets, Bus. InSDER (June 20, 2018, 9:44 AM), 
Similar questions might arise in a peacetime planetary defense mission that was undertaken jointly by NWS and NNWS - who would have to be precluded from executing which particular actions regarding the nuclear explosive device that was to be detonated against the asteroid? ${ }^{124}$

Other treaties also impinge further upon some states' legal competence for undertaking actions related to nuclear weapons. Five geographicallyspecific treaties establish regional "nuclear-weapon-free zones," within which the parties have assumed special commitments that supplement the NPT. ${ }^{125}$ The content of these treaties varies, but the Latin American agreement is typical in requiring parties to refrain from "engaging in, encouraging or authorizing, directly or indirectly, or in any other way participating in the

https:/www.businessinsider.com/r-germany-presses-us-on-potential-eurofighter-nuclear-role2018-6 [https://perma.cc/UXZ8-4FXY] (noting that under NATO agreements, Germany allows the United States to station nuclear weapons in Germany, and Germany operates several Tornado aircraft that are equipped to carry and deliver U.S. nuclear bombs): Holly Ellyatt, Russia's Lavrov Says the U.S. Is Training Europe to Use Nuclear Weapons Against It, CNBC (last updated Feb. 28, 2018, 7:15 AM), https:/www.cnbc.com/2018/02/28/russias-lavrov-saysus-breaching-nuclear-arms-agreement-ifax.html [https:/perma.cc/ES8F-DZPT]_(describing Russia's objection to NATO's joint nuclear missions); Tim Street, ORG Explains H5: NATO Nuclear Sharing, OXFORD Res. GROUP (June 29, 2018), https://www.oxfordresearchgroup.org.uk/Handlers/Download.ashx?IDMF=4c84f37f-19f04001-alf2-b13dadf348f0 [https:/perma.cc/9FHJ-NFFG]; OfFICE OF THE Historian, 232. Letter from the Under Secretary of State (Katzenbach) to Secretary of Defense Clifford, Apr. 10, 1968, Foreign Relations of the United States, 1964-1968, Volume XI, Arms Control and Disarmament, eds. Evans Gerakas, et. al. (Washington: Government Printing Office, 1997) https:/history.state.gov/historicaldocuments/frus1964-68v11/d232__ [https://perma.cc/P4N873GM]; Jeff King, Chris Lindborg, and Philip Maxon, NATO Nuclear Sharing: Opportunity for Change? BRITISH AMERICAN SECUR ITY INFORMATION COUNCIL, 9 BASIC GETTING TO ZERO PAPERS (Oct. 2008), https://www.files.ethz.ch/isn/92368/gtz09.pdf [https://perma.cc/8M93KXFJ]; William Alberque, The NPT and the Origins of NATO's Nuclear Sharing Arrangements, 57 IFRI PROLIFERATION PAPERS, (Feb. 2017), https:/www.ifri.org/sites/default/files/atoms/files/alberque_npt_origins_nato_nuclear_2017.p df [https://perma.cc/6D2F-BPMC].

${ }^{124}$ Note that the NPT deals with "nuclear weapons or other nuclear explosive devices," arts. I, II, so even a PNE would be explicitly covered. In this respect, the language of the NPT is similar to that of the LTBT, and unlike that of the OST. See supra text accompanying notes $107-09$.

125 See Thomas Graham Jr., The Alternate Route: Nuclear Weapon-Free Zones (2017); Nuclear-Weapon-Free Zones U.N. OfF. FOR DISARMAMENT AFF., https://www.un.org/disarmament/wmd/nuclear/nwfZ/ [https:/perma.cc/8JJ4-LZRJ] (last visited Sept. 18, 2018); Nuclear-Weapon-Free Zones (NWFZ) At a Glance, ARMs ConTRoL Ass'N, https:/www.armscontrol.org/factsheets/nwfz [https:/perma.cc/JET8-V6G4] (last updated July 2017). 
testing, use, manufacture, production, possession or control of any nuclear weapon." ${ }^{26}$ A future planetary defense mission that sought to enlist multiple countries in an operation involving a nuclear weapon against an asteroid would have a difficult time slipping through those prohibitions.

Finally, the 2017 Treaty on the Prohibition of Nuclear Weapons would impose yet additional constraints on participants' engagement with nuclear devices. ${ }^{127}$ This treaty has not yet entered into force, and most of the countries that are most active in space have not supported it, but a large roster of other states has endorsed it. ${ }^{128}$ The treaty prohibits parties from possessing, transferring, or using nuclear weapons and from allowing any stationing, installation, or deployment of any nuclear weapons or other nuclear explosive devices on their territory. ${ }^{129}$ In addition, it commits each party "never under any circumstances" to assist, encourage, or induce, in any way, anyone to engage in any activity prohibited to a party under the treaty. ${ }^{130}$ Again, such sweeping prohibitions would pose a significant challenge for international collaboration in any planetary defense mission involving a nuclear device.

In sum, the family of nuclear non-proliferation treaties would also inhibit close international cooperation in a planetary defense mission. Some of the most successful and sustained space missions have involved intimate collaboration among multiple states, as they pool their resources, expertise, and facilities in pursuit of goals that none of them could as readily accomplish or afford unilaterally. ${ }^{131}$ Artificially disentangling these spacefaring states,

\footnotetext{
126 Treaty of Tlatelolco, supra note 95, art. 1.1(a).

127 Treaty on the Prohibition of Nuclear Weapons, Sept. 20, 2017, 52 I.L.M. 347 https:/www.un.org/disarmament/wp-content/uploads/2017/10/tpnw-info-kit-v2.pdf [https://perma.cc/2ENV-8ALJ] [hereinafter TPNW].

${ }^{128}$ Signature/Ratification Status of the Treaty on the Prohibition of Nuclear Weapons, INT'L CAMPAign to AbOlish Nuclear WEAPONS, http//www.icanw.org/status-of-the-treaty-on-theprohibition-of-nuclear-weapons/ [http://perma.cc/E84Q-XZEW]; Positions on the Treaty, INT'L CAMPaign to ABolish Nuclear Weapons, http:/www.icanw.org/why-a-ban/positions/ [https://perma.cc/27PN-UG9Q] (last visited Sept. 18, 2018) (noting that 122 states voted in favor of adopting the TPNW, 60 states have signed it, and 14 have ratified). The countries that possess nuclear weapons, and their close allies, have declined to support the treaty.

129 TPNW, supra note 127, at art. 1.1.a, b, d.

130 TPNW, supra note 127 , at art. 1.1.e.

131 See, e.g., International Cooperation, NAT'L Aeronautics \& Space Admin., https://www.nasa.gov/mission_pages/station/cooperation/index.html_[https://perma.cc/LD5PQ5N41_(last visited Sept. 18, 2018); Elizabeth Howell, International Space Station: Facts, History \& Tracking, SPACE.COM (Feb. 8, 2018), https:/www.space.com/16748-internationalspace-station.html [http:/perma.cc/N2J8-JPMU]; D.A. Broniatowski et al., The Case for Managed International Cooperation in Space Exploration (CTR. FOR STRATEGIC \& INT'L STUD.,
} 
impeding their interaction because of differential status under other treaties, would therefore likely impose a cost on mission performance, but that is what international law requires. The states that have legally foresworn possession of nuclear weapons might have to be completely excluded from the operation; certainly, the degree of their engagement in the aspects related to the nuclear explosion would be greatly constrained. ${ }^{132}$

\section{LEGAL WORK-AROUNDS}

Even if the OST, the LTBT, and the collection of nuclear nonproliferation treaties greatly impede some, or all, states' abilities to employ a nuclear explosive device for planetary defense, there are some legally available solutions. This Part surveys several options, beginning with those that are contained within the familiar repertoire of standard treaty law. Next, the Part addresses a more novel concept, reliance upon the extraordinary prescriptive authority of the UN Security Council, and concludes that the powers arising under Chapter VII of the UN Charter offer the most advantageous path forward.

Finally, this Part addresses the more general, philosophical question of how much international law does, and should, matter in this type of situation. If humanity were truly facing an existential crisis, in the form of an onrushing asteroid that could not be abated in any other way, perhaps the constraints of the nuclear treaties should simply be peremptorily waived or disregarded. That sort of logic has some irresistible appeal, but this Part concludes that the world can, and must, develop a more capacious response, both for true emergencies and for the preparatory actions that might prudently be undertaken far in anticipation of a future, but not currently certain or imminent, crisis.

\section{A. Treaty Law}

\section{Amendment}

One obvious option, when a treaty's terms stand in the way of a set of

2006).

${ }^{132}$ For example, Kazakhstan, from where many space missions are launched, is a non-nuclearweapon state under the NPT, a party to the Central Asia Nuclear Weapon Free Zone Treaty, and a signatory and leading proponent of TPNW. Accordingly, Kazakhstan could not possess a nuclear device or allow one on its territory, and could not assist, encourage, or induce the use of a nuclear device. 
actions that might be vital to global security, would be to alter the treaty. Each of the treaties cited above contains individualized provisions for amendment. ${ }^{133}$

However, the amendment procedure is frequently cumbersome and timeconsuming; most of the treaties discussed here have never, or very rarely, been amended. The NPT, for example, specifies that an amendment cannot become effective for any party until it has been approved by a majority of all parties, all of the NWS, and all of the other parties that are members of the Board of Governors of the International Atomic Energy Agency. Even then, the amendment is operational only for the states that agree to accept it, creating a distinct possibility that the reformed rules could be applicable to some of the NPT parties, while others continued to cling to the original terms of the treaty. ${ }^{134}$

The LTBT is a bit easier to amend. There, an amendment requires support from a majority of all parties, including unanimity among the three "Original Parties" (Russia, the United Kingdom, and the United States) who retain veto power. Once approved by that process, the amendment enters into force for all parties, including those who did not support it. ${ }^{135}$

An alternative to formal amendment would be for the parties to the treaty to issue an authoritative joint statement of interpretation (or re-interpretation) of it, through which they could, by consensus, propound a revised meaning of the relevant terms. Parties could similarly supersede the instrument's text via their concerted behavior, effectively displacing some of the original obligations, including via customary international law. ${ }^{136}$ Again, however, a lack of unanimity would be troubling: what if some, but not all, parties to the treaty agreed to alter its meaning in the context of a planetary defense mission?

133 See generally, VCLT, supra note 76, arts. 39-41. See also Jutta Brunnee, Treaty Amendments, in The OXford GuDE to Treaties 347 (Duncan B. Hollis ed., 2012).

${ }^{134}$ NPT, supra note 108 , art. VIII.

${ }^{135}$ LTBT, supra note 4, art. II.

${ }^{136}$ VCLT, supra note 76, art. 31.3(b) (in construing a treaty, authorities should take into account "any subsequent practice in the application of the treaty which establishes the agreement of the parties regarding its interpretation." See, e.g., Seventh Review Conference of the States Parties to the Convention on the Prohibition of the Development, Production, and Stockpiling of Bacteriological (Biological) and Toxin Weapons and on Their Destruction, Additional Understandings and Agreements Reached by Previous Review Conferences Relating to Each Article of the Convention, UN Doc. BWC/CONF.VII/INF.5, (Sept. 28, 2011) (collecting the authoritative statements of interpretation agreed to by parties to the 1972 Biological Weapons Convention). 


\section{Withdrawal}

Besides amendment, another option is withdrawal. Each of these treaties (in somewhat varying terms) allows a party to exit the treaty if it determines that extraordinary events related to the treaty have jeopardized its supreme national interests. The withdrawal cannot be accomplished immediately: the LTBT and the NPT each requires three months' notice; the OST requires one year's notice. ${ }^{137}$

Obviously, withdrawal from a treaty of such consequence would be a momentous event; no party has ever withdrawn from the LTBT or the OST, or even publicly threatened or discussed the option. ${ }^{138}$ Only North Korea has withdrawn from the NPT, triggering profound international condemnation and sanctions. ${ }^{139}$ Withdrawal by a leading country — and a fortiori, a simultaneous exit from multiple treaties by multiple primary actors - would provoke a

\footnotetext{
137 OST, supra note 3, art. XVI; LTBT, supra note 4, art IV; NPT, supra note 108, art. X.1. As a variation, the parties could terminate the entire treaty by unanimous consent at any time, without a waiting period, under VCLT, supra note 76, art. 54. See generally, RESTATEMENT, supra note 70, sec. 332; Laurence R. Helfer, Terminating Treaties, in ThE OXFORD GUDE TO TReaties 634 (Duncan B. Hollis ed., 2012).

${ }^{138}$ See Lt. Col. Peter Garretson, Re-Opening the American Frontier: Recent Congressional Hearings on Space, SPACE REV. (July 3, 2017), http:/www.thespacereview.com/article/3275/1 [http://perma.cc/KE4L-UKMA]; Jeff Foust, Is It Time to Update the Outer Space Treaty?, SPACE REv. (June 5, 2017), http:/www.thespacereview.com/article/3256/1 [http://perma.cc/F773-EVHT]; John Hickman, Still Crazy after Four Decades: The Case for Withdrawing from the 1967 Outer Space Treaty, SPACE Rev. (Sept. 24, 2007), http://www.thespacereview.com/article/960/1 [http://perma.cc/22VP-ZPDJ].

Note that presumably a withdrawal must be justified by the withdrawing state's own supreme national interests; the provisions do not contemplate a good Samaritan exiting a treaty in order to serve some other state's supreme interests. In addition, note that the withdrawing state would still be bound by the parts of the relevant treaty that have become customary international law. OST art. IV is probably customary international law, while the status of relevant provisions of the LTBT or NPT is not clear. See OST, supra note 3, art. IV; LYALL \& LARSEN, supra note 9 , at 53 (explaining that a state that withdrew from the OST would still be bound by those treaty provisions that have passed into customary international law).

${ }^{139}$ Frederic L. Kirgis, North Korea's Withdrawal from the Nuclear Nonproliferation Treaty, AM. Soc'Y OF INT'L L. INSIgHTS (Jan. 24, 2003), https:/www.asil.org/insights/volume/8/issue/2/north-koreas-withdrawal-nuclearnonproliferation-treaty [http://perma.cc/EU9H-J7Y2]; Chronology of U.S.-North Korean Nuclear and Missile Diplomacy, ARMs CONTROL Ass'N, https://www.armscontrol.org/factsheets/dprkchron [http://perma.cc/M53A-36LV] (last updated Sept. 14, 2018); John Gershman \& Wade L. Huntley, North Korea \& the NPT, Is T. FOR POL'Y STUD. (Oct. 2, 2005), https://ips-dc.org/north_korea_the_npt/ [http://perma.cc/T49SYZGM].
} 
crisis. ${ }^{140}$ But perhaps a withdrawal done for the specific purpose of undertaking a vital planetary defense mission could be tolerated - especially if the affected state(s) promptly re-join the treat(ies) once the mission was successfully concluded. ${ }^{141}$

\section{Novation}

Another option could be novation - the negotiation and conclusion of a new treaty dealing in a different way with some or all of the subject matter of the existing accords. The replacement instrument could then supersede the original documents, displacing their older rules with newer provisions precisely tailored to the exigency of planetary defense. However, the creation of a successor agreement would likely be a difficult and time-consuming diplomatic activity, and even if successful, it would establish the new provisions only for states that voluntarily became parties to the new arrangement; a state that decided to cling only to the original instrument would not have its treaty rights and responsibilities altered. ${ }^{142}$

\section{Action by Non-Parties}

Another strategy would be to arrange to have the planetary defense activities undertaken only by states that have not joined the particular treaty

\footnotetext{
${ }^{140}$ Some important treaties permit more finesse: a temporary and partial suspension of selected provisions of the treaty, rather than a complete withdrawal. Treaties on human rights, for example, sometimes allow a derogation in emergency circumstances. See International Covenant on Civil and Political Rights art. 4, Dec. 16, 1966, S. Exec. Doc. E, 95-2 (1978), 999 U.N.T.S. 171 (entered into force Mar. 23, 1976) (allowing a party to derogate from certain provisions of the treaty in a time of officially declared public emergency that threatens the life of the nation); Emilie M. Hafner-Burton et al., Emergency and Escape: Explaining Derogations from Human Rights Treaties, 65 INT'L ORG. 673 (2011). None of the treaties under consideration in this Article contains that sort of provision. In addition, some provisions of the LTBT and other treaties might well be regarded as suspended during a time of international armed conflict, but not under the circumstances of a planetary defense danger.

${ }^{141}$ The withdrawing state could even re-join the treaty immediately, without waiting until after it had completed the planetary defense mission, if it submitted a reservation to exclude or modify the provisions of the treaty related to the mission it was about to undertake, and if other parties accepted the reservation. VCLT, supra note 76, arts. 2.1(d), 19-23. See Ins TITUTIONAL IssuES, supra note 69, at 27 (suggesting that in a planetary defense emergency, an expedited, temporary withdrawal from a treaty may be tolerated).

142 See generally, VCLT, supra note 76, arts. 30, 59; RESTATEMENT, supra note 70, sec. 323 See also Liara M. Covert, Before Celestial Bodies Collide - Enhanced Dialogue and Coordination: Precursors to a Treaty for Effective Near Earth Object (NEO) Response, 46 Proc. of the Inst. of Space L. 276 (2003).
} 
in question. ${ }^{143}$ As noted supra, France and China have never signed, ratified, or acceded to the LTBT; a few spacefaring states are outside the OST; and India, Israel, North Korea, and Pakistan have stayed away from the NPT. Accordingly, those states would be legally unconstrained about planetary defense activities regulated by those respective instruments. ${ }^{144}$ However, this artifice does not readily circumvent all the relevant treaties for any of the leading states, and as a political matter, certain key global actors (particularly Russia and the United States) might be unwilling to stand by and delegate nuclear planetary defense responsibility to others. In addition, treaty provisions that restrict parties from "assisting, encouraging, or in any way participating in" nuclear explosions would also disrupt collective action, and would even hinder indirect support.

\section{Excuse the Non-performance}

Finally, there is the important possibility that the leading states might simply violate the relevant treaties and the other parties might forgive or tolerate (or even welcome) that action. The states conducting the planetary defense operation might overtly acknowledge that they are departing from important legal commitments by employing nuclear explosive devices for the mission, and frankly admit that they are not pursuing a lawfully-prescribed path. They might then assert that the extreme conditions of an incoming

\footnotetext{
${ }^{143}$ It might also be possible to have the planetary defense mission be undertaken by a non-state actor, such as a private corporation or an international organization (such as the United Nations or the European Space Agency) that would build or receive nuclear and space launch capabilities, but was not a party to any of the relevant treaties. But individual states would still be involved in the program, at least as assisting, encouraging or inducing the activities, which could violate those states' treaty obligations. Notably, transferring a nuclear weapon "to any recipient whatsoever" would be a violation of the NPT. NPT, supra note 108, art. I. Moreover, each party to the OST is responsible for the space activities of its nationals, and for activities conducted via international intergovernmental organizations. OST, supra note 3 , arts. VI, XIII. See Kiernan Tinkler, Rogue Satellites Launched into Outer Space: Legal and Policy Implications, JUST SEC. (June 7, 2018), https://www.justsecurity.org/57496/rogue-satelliteslaunched-outer-space-legal-policy-implications/ [http://perma.cc/GF73-AJ74]; Tronchetti, supra note 67, at 1035-36; George D. Kyriakopoulos, Legal Challenges Posed by the Action of Non-State Actors in Outer Space, in McGill Monograph SerIEs V: Conflicts IN Space AND THE RULE OF LAW 273 (Maria Manoli \& Sandy Belle Habchi eds., 2018).

144 States that have declined to join the relevant treaty would nonetheless be bound by any provisions that have become customary international law, such as OST art. IV. See OST, supra note 3 , arts. IV.
} 
asteroid constituted "circumstances precluding the wrongfulness" 145 of their interventions, invoking the acknowledged principles of distress, necessity, and consent. ${ }^{146}$

Distress establishes a justification or excuse for temporary noncompliance with a treaty obligation when there is "no other reasonable way" to save human life. ${ }^{147}$ The companion concept of necessity applies when an otherwise-unlawful act is "the only way for the State to safeguard an essential interest against a grave and imminent peril," which does not necessarily jeopardize human lives. ${ }^{148}$ These criteria are stringent. They are not intended to allow states to wiggle too easily out of binding legal commitments-it would have to be a scenario in which a nuclear explosion objectively became the only viable mechanism for avoiding a catastrophe on Earth. ${ }^{149}$ A state may not invoke distress if the situation is due, in part, to its own conduct ${ }^{150}$ (including, perhaps, its delict in not pursuing alternative non-nuclear remedies early enough) or if the act in question is likely to create a comparable or

145 Draft Articles on Responsibility of States for Internationally Wrongful Acts, with Commentaries 169, Rep. of the Int'l Law Comm'n, 53d Sess., Apr. 23-June 1, July 2-Aug. 10, 2001, U.N. Doc. A/56/10, GAOR, 56th Sess., Supp. No. 10 (2001), G.A. Res. 56/83 (Dec. 12, 2001), corrected by A/56/49(Vol. I)/Corr.4 [hereinafter ILC]. See Stubbe, supra note 9, at 7274 (describing the status of the ILC draft articles).

146 The related concept of force majeure would not quite be applicable for a planetary defense mission. That excuse applies when an irresistible force compels a state to violate a legal duty, such as when a severe storm causes a state's ship or aircraft to navigate into a location it is legally forbidden to enter. Force majeure is not available when a state voluntarily undertakes an action; only when the state is physically unable to perform its obligations. In the context of planetary defense, an asteroid striking Earth may create conditions under which an impacted state would subsequently find it simply impossible to comply with some of its legal commitments under other treaties (such as an obligation to pay money or to export specified materials), but it would not justify departing from treaty obligations before the impact, by voluntarily using nuclear devices to prevent the asteroid collision. ILC, supra note 145, at art. 23.

${ }^{147}$ ILC, supra note 145 , at art. 24 . The distinguishing feature of distress, in this context, is that the state actor is motivated to save his or her own life or the lives of people entrusted to his or her care, regardless of nationality; it is not aimed at more general emergencies, as necessity can be. Id., cmt. 1,7 .

${ }^{148}$ ILC, supra note 145 , at art. 25 . Necessity may be invoked to protect a wide variety of critical interests, including preserving the environment or ensuring the safety of a population. $I d$., $\mathrm{cmt}$. 14.

${ }^{149}$ ILC, supra note 145 , at art. 25 , comment 15 (a plea of necessity is excluded if the illegal act can be avoided by pursuing other available legal options that are simply more expensive or less convenient). See Gabčíkovo-Nagymaros Project (Hung,/Slovak.), 1997 I.C.J. 4, at 39-46 (Sept. 25,1997 ) (denying a claim of necessity).

${ }^{150}$ ILC, supra note 145 , at art. 24.2(a), comment 9. 
greater peril for others ${ }^{151}$ (including, perhaps, if a nuclear explosion would shatter the asteroid, rather than divert it, generating even more grievous, widespread harm). Necessity, likewise, applies only to extreme cases; it is not available if the danger is merely possible, distant, or contingent, ${ }^{152}$ and the acting state cannot be the sole judge of how imperative the motivation is. ${ }^{153}$

Consent can also be a circumstance that precludes wrongfulness. That is, any state that requests, participates in, or otherwise supports a nuclear planetary defense mission would effectively waive its objection to the violation of the relevant treaties. Widespread multilateral engagement or at least endorsement for the anti-asteroid nuclear activity would therefore carry legal significance. However, states that affirmatively object or that passively decline to consent would not be precluded from complaining about the breach of their legal rights. ${ }^{154}$

${ }^{151}$ ILC, supra note 145, at art. 24.2(b), comment 10 (citing an illustration of a military aircraft carrying explosives that might cause a disaster in making an illegal emergency landing at a civilian airport, so it might not be able to invoke the distress doctrine).

${ }^{152}$ ILC, supra note 145 , at art. 25 , comments $15-16$ (noting that a peril that will occur in the distant future might nonetheless be considered imminent as soon as it is discovered, if a long lead time would be required to counteract it).

${ }^{153}$ ILC, supra note 145, at art. 25, comment 16 (noting that informed experts might have different views about how grave and imminent a peril is, and about whether the proposed response is the only effective step available).

${ }^{154}$ ILC, supra note 145, at art. 20. See I.C. MacGibbon, The Scope of Acquiescence in International Law, 31 BRIT. Y.B. INT'L L. 143 (1954) (assessing how to construe state inaction). Since a planetary defense operation would be so prominent and conspicuous, it might be fair to construe silence and inaction as consent - but there could still be states that affirmatively object. See also Tronchetti, supra note 67, at 1039 (observing that under the non-legally-binding International Charter on Space and Major Disasters, art. 5(4), signed October 20, 2000, states have agreed that no liability shall accrue for actions or inactions undertaken under the charter). See InT'L Charter SPACE \& Major Disasters, https:/disasterscharter.org/web/guest/home;jsessionid=09E2940249756FFE5E129EE1B1FE E467.jvm1 [http://perma.cc/YB87-6SWT] (last visited Sept. 18, 2018). Similar cross-waivers of liability exist for many space operations, such as among participants in the International Space Station under the Agreement Concerning Cooperation on the Civil International Space Station, Jan. 29, 1998, T.I.A.S. 12927 (entered into force Mar. 27, 2001); International Space Station Legal Framework, Euro. SPACE AGENCY, https://www.esa.int/Our_Activities/Human_Spaceflight/International_Space_Station/Internati onal_Space_Station_legal_framework [http://perma.cc/RBJ9-2X2B]_(last updated Nov. 19, 2013). See generally Von der Dunk, supra note 74, at 15-16 (reviewing liability waivers). Note, however, that a party to a treaty like the LTBT or the Treaty of Tlatelolco is also obligated not to encourage or induce a state to undertake any action inconsistent with the treaty; such provisions would preclude the party from consenting or acquiescing to actions of that sort. 
Another related alternative could be to invoke the doctrine about a "fundamental change of circumstances" to suspend the operation of the relevant treaties. Under international law, a party may dodge a treaty's provisions if the relevant conditions have been altered in a way that is unforeseen, affects an "essential basis" for the parties' joining the treaty, and radically transforms the obligations. ${ }^{155}$ This escape hatch might initially seem applicable in a planetary defense scenario, but modern international law has established a tough standard for employing it. In particular, the "unforeseeability" criterion would be problematic here. ${ }^{156}$

Finally, the doctrine of individual and collective national self-defense might also be thought applicable here, because it is preserved as an "inherent right" of sovereigns under article 51 of the UN Charter. ${ }^{157}$ However, this particular right of self-defense applies only in the event of an "armed attack," and the relevant portions of the Charter address provocations amounting to a "use of force" or an "act of aggression," not natural phenomena such as an asteroid impact. ${ }^{158}$ That important body of law, therefore, is essentially irrelevant to planetary defense, despite the similarity of some of the rhetoric. ${ }^{159}$

LTBT, supra note 4, art. I.2; Treaty of Tlatelolco, supra note 95, art. 1.2.

155 VCLT, supra note 76, art. 62.

${ }^{156}$ See Gabčikovo-Nagymaros Project, supra note 149, at 64-65 (denying a claim of changed circumstances);. Barry E. Carter, Allen S. Weiner, \& DunCan Hollis, International LAw 118-19 (7th ed., 2018) (discussing how modern international law has deliberately narrowed the availability of this excuse for non-performance of treaty obligations).

${ }^{157}$ U.N. Charter, supra note 2, art. 51.

${ }^{158} I d$. arts. 51, 2.4, 39. See Tronchetti, supra note 67, at 1033.

${ }^{159}$ In its 1996 advisory opinion on the legality of the threat or use of nuclear weapons, the International Court of Justice famously determined that it could not conclude definitively whether a use of nuclear weapons "would be lawful or unlawful in an extreme circumstance of self-defense, in which the very survival of a State would be at stake." Legality of the Threat or Use of Nuclear Weapons, Advisory Opinion, 1996 I.C.J. Rep. 266 105(2)(E) (July 8). See also id. $\uparrow 96$ (affirming "the fundamental right of every State to survival, and thus to its right to resort to self-defence"). The jeopardy to a state's very survival might be present in a planetary defense scenario, so it might be thought that this paragraph of the advisory opinion represents legal authority in support of the possible use of a nuclear device in self-defense against an asteroid. However, the ICJ's analysis and conclusions are pervasively grounded in the context of international humanitarian law (the body of law relevant to armed conflict, also known as the law of war), $i d$. $\uparrow 42,51,78,85$, and 96 (tying the right of self-defense to article 51 of the UN Charter, where the right is triggered by an "armed attack.") An incoming NEO would hardly qualify as an "armed attack," so the self-defense provisions of art. 51, and the entire Advisory Opinion, are largely irrelevant to the present legal analysis. The use of a nuclear explosive device in response to an asteroid might well constitute a "use of force," but it would not be a use of force "against the territorial integrity or political independence of any state," so 


\section{B. UN Security Council Action}

Instead of any of these options, this Article concludes that the wisest, most reliable choice to establish an avenue for using a nuclear device in planetary defense in a manner consistent with international law would be to proceed via the UN Security Council. The UN Charter affords the Security Council extraordinary authority for maintaining international peace and security. Pursuant to its Chapter VII responsibility, the Security Council may "determine the existence of any threat to the peace," and "decide what measures shall be taken" in response. ${ }^{160}$ All United Nations members agree to "accept and carry out" the decisions of the Security Council, ${ }^{161}$ and to "join in affording mutual assistance in carrying out the measures decided upon by the Security Council." 162 In particular, states have undertaken to "make available to the Security Council, on its call ... armed forces, assistance, and facilities ... necessary for the purpose of maintaining international peace and security." 163 A binding Security Council resolution therefore provides international law's surest, most effective measure for uniting and compelling all states to support and assist a planetary defense measure, and for relieving them of potentially conflicting legal obligations. ${ }^{164}$

article 2(4) would be irrelevant. In fact, as the court noted, $i d$. 139 , "A weapon that is already unlawful per se, whether by treaty or by custom, does not become lawful by reason of its being used for a legitimate purpose under the Charter." See also Macak, supra note 98; Gerrard \& Barber, supra note 32, at 39-40 (arguing that a claim of self-defense should be justifiable in a planetary defense situation, because the use of weapons there would be a "victimless activity, harming no one and causing no violation of another nation's sovereignty."); INSTITUTIONAL Issues, supra note 69, at 10-11,28 (arguing that self-defense is valid against any threat). Another legal theory, not explored here, could argue that a very general right of national selfdefense, against all types of threats, constitutes a "general principle of law," untethered to article 51 and independently applicable to a national response to an asteroid as well as to military dangers. See generally Martins Paparinskis, General Principles and the Other Sources of International Law: Conclusions, in GENERAL PRINCIPLES AND THE COHERENCE OF INTERNATIONAL LAW (Mads Andenas, et al. eds., forthcoming 2018); Tronchetti, supra note 67, at 1033 (asserting that every state has the right of self-defense to protect its population against any threat, subject to its compliance with international law); ILC, supra note 145, art. 21 (discussing self-defense under the UN Charter as a circumstance precluding the wrongfulness of a state's action); U.N. Charter, supra note 2, art. 51 (referring to self-defense as an "inherent right.")

${ }^{160} \mathrm{Id}$. art. 39.

${ }^{161} I d$. art. 25.

162 Id. art. 49.

${ }^{163} \mathrm{Id}$. art. 43.

164 See Tronchetti, supra note 67, at 1031 (stressing that ordinarily, "no State can be forced to 
Of course, the Security Council has never had the occasion to impose its will upon all member states in the matter of planetary defense, and most traditional Chapter VII resolutions have concerned intense military provocations involving a single state or region, such as an international armed attack or an act of aggression, or a profound breakdown of internal law and order. ${ }^{165}$ But the Security Council in recent years has conspicuously exercised its legislative powers and expanded the parameters of a "threat to the peace," applying that label to diverse types of incipient dangers, such as terrorism and the proliferation of nuclear and other weapons, untethered to a specific geographic site. ${ }^{166}$ Most tellingly, in 2014, the Security Council also labeled the Ebola virus as a threat to international peace and security, establishing a precedent for invoking Chapter VII powers against a natural phenomenon. ${ }^{167}$

undertake or cooperate in an international action for planetary defense," citing G.A. Res. 51/122 at 3 (Dec. 13, 1996)); Larsen, supra note 74 (evaluating alternative models for international decision-making regarding asteroid threats).

${ }^{165}$ See, e.g., S.C. Res. 660 (Aug. 2, 1990) (finding a breach of international peace and security in Iraq's invasion of Kuwait); S.C. Res. 1590 (Mar. 24, 2005) (finding that the situation in Sudan (Darfur) constituted a threat to international peace and security); S.C. Res. 2094 (Mar. 7, 2013) (condemning North Korea's nuclear weapon test and demanding a series of remedial actions).

166 See, e.g., S.C. Res. 1540 (Apr. 2, 2004); S.C. Res. 1695 (July 15, 2006); S.C. Res. 1718 (Oct. 14, 2006) (citing proliferation of nuclear, chemical, and biological weapons and their means of delivery as constituting a threat to international peace and security); S.C. Res. 1787 (Dec. 10, 2007); S.C. Res. 2178 (Sept. 24, 2014) (reaffirming that terrorism in all its forms and manifestations constitutes one of the most serious threats to peace and security); S.C. Res. 1534 (Mar. 26, 2004) (exercising Chapter VII powers in support of the international criminal tribunals for Rwanda and the former Yugoslavia). In other cases, the Security Council has not yet adopted the precise rhetoric and special powers of Chapter VII, but it has come close. See, e.g., S.C. Res. 688 (Apr. 5, 1991) (gravely concerned about the repression of the Iraqi civilian population, which has led to a massive flow of refugees towards and across international frontiers, threatening international peace and security); S.C. Res. 1208 (Nov. 19, 1998) (addressing refugee flows); S.C. Res. 2417 (May 24, 2018) (citing food insecurity and famine). See also Patrik Johansson, Equivocal Resolve? Toward a Definition of Chapter VII Resolutions (Umeå Working Papers in peace and Conflict Stud., no. 7) (2008); Katharina Remshardt, Under What Conditions Has the UN Been Able to Use Its Chapter VII Powers?, E-INT'L ReL. STUDENTS (Nov. 13, 2010), http://www.e-ir.info/2010/11/13/under-what-conditions-has-theun-been-able-to-use-its-chapter-vii-powers/ [https://perma.cc/4398-837J]; Christopher K. Penny, Climate Change and the Security Council: A Preliminary Framework for Implementing Remedial Measures Through Chapter VII of the UN Charter (CISDL Legal Working Paper, 2007).

${ }^{167}$ S.C. Res. 2177 (Sept. 18, 2014) (determining that the unprecedented extent of the Ebola outbreak in Africa constituted a threat to international peace and security). See also S.C. Res. 1308 (July 17, 2000) recognizing that the HIV/AIDS crisis may pose a risk to stability and security); S.C. Res. 2349 (Mar. 31, 2017) (addressing climate change). 
Arranging a mandatory, global response to an incoming large asteroid would not stretch the prescriptive scope of Chapter VII impermissibly far. ${ }^{168}$

Notably, when the Security Council determines the existence of a threat, decides on a response, and authorizes or orders countries to carry out a mandate, its law-making powers supersede prior inconsistent treaty obligations. Under article 103 of the UN Charter, if there is a conflict between states' obligations under the Charter and their obligations under any other international agreement (such as the OST, LTBT, or NPT), the obligations under the Charter shall prevail. ${ }^{169}$ A Security Council decision does not "amend" the prior treaties, but it effectively displaces them, providing a new, superior legal rule. ${ }^{70}$

168 Tronchetti, supra note 67, at 1034. Some have challenged the Security Council's new propensity to assume this type of general legislative role, arguing that international law should be created by states via treaty. See The Security Council as Global Legislator (Vesselin Popovski and Trudy Fraser eds., Routledge, 2014); Shirley V. Scott, Climate Change and Peak Oil as Threats to International Peace and Security: Is It Time for the Security Council to Legislate? 9 MeLB. J. InT'L L. 495 (2008); José E. Alvarez, Hegemonic International Law Revisited, 97 AM. J. INT'L L. 873-888 (2003); Daniel H. Joyner, Non-proliferation Law and the United Nations System: Resolution 1540 and the Limits of the Power of the Security Council, 20 Lemen J. Int'L L. 489 (2007); Eric Rosand, The Security Council as "Global Legislator": Ultra Vires or Ultra Innovative?, 28 FoRDHAM INT'L L. J. 542 (2005); Matthew Happold, Security Council Resolution 1373 and the Constitution of the United Nations, 16 Lemen J. Int'L L. 593 (2003); Paul C. Szasz, The Security Council Starts Legislating, 96 AM. J. InT'L L. 901 (2002); Ian Johnstone, Legislation and Adjudication in the UN Security Council: Bringing Down the Deliberative Deficit, 102 Av. J. INT'L L. 275 (2008).

Note that U.N. Charter art. 42, specifies that the Security Council may act via "air, sea, or land forces," and the non-mention of space forces could be deemed significant. U.N. Charter, supra note 2, art. 42. Of course, in 1945 the drafters of the Charter did not also contemplate and specify the availability of space forces, and inclusion of that component should now be implicit. See Ricky J. Lee, The Jus ad Bellum in Outer Space: The Interrelation Between Article 103 of the Charter of the United Nations and Article IV of the Outer Space Treaty, 45 Proc. ON L. Outer SPACE 139, 145-47 (2002); Gerardine Meishan Goh, Keeping the Peace in Outer Space: A Legal Framework for the Prohibition of the Use of Force, 20 SPACE POL'Y 259, 266 (2004).

${ }^{169}$ U.N. Charter, supra note 2, art. 103. But see Lee, supra note 168, at 141-42 (questioning whether a Security Council resolution can require a state to take action in contravention of a treaty).

${ }^{170}$ Many people perceive a legitimacy problem or democracy deficit in the UN Security Council, since its membership - especially the five permanent members - does not reflect the composition of the world community as a whole. In particular, for purposes of making decisions regarding planetary defense, it is notable that the Security Council does not include all the countries that possess nuclear weapons, all the countries that exercise space capabilities, or all the countries that might be strongly affected by a NEO. In addition, there is the perpetual 
As a political matter, an exercise of the Security Council would carry the further advantage of underscoring the characterization of the future planetary defense exercise as a unique emergency, justifying an exceptional departure from traditional legal routines-this would be a highly unusual procedure, reflecting the grave circumstances. In addition, going through the Security Council would ensure that the planet's most powerful and influential states, those most capable of undertaking this unprecedented and intricate space mission, would be fully engaged from the outset. The veto power wielded by the five permanent members of the Security Council, which could be viewed as a potential impediment to swift movement, would also ensure that the course of action ultimately selected represented a consensus among the crucial participants. ${ }^{171}$

In sum, a Chapter VII resolution from the UN Security Council provides by far the fastest, most deft mechanism for dealing with treaty provisions that stand in the way of an effective nuclear planetary defense mission. A resolution could be tailored to the specific needs of the immediate situation, and it could designate particular countries to perform and to support the various necessary functions, notwithstanding their other miscellaneous contrary prior legal obligations. ${ }^{172}$ No other body, including the UN General Assembly, wields comparable law-making authority. ${ }^{173}$

\section{Three Scenarios}

Before proceeding to offer a model draft of a proposed Security Council resolution enabling nuclear planetary defense, one other set of topics must be

danger that effective action might be delayed or defeated in the Security Council by the threat or exercise of the veto power. Under the UN Charter, states that are not members of the Security Council are sometimes allowed to participate in its deliberations, without having a vote. See U.N. Charter, supra note 2, arts. 31-32.

${ }^{171}$ The Security Council is organized to function continuously and to convene at very short notice as necessary to respond to emergencies. $I d$. art. 28.

172 A variation - especially applicable in a non-emergency situation, such as prior to the discovery of a large threatening NEO - would be for the Security Council to exercise its powers under Chapter VI, rather than Chapter VII of the Charter. Those provisions are directed at "Pacific Settlement of Disputes," rather than at a danger shared by all countries, but there are some similarities in approach. Article 33 of the Charter addresses a situation the "continuance of which is likely to endanger the maintenance of international peace and security," and calls for "a solution by negotiation, enquiry, mediation, conciliation, arbitration, judicial settlement, resort to regional agencies or arrangements, or other peaceful means." This procedure could be a predicate to the Security Council's invocation of its mandatory powers under Chapter VII. Id. ch. VI.

${ }^{173}$ See id. ch. IV (discussing the powers of the General Assembly). 
addressed: questions of timing and probability, and the concomitant need to differentiate between emergency and non-emergency situations, and between certainty and possibility regarding the likelihood, location and effects of an asteroid strike. Three distinct types of planetary defense situations must be differentiated.

First, in a genuine global emergency, when a large asteroid is bearing down on Earth with only a short advance warning and little lead time for careful deliberation and international negotiation, most people and countries would surely rally behind the imperative for urgent action. They might not immediately cede full carte blanche powers to whatever self-appointed state volunteered to undertake a hasty nuclear planetary defense mission, but they might relatively quickly come to a consensus about Security Council action to authorize and plan an effective intervention. Failing agreement in the Security Council, states might reasonably demand that those who were capable of launching a protective operation should do so, even if it involved use of a nuclear weapon, regardless of any treaty constraints. The instinct would be strong to tear up or disregard the law, doing what is necessary for survival.

In the aftermath (assuming that the mission was successful) there would be sufficient opportunity to weigh the possible legal responsibilities. Defenses such as distress, necessity, and consent might excuse the actors' violation of their treaty obligations, and it would be deemed absurd and unreasonable ${ }^{174}$ to interpret international legal standards that had been crafted for very different purposes to stand in the way of altruistic action that was necessary to safeguard sheer human existence. ${ }^{175}$ This might well be an instance where seeking forgiveness after the fact is preferable to seeking permission beforehand. ${ }^{176}$

\footnotetext{
174 As noted supra, text accompanying note 78 , under the VCLT, recourse may be had to supplementary means of interpretation (i.e., consulting the negotiating history of the treaty, in addition to the ordinary meaning of the words used in the document) to determine the meaning of the instrument, when the usual mode of analysis "leads to a result which is manifestly absurd or unreasonable." VCLT, supra note 76, art. 32. However, this procedure merely allows consultation of the earlier context of the development of the treaty; it does not provide a more general escape hatch for disregarding the treaty's terms or rejecting its clear meaning.

175 As noted, supra note 64 states undertaking a planetary defense mission will also need to attend to the Liability Convention, which includes absolute financial responsibility to compensate those damaged on Earth by space activities.

${ }^{176}$ For comparison, the NATO bombing campaign against Yugoslavia, undertaken in 1999 in response to the atrocities in Kosovo, lacked any clear authorization under international law, but many concluded that it should be pursued nonetheless, because it served critical humanitarian goals. Subsequently, this war was frequently described as being "illegal, but legitimate," and
} 
A second scenario, however, also requires attention. What if there is danger, but also doubt-what if the best calculations that the scientific community can offer are hedged in probabilities, with important uncertainty about the likelihood of an Earth impact, its location, and the magnitude and extent of the damage? It is quite plausible that the experts may disagree about the composition and trajectory of the asteroid, especially early in the process, when the fateful intersection with Earth's orbit remains somewhat distant. ${ }^{177}$ In the circumstances that may prevail in advance of any last-minute emergency, states may well differ in their diagnoses and prescriptions. Some may favor immediate action of one sort, while others may advocate a different type of response or counsel more patience for the development of greater certainty about the eventual impact and the creation of improved non-nuclear planetary defense methods. Especially if the asteroid were projected to cause devastation on a local or regional scale, rather than worldwide, states located in the predicted concussion zone may view the inhibitions of international law differently from others - and the roles might switch, if additional data led to refined estimates of the asteroid's probable arrival point.

In these conditions, when the perceived threat is looming but not yet imminent, states may be appreciably less willing to trust an assertive space actor, and they may not be so willing to preemptively suspend important treaty provisions. Especially where nuclear explosives are concerned, some may be suspicious that a volunteering state was really attempting to develop or maintain its weapons capabilities, and was cynically using the distant asteroid as a pretext. ${ }^{178}$

the precedential value of that experience has been widely debated. See INDEP. INT'L COMm'N on Kosovo, The Kosovo Report: Conflict, International Response, Lessons Learned (2000); Jack Goldsmith, More on the UN Charter, Syria, and "Illegal but Legitimate," LAWFARE (Sept. 5, 2013), https:/www.lawfareblog.com/more-un-charter-syria-and-illegallegitimate [https:/perma.cc/E4XS-2TUA]; Marko Milanovic, Illegal But Legitimate?, EJIL: TALK! (Apr.10, 2017), https://www.ejiltalk.org/illegal-but-legitimate/ [https://perma.cc/QJ5WM83U].

177 See, e.g., Planetary Defense Conference Exercise-2017, Jet Propulsion Laboratory (May 15, 2017), https://cneos.jpl.nasa.gov/pd/cs/pdc17/ [https://perma.cc/9UXM-D899] (presenting a simulation exercise that begins with substantial uncertainty about the likelihood of a NEO impact and the projected location; knowledge about the asteroid's parameters improves over time, demanding additional decisions from the participants); MELAMED \& MELAMED, supra note 68, at 5-7 (discussing a simulated NEO impact scenario).

${ }^{178}$ Gerrard \& Barber, supra note 32, at 38-39; Mick, supra note 80; Patrick E. Tyler, Chinese Seek Atom Option to Fend Off Asteroids, N.Y. TIMes 4 (Apr. 27, 1996) (reporting Chinese opposition to the CTBT on the grounds that nuclear explosions may be needed to divert an asteroid). Most states have observed a moratorium on nuclear testing for twenty years or more, 
Third, at an even earlier stage in the analytical process, some might argue that if a nuclear device might ever potentially be needed for planetary defense, we should start preparing for that eventuality now, not waiting until a threatening asteroid is detected on the horizon. To be prudent, the argument might run, we should not rely upon whatever nuclear explosive devices, associated equipment, and operational techniques happened to be available in states' inventories when the need actually arises. Instead, we should immediately begin to design, develop, test, and manufacture the exact type (or types) of nuclear explosives that would be optimally suitable for this most demanding and novel mission, and we should thoroughly practice their functioning. Even if the odds are strongly against ever needing to bank on a nuclear device, the consequences of a lack of preparedness are extreme, and we should not leave the planet's fate to devices that simply happened to be on hand-we should not wait until the crisis is upon us to make sure we have the capability to respond effectively. ${ }^{179}$

In that third scenario-roughly where the world stands today-states might well adopt very different postures. Some might advocate abrogating the LTBT, so as to allow the testing in space of nuclear devices intended to be optimized for deflecting or destroying asteroids, while others might see those actions as attempts to wreck the fragile strands of arms control. ${ }^{180}$ Some might

despite their potential interest in using explosive tests to develop new types of nuclear weapons or to validate the continuing viability of their existing stockpiles. Some may therefore see a nuclear planetary defense mission as an opportunity to test their weapons under the shelter of a more legitimate cover story (and some states will be suspicious that others may be pursuing such an opportunity). See Nuclear Testing, Comprehensive Test Ban Treaty Org. PrePaRATORY COMMISSION, https:/www.ctbto.org/nuclear-testing/ [https:/perma.cc/UJ8H2R9D] (last visited Sept. 18, 2018).

179 See NAS SURVEYS AND STRATEGIES, supra note 10, at 76 (describing adaptations that would be necessary to convert a standard nuclear weapon into a planetary defense device and suggesting that it would be a time-consuming process); Strauss, supra note 38 (describing proposals for experimental nuclear interceptors to divert asteroids); Brian Kaplinger et al., Nuclear Fragmentation/Dispersion Modeling and Simulation of Hazardous Near-Earth Objects, 90 ACTA ASTRONAUTICA 156 (2013) (noting the lack of experimental data in evaluating different approaches to the use of a nuclear explosion for asteroid mitigation); DEALING WITH THE THREAT TO EARTH FROM AsTEROIDS AND COMETS, supra note 13, at 65 (positing that a campaign involving multiple launches might be necessary to develop appropriate techniques for use of nuclear devices against an asteroid).

180 Thomas Graham Jr. \& Russell L. Schweickart, NASA's Flimsy Argument for Nuclear Weapons, SCI. AM. (Mar. 1, 2008 (criticizing the concept of using a nuclear explosive to divert an asteroid, because it would jeopardize progress on the much greater immediate imperative, elimination of nuclear weapons); Gerrard \& Barber, supra note 32, at 18-19; SAGAN, supra 
seek to withdraw from the NPT, in order to collaborate more effectively on the nuclear weapons aspects of a planetary defense mission, while others might decry that as a dissolution of the consensus against the further dissemination of nuclear weapons. Some might be eager to renounce the OST, ${ }^{181}$ in order to proceed expeditiously to develop and deploy the most capacious planetary defense mechanisms, while others would oppose the abrupt ruination of the foundation of space law. The array of circumstances that might be available to preclude a finding of international legal wrongfulness in a true emergency (such as the doctrines of necessity and distress) would be much less availing if employed well before the "last clear chance."

In sum, some foreseeable circumstances, involving an imminent threat to Earth, might prompt a global consensus that tosses aside the treaty constraints identified above, but other cases could be much more controversial. Making momentous decisions in an emergency is not optimal; a better global strategy would be to evaluate the options well in advance, when we have the luxury of time and unforced legal contemplation. The next Part of the Article, therefore, presents one such construct: a proposed Security Council resolution to be adopted today, as a far-sighted precursor to future emergency action.

\section{Proposed Security CouncIL Resolution}

What follows is a candidate Security Council resolution, together with annotations that cite the precedents and origins of some of the passages and explain the drafter's options and choices. It is styled as a resolution that could be adopted today, but it attempts to deal with future contingencies that could pose either a stark emergency with worldwide consequences, or a somewhat less certain and less global catastrophe. It resolves some controversies immediately, and defers others for later development, depending upon the emerging facts and planetary defense capabilities.

The Security Council, ${ }^{182}$

note 37, at 317; Douglas Birch, The Plans to Use Nuclear Weapons to Blow Up Incoming Asteroids, ATLANTIC (Oct. 16, 2013) (reporting concerns that the concept of using a nuclear device against an asteroid might have been driven by a post-cold war need to find useful employment for U.S. nuclear weapons laboratories).

${ }^{181}$ See Hickman, supra note 138 (arguing that the OST has disincentivized exploration of space, by restricting sovereign claims). See also U.S. Gov't Accountability OfF., GAO-14-449, Nuclear Weapons: Actions Needed by NNSA to Clarify Dismantlement Performance GOAL 40-41 (Apr. 2014) (reporting that the U.S. government is delaying the dismantlement of excess nuclear weapons, in order to retain some for possible use in planetary defense).

182 The paragraphs of the preamble of a Security Council resolution are not traditionally 
1. Aware of the grave dangers to humanity posed by potentially hazardous near-Earth objects (NEOs), which carry the possibility of inflicting devastating damage upon localities, regions, and the entire planet, irrespective of national borders, ${ }^{183}$

2. Commending the International Asteroid Warning Network (IAWN) and the Space Mission Planning Advisory Group (SMPAG) for their contributions in research, consciousness-raising, and organizing national and collective responses to the severe problems, ${ }^{184}$

3. Deeply concerned about the need to prepare for a potential catastrophe of unprecedented scope and scale and to take extraordinary measures now and in the future, possibly at sudden, unforeseeable times, ${ }^{185}$

4. Convinced that a coordinated, international effort will enable the most effective response to a NEO danger, ${ }^{186}$

5. Strongly endorsing the continued critical importance and vitality of the Treaty on Principles Governing the Activities of States in the Exploration and Use of Outer Space, Including the Moon and Other Celestial Bodies of 1967 (Outer Space Treaty), the Treaty Banning Nuclear Weapon Tests in the Atmosphere, in Outer Space and Under Water of 1963 (Limited Test Ban Treaty), the Treaty on the Non-Proliferation of Nuclear Weapons of 1968 (Non-Proliferation Treaty), and other relevant international instruments, ${ }^{187}$

numbered, but here numbers have been inserted for ease of reference.

${ }^{183}$ This resolution would be adopted today, when there is no potentially hazardous NEO on the horizon, but with the understanding that such a danger could be detected at any time, possibly with little advance warning before impact. The concept is that today's action by the Security Council would set the stage for later, more definitive action in a genuine crisis.

${ }^{184}$ IAWN and SMPAG were acknowledged in G.A. Res. 68/75, ๆ 8 (Dec. 11, 2013), but were not there identified by name; this resolution would be the first explicit endorsement of those entities by the Security Council and would elevate their recognition.

${ }^{185}$ This resolution is somewhat unusual in seeking to deal prospectively with a serious problem that has not yet ripened; the Security Council would be recognizing that considerable additional advance planning and preparation would be necessary to deal with the eventuality of a hazardous NEO.

${ }^{186}$ A critical component of the resolution is the acknowledgement of the importance of the global nature of the necessary response. Although only a handful of states will be in a position to participate directly in a space mission to intercept and divert or destroy an incoming large NEO, all states will have a stake in the activity and different types of contributions may be required from each.

${ }^{187}$ Here, the Security Council would underscore the importance of the OST, LTBT, and NPT, as well as other unnamed relevant international law instruments (such as those establishing regional nuclear-weapon-free zones) and the continuing commitment to their viability. The 
6. Recognizing that traditional international legal and political instruments and arrangements may not be sufficient to enable an effective response to a large $\mathrm{NEO},{ }^{188}$

7. Mindful of its primary responsibility under the Charter of the United Nations for the maintenance of international peace and security, especially in the face of novel and emerging global threats, ${ }^{189}$

8. Acting under Chapter VII of the Charter of the United Nations, ${ }^{190}$

1. Determines that a large NEO on a collision course with Earth would constitute a threat to international peace and security, demanding a response that is timely, effective, and global; ${ }^{191}$

2. Decides to take action, and to authorize member states to take action, now and in the future, to anticipate and respond to this threat; 192

3. Anticipates that the Security Council will be prepared, as appropriate, to authorize and require member states to use all necessary measures to

resolution could also call out the Liability Convention, supra note 64, and other components of space law.

${ }^{188}$ In partial contrast to preambular paragraph 5 , the point here is that existing international law instruments, for all their value, may not enable a sufficient, timely response to an incoming NEO, so the current legal rights and responsibilities may need to be augmented, modified or suspended.

${ }^{189}$ This paragraph constitutes the Security Council's recognition of its special responsibilities for dealing with global threats to the peace, including previously-unacknowledged dangers such as NEOs. See U.N. Charter, supra note 2, art. 24.

${ }^{190}$ This expression invokes the special powers of the Security Council pursuant to Chapter VII of the UN Charter, the source of its authority to establish binding rules for UN member states. See id. arts. 25, 39, 48. As noted, supra note 172, the Security Council might elect to proceed first via its Chapter VI powers, and exercise Chapter VII only when the threatening NEO is detected.

${ }^{191}$ This paragraph is one of the most important and precedent-setting passages of the proposed resolution. It echoes the first preambular paragraph and translates it into operational text. A "determination" that something constitutes a "threat to the peace" is the formal predicate for the Security Council to exercise its Chapter VII powers. See id. art. 39. The Security Council has never previously determined that anything like an asteroid constitutes a threat to the peace, but it would be within the Security Council's power to expand its precedents in this way. See supra text accompanying notes 165-68 (describing prior Security Council practice in the exercise of Chapter VII).

${ }^{192}$ Some of the relevant actions in response to the NEO threat will be undertaken by the Security Council itself; in addition, the Security Council will authorize states to undertake some actions and could in the future order states to undertake some actions, some of which might be inconsistent with other pre-existing legal obligations. 
respond to the NEO threat; ${ }^{193}$

4. Understands that a future notification about a NEO danger might provide only a short warning time, and could be accompanied by considerable uncertainty regarding whether and where the object might strike Earth, and regarding the scale of the damage the object might inflict, and concluding that this uncertainty should not delay or preclude effective action; ${ }^{194}$

5. Seeks to promote the development of enhanced capabilities for detecting and responding to NEO dangers in a timely, effective fashion; ${ }^{195}$

6. Calls upon IAWN and its participants to redouble their efforts, individually and in concert, to further develop the data base of NEOs by discovering, characterizing, tracking, and monitoring the population, to disseminate and coordinate relevant information in a timely fashion, to alert the world community to incipient dangers, and to coordinate campaigns for closer inspection of key celestial bodies; ${ }^{196}$

193 The phrase "all necessary measures" (or "means") has become the critical term for authorizing the use of military force. See, e.g., S.C. Res. 1973 (Mar. 17, 2011) (authorizing states to take "all necessary measures" to protect civilians in Libya; S.C. Res. 678 (Nov. 29, 1990) (dealing with Iraq's invasion of Kuwait). In this resolution, the Security Council is not yet taking that step, but is indicating its willingness to do so promptly in the future, should circumstances warrant.

194 This paragraph reflects the persistent uncertainties about the amount of advance warning that might be available prior to a NEO strike; about the possibly large and persistent "error ellipse" in mapping where the NEO might hit; and about the characteristics of the NEO (e.g., size, composition) that will affect whether it will inflict damage of a local, regional, or global character. Nonetheless, as an exercise of the precautionary principle, the Security Council will not allow the incompleteness of available information to block or delay protective action. See supra note 63 (discussing the precautionary principle).

195 This paragraph constitutes one of the core elements of the resolution: the effort to spur greater activity toward earlier, more accurate detection, tracking and characterization of NEO threats, and toward enhanced capabilities for remediating the dangers. The existing inventory of NEOs is reasonably complete (but not yet perfect) for the biggest NEOs (i.e., objects larger than about $1 \mathrm{~km}$ in diameter), but it is far less adequate for smaller objects that could still inflict great damage. See supra text accompanying notes 23-24 (describing the current catalog of NEOs).

${ }^{196}$ IAWN is a loose confederation or a virtual network of national space agencies, nongovernmental entities, and other actors, rather than of states; it has little established infrastructure, but serves as a clearinghouse for information and as a coordinator of diverse actions. See supra text accompanying note 45 (describing IAWN). Note that this resolution does not separately address the activities of private commercial actors in space, including the incipient interest in mining asteroids to recover valuable minerals. See generally New NASA Mission to Help Us Learn How to Mine Asteroids, NAT'L Aeronautics \& Space Admin. (Aug. 8, 2013), https:/www.nasa.gov/content/goddard/new-nasa-mission-to-help-us-learn-how-to- 
7. Calls upon SMPAG and its participants to likewise redouble their efforts, individually and in concert, to develop the technologies, tools, and techniques that would be necessary to mitigate the dangers of a NEO, including evaluating and recommending options for timely diverting or destroying it; ${ }^{197}$

8. Calls upon each member state to disseminate in a timely and comprehensive fashion any information it obtains regarding NEO dangers, taking care to ensure that the information can be understood accurately and without inducing panic; ${ }^{198}$

9. Calls upon all member states to assist, cooperate with, and support planetary defense activities to the best of their abilities, pursuant to their common but differentiated responsibilities; ${ }^{199}$

mine-asteroids [http://perma.cc/RY4B-CYNQ]; Providing Resources to Fuel Industry and Sustain Life in Space, PlanETARY ReSOURCES, https:/www.planetaryresources.com/ [http://perma.cc/B4HP-C2EN ] (last visited Sept. 20, 2018) (private corporation interested in mining celestial bodies); Andrew Wong, Space Mining Could Become a Real Thing - and It Could Be Worth Trillions, CNBC (May 15, 2018), https:/www.cnbc.com/2018/05/15/miningasteroids-could-be-worth-trillions-of-dollars.html [http://perma.cc/CB5B-W2ET]. See supra note 143 (discussing each state's responsibility under OST art. VI for the space activities of its nationals).

${ }^{197}$ Like IAWN, SMPAG has few resources of its own; it functions to share information more effectively among its participating entities and to coordinate their individual activities. See supra text accompanying notes 46-48. (describing SMPAG). In this paragraph, the Security Council might decide to instruct that SMPAG should concentrate specifically on developing the array of non-nuclear planetary defense options; in the present version, that limitation is not included.

${ }^{198}$ Existing international law does not include a direct, comprehensive obligation for states to share information they may obtain regarding NEO dangers; this paragraph of the resolution calls upon them to do so, but does not constitute a legal requirement. See OST, supra note 3, arts. I, XI. There is, of course, a grave danger that any public notification about an incoming NEO could be subject to exaggeration and distortion, generating panic, but this resolution proposes to disclose the information fully and to try to manage the resulting public reactions, rather than to try to maintain secrecy.

${ }^{199}$ In a Security Council resolution, the phrase "calls upon" is generally understood not to create a binding legal obligation because either the term is non-legally-binding or it is ambiguous enough that it would not be the chosen language of drafters who were endeavoring to create a legal obligation; in contrast, use of verbs such as "demands" or "decides" connotes a legallybinding responsibility. James D. Fry, Dionysian Disarmament: Security Council WMD Coercive Disarmament Measures and Their Legal Implications, 29 Mich. J. Int'l L. 197, 22932 (2008); see also Stephen P. Mulligan, Cong. Research Serv., Withdrawal from the Iran Nuclear Deal: Legal Authorites and Implications (May 17, 2018), https://fas.org/sgp/crs/nuke/LSB10134.pdf [https:/perma.cc/A4W8-2BXJ]. Here, the paragraph establishes a general call for support for planetary defense efforts, rather than any 
10. Strongly urges member states urgently to expand their efforts and to devote additional resources to develop NEO mitigation technologies, tools, and techniques and to accelerate their flight testing to improve the ability to alter a NEO's trajectory under increasingly realistic and stressful conditions, consistent with their respective treaty obligations; ${ }^{200}$

11. Stands ready, upon the request from a member state, to authorize, if essential to a planetary defense test or mission, the testing of a non-nuclear weapon against a celestial body, notwithstanding article IV of the Outer Space Treaty, pursuant to article 103 of the Charter of the United Nations; ${ }^{201}$

specific commitment to a particular measure. But see Legal Consequences for States of the Continued Presence of South Africa in Namibia (South West Africa) Notwithstanding Security Council Resolution 276 (1970), Advisory Opinion, 1971 IC.J. Rep. 16, I 108-116 (June 21) (ICJ finds that a Security Council Chapter VII resolution that only "calls upon" states to act can impose a legally binding duty). The phrase "common but differentiated responsibilities" is drawn from international environmental law, where states' resources and other circumstances enable them to provide very different types of support to global undertakings, but all states should participate in some way. See United Nations Framework Convention on Climate Change art. 3.1, May 9, 1992, S. Treaty Doc No. 102-38, 1771 U.N.T.S. 107; Common but Differentiated Responsibilities and Respective Capabilities (CBDR-RC), ClimateneXus, https:/climatenexus.org/climate-change-news/common-but-differentiated-responsibilitiesand-respective-capabilities-cbdr-rc/_[http://perma.cc/LT6X-K223] (last visited Sept. 20, 2018); Ctr. for Int'l Sustainable Dev. (CiSDl), The Principle of Common But Differentiated RESPONSIBILITIES: ORIGINS AND SCOPE (2002).

${ }^{200}$ This paragraph of the resolution presses states to devote more urgency to the planetary defense mission, by increasing the tempo of their space activities to counteract NEOs and devoting additional resources to the task. In this version, the resolution concentrates on efforts to divert an asteroid; it could also stress the possibility of destroying the asteroid if changing its trajectory proves impossible. See supra text accompanying note 38 (discussing the advantages and disadvantages of fracturing an incoming asteroid). In addition, the resolution might address terrestrial efforts to abate the effects of a NEO strike, such as via sheltering in place, emergency evacuation of the area to be affected, the training of first responders, the pre-positioning of relief supplies, etc., but those land-based routines are largely outside the scope of this Article. This paragraph contemplates that the global effort to improve asteroid-deflection capabilities might require a protracted campaign over many years, perhaps starting with relatively small space objects and working up toward an ability to manipulate larger, more difficult NEOs. It would be premature, at this point, for the Security Council to designate any particular state(s) to prepare for or undertake a planetary defense mission, since there is no known threat and little in situ capability. See supra text accompanying notes 53-61 (describing potential concepts for planetary defense technologies).

${ }^{201}$ OST art. IV, para. 2 forbids "the testing of any type of weapons" on celestial bodies. OST, supra note 3 , art. IV., para 2 . It is possible that some planetary defense missions could necessitate the use of explosives or other devices that could be construed as weapons, so this provision might have to be abated. See supra note 101 (regarding testing of non-nuclear 
12. Stands ready, in anticipation of a possible future NEO emergency, to convene immediately, to authorize and require particular member states to plan, prepare, and undertake a planetary defense space mission, and to authorize and require other member states to participate in, contribute to, and support the mission as appropriate; ${ }^{202}$

13. Declares its readiness, in the event of future meetings addressing a NEO threat, to invite affected member states, particularly those likely to be affected by the impact and those capable of contributing to mitigation efforts, to participate in the Security Council's deliberations; ${ }^{203}$

14. Contemplates that in some future extreme circumstances, it might be necessary to employ a nuclear explosive device as a last resort for a planetary defense mission, and in this connection declares: ${ }^{204}$

weapons on a celestial body). Under article 103 of the UN Charter, in the event of a conflict between a member state's obligations under the Charter and its obligations under any other international agreement, the Charter shall prevail. See U.N. Charter, supra note 2, art. 103. The Security Council, in the exercise of its Chapter VII powers, could therefore create an obligation under the Charter that would over-rule the OST. In this proposed resolution, the Security Council would not currently derogate from the OST provision, but would express its willingness to do so, if a state indicated that testing of a weapon on a celestial body was essential for the development of an effective planetary defense capability. In this paragraph, the scenario is confined to the testing of non-nuclear weapons. See supra text accompanying notes 60-61 and 91-101 (describing explosive interceptors for planetary defense and discussing the definition of a weapon respectively).

${ }^{202}$ The Security Council is structured to be able to function continuously and it can convene at very short notice to deal with emergencies. U.N. Charter, supra note 2, art. 28. Another option here would be for the Security Council to create a committee to deal with NEO issues on a daily basis, rather than bringing every aspect to the attention of the full Security Council itself. See, e.g., S.C. Res. 1540 (Apr. 28, 2004) (creating a committee to monitor the proliferation of weapons of mass destruction and implement Security Council measures); S.C. Res. 1718, $₫ 12$ (Oct. 14, 2006) (establishing a committee to implement sanctions on North Korea); S.C. Res. 1373 (Sept. 28, 2001) (the Counter-Terrorism Committee). In any event, there is always the potential problem of the veto power, as any of the five permanent member states can block action. Supra text accompanying notes 169-71 (discussing the problematic features of the Security Council).

${ }^{203}$ Pursuant to article 31 of the UN Charter, the Security Council may invite any member state to participate in its discussions, without the right to vote, when the interests of that state are specially affected. U.N. Charter, supra note 2, art. 31. This could implicate many states, so each may have only limited participation, but the opportunity to hear from multiple stakeholders could be beneficial. It is also possible that the UN General Assembly, in which all member states are voting members, may also convene to discuss the NEO danger.

${ }^{204}$ In this resolution, the Security Council is not yet authorizing the use of a nuclear explosive device against an asteroid; that would be premature. But it is signaling its awareness that such a scenario might emerge, potentially on short notice, and its willingness to engage on an 
a. that the Outer Space Treaty, the Limited Test Ban Treaty, the Nuclear Non-Proliferation Treaty and other relevant nuclear arms control agreements are of utmost importance, and all parties shall comply with their provisions, ${ }^{205}$

b. that the current moratoria against the conduct of any nuclear weapon test explosions or any other nuclear explosions should be continued; ${ }^{206}$

c. that the Security Council will be prepared, in the event of an anticipated global catastrophe caused by a NEO that cannot be diverted in any other way, to consider the possibility of superseding the relevant treaty provisions, in order to enable one or more member states to be designated to carry out the necessary planetary defense mission and to enable other member states to assist, participate in, and support that mission, notwithstanding any other treaty commitments, pursuant to article 103 of the Charter of the United Nations; $; 07$ and

expedited basis at that time. It is possible that the Security Council would be called upon to adopt a series of increasingly-specific Chapter VII resolutions, as the emerging facts about an incoming asteroid become clearer.

${ }^{205}$ This resolution does not derogate in any way from the existing treaty obligations regarding nuclear arms control, but signals the Security Council's willingness to consider that action, should a NEO emergency require it.

${ }^{206}$ No state other than North Korea has tested a nuclear weapon since 1998. See Daryl Kimball, The Nuclear Testing Tally, ARMs CONTROL Ass'N, https://www.armscontrol.org/factsheets/nucleartesttally [http:/perma.ce/TJ4Q-PHYZ] (last updated Sept. 3, 2017). The permanent members of the Security Council have declared that a nuclear explosion by any state would constitute a violation of the object and purpose of the CTBT, prior to that treaty's entry into force. See supra note 115 (regarding the CTBT).

${ }^{207}$ In this resolution, the Security Council contemplates "superseding" the operation of the relevant treaties, by enacting a Chapter VII resolution that would displace selected elements of the treaty as the governing rule of law, pursuant to UN Charter art. 103. See U.N. Charter, supra note 2, art. 103. In so doing, the Security Council does not "amend" or "suspend" those treaties, but establishes a superior rule governing the behavior of states. This procedure would avoid the alternatives of utilizing those treaties' provisions regarding amendment or withdrawal. See supra text accompanying notes 133-35 and 137-41 (regarding amendment and withdrawal provisions respectively). For the states carrying out a nuclear planetary defense mission, the central elements of those agreements would be at stake; for the other states participating in or supporting the operation, the relevant treaty provisions would include those regarding assisting, encouraging, or inducing actions that would be in violation of the particular treaty. When the time for a planetary defense mission arises, the Security Council would likely designate the particular state(s) to conduct the mission and specify supporting roles for others (or delegate to the leading state(s) the task of lining up the other participant(s)). It is possible that a single state, such as the United States, would undertake the entire mission, but it is more likely that an international coalition would be assembled, as reflected in preambular para. 4. 
d. that if a nuclear explosive device is deployed for a planetary defense mission, it shall remain at all times under the jurisdiction and control of a member state that is legally permitted to possess such a device, and that other member states may participate in the mission in a way that respects their respective legal obligations; ${ }^{208}$

15. Declares its resolve to monitor closely the problem of NEOs and to receive regular reports on this topic from the Committee on the Peaceful Uses of Outer Space and other relevant bodies; $;{ }^{209}$ and

16. Decides to remain actively seized of the issue. ${ }^{210}$

$* * * * *$

This proposed Security Council resolution is parsimonious. It exhorts the spacefaring countries, individually and in concert, to augment and embellish their efforts to discover additional potentially-hazardous asteroids, to enhance the ability to track and characterize them, and to develop and test promising

See generally Joseph N. Pelton, International Cooperation and Collaboration in Planetary Defense Efforts, in HandBook of Cosmic Hazards and Planetary Defense 1007 (Joseph N. Pelton \& Firooz Allahdadi eds., 2015).

${ }^{208}$ Under the NPT, five states are designated as NWS and allowed to possess nuclear weapons; in addition, four states are not parties to that treaty. See supra text accompanying notes 11821 (discussing the structure of the NPT). This resolution allows NNWS to participate in a nuclear planetary defense mission in a manner that "respects" their NPT obligations, even if it departs from some of the specifics of that treaty (such as the provisions that inhibit the closest interactions between NWS and NNWS).

${ }^{209}$ This resolution does not address the important questions about who would pay for the planetary defense mission and about possible international financial support for any states that are impacted on Earth if the mission fails, or if it is not undertaken. There are several possibilities here, including use of the standard United Nations formula for allocating dues. See MELAMED \& MELAMED, supra note 68, at 3 (estimating that an asteroid deflection effort would cost $\$ 1$ billion per launch); Henry R. Hertzfeld \& Pierre-Alain Schieb, Economic Challenges of Financing Planetary Defense, in HANDBOOK OF COSMIC HAZARdS AND PlanetaRy DeFENSE 993 (Joseph N. Pelton \& Firooz Allahdadi eds., 2015) (emphasizing the difficulty of raising sufficient funds for a planetary defense initiative).

${ }^{210}$ Another important element not included in this draft resolution and beyond the scope of this Article concerns legal liability for damage inflicted by a planetary defense mission that succeeded in altering the trajectory of the incoming asteroid somewhat, but did not succeed in causing it to miss Earth or orbiting satellites altogether - so the damage was felt by states that would not have been affected if no intervention had been undertaken. The Liability Convention imposes absolute liability on the launching state for damage inflicted on Earth and liability for fault for damage inflicted on space assets; a Security Council resolution might well alter that exposure, in order to avoid deterring states from undertaking the mission. See supra note 64. 
mechanisms for diverting an asteroid, should a substantial and imminent peril appear. It calls for greater attention to planetary defense by leadership figures and the general public, as well as by the Security Council itself. It bolsters both IAWN and SMPAG, and elicits their even greater efforts in the future. It reinforces the global commitment to the principal treaties in this field: the OST, LTBT, and NPT. The resolution declares, for the first time, that a large NEO could constitute a "threat to the peace," triggering the Security Council's extraordinary powers pursuant to Chapter VII of the UN Charter, and it positions the Security Council to authorize and to require additional actionincluding even the use of nuclear explosive devices, contrary to the standing rules contained in applicable treaties - should the need arise.

But this resolution does not go so far as to approve the testing or conduct of a nuclear planetary defense mission. That would be premature at this point, when no imminent hazard looms on the horizon, and because the arms limitation provisions of the OST, LTBT, and NPT continue to play such essential roles underpinning global security on Earth. If the need does arise, via some benighted twist of the orbits, the Security Council would hastily reconvene and chart an emergency path. The optimal remedy in that future scenario would depend heavily upon the then-applicable facts: How large and massive is the asteroid; how certain are the experts about its trajectory and impact point; how much time do we have to react; what planetary defense implements have been developed, tested, and made ready? A nuclear explosion might be the most efficacious, or even the only, recourse, but even then we would need to know more about the readiness and the willingness of the various nuclear- and space-capable states, and about the state of their political relationships and their ability to collaborate effectively with each other.

Time may then be short—perhaps too short—but at the present moment, this is the best the Security Council can do in anticipating the various severe contingencies and teeing up future options in an appropriate fashion. The proposed resolution designates a mechanism that can be implemented quickly, without eliciting the creation of a new international organization or the promulgation of novel procedures. It employs established international legal routines in a novel way, and respects existing treaties by formally acknowledging and then partially superseding them rather than simply tossing them aside. 


\section{CONCLUSION}

Astronomers are fond of observing that the real question is not "whether" Earth will again be struck by a large asteroid, but "when." We can detect around the planet the remnants of scores of impact craters of diverse size and age left by previous NEOs, and the pockmarks are even more obvious on the Moon and other celestial bodies, where erosion has not degraded their silhouettes. As asteroids pinball around the Solar System, it is only a matter of time before the next jarring impact - time that might be measured in months or in millions of years.

The potential consequences of such a collision beggar belief. Prehistoric experience demonstrates that all of human civilization, as well as most or all other forms of life on Earth, may hang in the balance. Even a more moderately sized asteroid could devastate a community or a country in an instant. As Igor Ashurbeyli assesses the stakes, developing countermeasures to this apocalyptic threat "must become the most important task that humanity must solve in the $21^{\text {st }}$ century." 211

But the time frame matters, too. If we knew, hypothetically, that an extinction-level event was not going to occur for thousands or millions of years, why would we devote time, attention, and money to it now? A known risk of extermination, eons into the future, would pose profound philosophical and psychological conundrums, but preemptively responding to it would not be on anyone's active "to-do list" for generations.

Still, timing matters in another way, too. With our present state of astronomical intelligence, we cannot be certain about our planet's prolonged safety, and we must exhibit appropriate modesty about our confidence in the completeness of the inventory of known NEOs. Accordingly, the planet may not have much advance notice about the next Chicxulub, and we may be no more able than the dinosaurs to immediately invent our way out of an unanticipated fatal space specter. Frances Lyall and Paul B. Larsen summarize the issue this way: "Time might be too short adequately to deal with the crisis-missile or other technology has to be prepared."212

\footnotetext{
${ }^{211}$ Ashurbeyli, supra note 40, at 7. Stephen Hawking has also cited "overdue asteroid strikes" as one of the reasons why human beings may have to populate a new planet within 100 years, Julia Zorthian, Stephen Hawking Says Humans Have 100 Years to Move to Another Planet, TIME (May 4, 2017), http:/time.com/4767595/stephen-hawking-100-years-new-planet [http://perma.cc/FJE5-94ME].

${ }^{212}$ Lyall \& LARSEN, supra note 9, at 239. See also YEOMANS, supra note 8, at 19 (imagining a realistic scenario in which a deadly comet could not be detected until it was merely months away from an Earth impact).
} 
It is difficult for humans to think rationally about this sort of problem-it is hard to get our collective minds around such enormous consequences and such tiny probabilities simultaneously - especially when people have so little first-hand experience with the causal phenomenon. A 2010 study by the National Academy of Sciences referred to this as a classic "zero times infinity" problem that thwarts human cognitive processing. ${ }^{213}$ Cass Sunstein and Richard Zeckhauser label the resulting bias in decision-making as "probability neglect" - a propensity to misunderstand the fearsome risks that are so difficult to conceptualize. ${ }^{214}$ Behavioral economics literature abounds with examinations of the collective non-rationality in our species' approach to high-severity/low-probability events, leading to extreme discounting of remote future catastrophes, to the detriment of individuals and society. ${ }^{215}$

The underdeveloped state of international law on trans-border disasters reflects this cognitive deficit. Perhaps this should not be surprising - the tasks of preventing, responding to, and rebuilding after global catastrophes are daunting. These are topics that sovereign states, as well as individual human beings, shy away from addressing - they are uncomfortable to think about; they can involve sharing resources, as well as sympathy, with foreigners; and they seem to call for spending immense sums of money on vanishingly remote contingencies. It will never be easy to marshal political support for developing, improving, and sustaining planetary defense capabilities that in all likelihood will never be exercised during any government official's term in office or even lifetime. ${ }^{216}$ Nevertheless, planetary defense represents one

${ }^{213}$ NAS SURVEYS AND STRATEGIES, supra note 10, at 7 (noting a near-zero probability of the event occurring in any immediate time period, but a near-infinite amount of damage inflicted if it does occur).

214 Cass R. Sunstein \& Richard Zeckhauser, Overreaction to Fearsome Risks, 48 EnvTL. \& REsource ECON. 435, 436 (2011); see also, Posner, supra note 37.

215 See, e.g., Howard Kunreuther \& Geoffrey Heal, Managing Catastrophic Risk, in 3 ENCYClOPEDIA OF ENERGY, NAT. RESOURCE, AND ENVTL. ECON. 52 (Jason F. Shogren ed., 2013) (asserting that losses from catastrophic risks have increased because behavioral biases prevent individuals and businesses from taking appropriate protective measures); David H. Krantz \& Howard C. Kunreuther, Goals and Plans in Decision Making, 2 Judgment \& DeCISION MAKING 137 (2007) (examining the puzzling behavior of people under-insuring against catastrophic risks).

${ }^{216}$ See generally, Robert L. Park et al., The Lesson of Grand Forks: Can a Defense Against Asteroids Be Sustained?, in HazARDs Due to Comets AND Asteroms 1225 (Tom Gehrels ed., 1994) (comparing the problem of sustaining political and financial support for planetary defense to the comparable problem of preparing against unlikely but potentially catastrophic missile attack); Int'l Law Comm'n, Rep. on the Work of Its Sixty-Fourth Session, U.N. Doc. A/71/10, 
of the occasions in which these psychological barriers must be overcome.

The extended time frame in dealing with asteroids places special burdens on the effort to think rationally about very-low-probability dangers, because the people at risk are (likely) not ourselves but our far-distant progeny, generations so remote that the emotional connection to them is strained. We can appreciate that the good work of IAWN and SMPAG today may help increase the odds of our species' survival, but we must also be aware that the counter-asteroid technology available to earthlings a century or two from now will surely surpass today's puny capabilities in ways we cannot imagine. ${ }^{217}$

One plausible formula would be to posit that a major NEO impact (a collision with a body of 3-5 km diameter) could kill, say, half the world's population (soon to reach eight billion people) some time in the next million years. On an actuarial basis, that works out to 4,000 statistical deaths annually. That is surely a significant fatality rate-enough to warrant substantial financial investment-even though the incidents would be extraordinarily "lumpy," in the sense that for almost all of those one million years, there would be no deaths at all due to asteroids, but in one year there would be an unprecedented catastrophe. At this rate, asteroids would rank above many other natural and bizarre phenomena that people fear (and that societies attempt to do something about), such as floods, tornados, airplane crashes, terrorism, or choking. Asteroids, however, would still fall far below other leading causes of death, such as automobile accidents, communicable diseases, and tobacco use. ${ }^{218}$

This weird combination of probabilities and consequences promotes what many call the "giggle factor": humans' seemingly congenital reluctance to discuss planetary defense seriously without retreating to the silliest tropes about alien attacks or sci-fi thrillers. The topic seems to be ripped from

\footnotetext{
at $12-72$ (2016).

217 See Michael B. Gerrard, Risks of Hazardous Waste Sites Versus Asteroid and Comet Impacts: Accounting for the Discrepancies in U.S. Resource Allocation, 20 RISK ANALYSIS 895 (2000) (pondering why the United States allocates some $\$ 6$ billion annually to the cleanup of hazardous waste sites but only $\$ 3$ million to planetary defense). Jonathan Schell has movingly articulated how a global nuclear war could result in two distinct, intertwined tragedies: the deaths of all currently living human beings and the prevention of the existence of all future generations. An asteroid could likewise result in those two types of unthinkable exterminations. See Jonathan Schell, The Fate of the Earth (1982). See also Seth D. Baum et al., LongTerm Trajectories of Human Civilization, FoRESIGHT (forthcoming Aug. 2018).

${ }^{218}$ Chapman \& Morrison, supra note 37; Gerrard \& Barber, supra note 32, at 12-17; NAS Surveys and STRATEGIES, supra note 10, at 26-27; Posner, supra note 37, at 90; Dealing with the Threat to Earth From Asteroids and Comets, supra note 13, at 31; YeOMans, supra note 8 , at 123 .
} 
kitschy movie trailers, not news headlines. ${ }^{219}$

An additional fear factor here is the danger of surprise. If a significant asteroid were to arrive without warning - as in the Chelyabinsk incident-the afflicted country might perceive that it had been attacked by a hostile neighbor, rather than by a fickle Mother Nature. If, by further malign luck, the event happened to occur during a period of heightened international tensions, the propensity to misinterpret, and to respond precipitously, would rise. The unforeseen space object could thus catalyze a larger human-caused tragedy. ${ }^{220}$

The easiest part of the policy prescription is to recommend that more should be done to gather and disseminate the relevant data about NEOs. NASA, IAWN, and other actors should press forward zealously to enhance the inventory of known asteroids and should expand their efforts to track and characterize those that might plausibly pose a threat. This survey may get expensive: space-based telescopes may be necessary in order to detect space objects that can be obscured by the Sun, and long-distance space missions may be required in order to collect more information about the structure, composition, and flight characteristics of asteroids of interest.

Efforts should also proceed expeditiously to develop a quiver of technologies, tools, and techniques that can be employed someday to maneuver a threatening NEO away from Earth. These capabilities are just emerging today; some do not yet appear even on drawing boards. Because the world cannot now know when they would be operationally required, we should invest in their growth and refinement now. Since future NEO threats can be so diverse, a robust collection of capabilities could be necessary-they should be regarded as complementary, rather than redundant. ${ }^{221}$ Nuclear

${ }^{219}$ Martin E.B. France, Planetary Defense: Eliminating the Giggle Factor, AIR \& SPACE PowER J. (Aug. 7, 2000); Gerrard \& Barber, supra note 32, at 17; BuRRows, supra note 33, at 91-122. ${ }^{220}$ SECURE WORLD, supra note 43., at 18; Baum, supra note 217, at 5-6, 11-12. See also Air Force Remains Silent after Huge Meteor Hits Near US Military Base, Fox News (Aug. 3, 2018), http//www.foxnews.com/science/2018/08/03/air-force-remains-silent-after-hugemeteor-hits-near-us-military-base.html [http://perma.cc/HJ8C-ZLZE] (incorrectly and ominously reporting about a small asteroid that exploded without advance warning above Greenland, not far from a U.S. military base); Chelsea Gohd, Fireball Explodes over Greenland Near US Military Base, SpACE.COM (Aug. 6, 2018), https:/www.space.com/41393-fireballexplodes-over-greenland-military-base.html [http://perma.cc/X7C7-UYR3].

${ }^{221}$ Dealing with the Threat to Earth From Asteroms and Comets, supra note 13, at 66 (advocating the development of multiple planetary defense options). See supra text accompanying notes 10-19 (describing the variability in asteroid characteristics that could affect planetary defense tactics). 
technology is today the most mature of the candidate planetary defense methods; ironically, it is also the most legally and politically problematic.

There is no cause, at the moment, to disrupt any of the existing treaty provisions that can constrain specific planetary defense trials or operations. As the draft Security Council resolution suggests, at some point, it may be opportune to experiment with a non-nuclear kinetic impactor against a NEO in a manner that might qualify as a test of a weapon, sparking concerns under article IV of the OST. ${ }^{222}$ Certainly anything using nuclear explosive devices will raise the greatest sensitivities. The world, and the Security Council in particular, should be attentive to those scenarios, but no immediate action is required or appropriate.

When an asteroid emergency does arise, the decision about whether to employ a nuclear explosive should be driven, in the first instance, by technical considerations - is this the best (or only) mechanism for diverting disaster? If it is a close call (e.g., if the NEO danger is only contingent rather than certain, if the damage that might be inflicted is of a regional rather than a global nature, or if the suitability of non-nuclear techniques is debatable), then political factors will exert influence, too. How accepting will states be about breaking the decades-long taboo against nuclear explosions, how skeptical might they be about any covert motivations, and how amicable can the states possessing nuclear devices be about allocating the action responsibilities among themselves?

A principal message of this Article is that international law should play a significant role in the global decision-making process too - and that the legal circumstances are worth thinking through in advance so we can develop a coherent plan, based upon solid analysis and a suitable consensus, rather than simply tearing up treaties at the last moment. Our fidelity to the rule of law today is undercut if we casually assume that we will all toss the treaties aside in a future crisis. Lawyers have to be more deft than that, more poised at anticipating and responding to a planetary emergency.

If a nuclear device is to be used against an incoming NEO, a Security Council resolution pursuant to Chapter VII would provide the preferable mechanism for securing legal authorization. That approach is faster than an amendment of the relevant treaties and more targeted than a withdrawal from those instruments. It offers global coverage, applicable simultaneously to the concerns of all states. A Security Council resolution is, admittedly, subject to the veto power of the five permanent members, but once that hurdle is overcome, it avoids the tacit veto power that any other state might exert by

${ }^{222}$ See supra note 201 (draft Security Council resolution, para. 11). 
withholding its consent to the departure from other legal instruments and norms. Importantly, a suitable Security Council resolution avoids "wrongfulness"-it ensures that the authorized actions enjoy full legal sanction, needing no other excuse or justification. ${ }^{223}$

The most stressful part of the analysis here is the potential clash over the nuclear option because two incommensurate sets of values are at stake. On the one hand, if a nuclear device really were essential for planetary defense, then of course it should be implemented. International law, like the U.S. Constitution, is not a "suicide pact," 224 and if the law stubbornly gets in the way of actions that are essential for human survival, then the law simply cannot stand. On the other hand, it would be equally absurd to allow the very remote possibility of an asteroid impact to undercut the foundations of contemporary international security. The central treaties at stake here-the OST, LTBT, and NPT - constitute the hard-won paramount pillars of nuclear arms control; they must not be challenged by any pretextual excuses for evasion. The pressures toward an arms race in space are already substantial and growing; planetary defense should not further stoke those fires. ${ }^{225}$

To be viable, the international planetary defense process must exhibit all the criteria for legitimate decision-making: the framework should be "proper, fair, transparent, comprehensive, workable, politically, institutionally, and legally sound, and feasible." ${ }^{226}$ Financing the necessary efforts, and resolving potential tort liability for unsuccessful diversion efforts remain as critical outstanding issues. ${ }^{227}$

Unlike other types of natural calamities (earthquakes and hurricanes, for example) an asteroid represents an ur-disaster (in the sense of being primitive, arising from original artifacts from the creation of the Universe) that can (sometimes) be foreseen with accuracy and (sometimes) abated. The current detection and warning network is far from leak-proof, but it can be made much more reliable and resilient.

\footnotetext{
${ }^{223}$ See supra, text accompanying notes $145-56$ (regarding circumstances that preclude the wrongfulness of a treaty violation).

${ }^{224}$ See Terminiello v. Chicago, 337 U.S. 1, 36 (1949) (Jackson, J., dissenting); Kennedy v. Mendoza-Martinez, 372 U.S. 144, 160 (1963).

${ }^{225}$ See Todd Harrison et al., Space Threat Assessment 2018, CTR. FOR STRATEGIC \& INT'L STUD. (2018); Secure World Foundation, Global Counterspace Capabilities: An Open Source Assessment (Brian Weeden \& Victoria Samson eds., 2018); NAt'L Acad. OF Sci., National Security Space Defense and Protection (2016).

${ }^{226}$ InSTITUTIONAL IssUES, supra note 69, at 1.

${ }^{227}$ Hertzfeld \& Schieb, supra note 209.
} 
We are not helpless, but neither are we ready. ${ }^{228}$ Existing or near-existing technology can suffice to detect, track, and characterize most threatening NEOs, and one day to divert them, but the methodologies have not yet been developed, tested, and deployed - and time may be short.

Planetary defense offers a marvelous modern opportunity for echoing the Biblical injunction to convert swords into plowshares: the technology for rocketry, lasers, and nuclear chain reactions, originally developed or at least refined for military purposes, can be adapted for the purpose of safeguarding humanity from a deadly alien threat. But doing so requires endorsement from a higher power (in this case, the UN Security Council), and a safeguard mechanism for ensuring that the nuclear sword will not retain its original functionality.

${ }^{228}$ See Global ReSPONSE, supra note 13, at 3, 16. 